\title{
Usted ya \\ en la universidad \\ y no saber escribir
}

Escritura y poder en la universidad

\section{Sandra Soler Castillo}



Soler Castillo, Sandra Teresa

Usted ya en la universidad y no saber escribir : escritura y poder en la universidad / Sandra Teresa Soler Castillo. -- Bogotá : Universidad Distrital Francisco José de Caldas, 2013.

$146 \mathrm{p} . ; \mathrm{cm}$.

ISBN 978-958-8782-67-6

e-ISBN 978-958-8782-98-0

1. Escritura 2. Comunicación escrita 3. Promoción de la escritura

4. Arte de escribir 5. Educación superior I. Tít. $808 \mathrm{~cd} 21$ ed.

A1392943

CEP-Banco de la República-Biblioteca Luis Ángel Arango 


\section{Usted ya \\ en la universidad \\ y no saber escribir}

Escritura y poder en la universidad

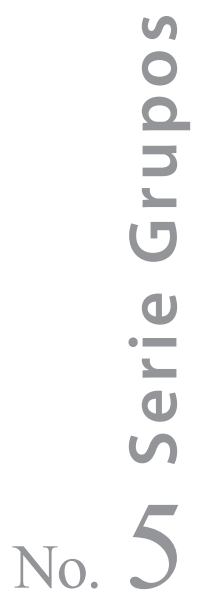

Sandra Soler Castillo

Grupo de Investigación Estudios del Discurso

Doctorado Interinstitucional en Educación

Universidad Distrital 2013

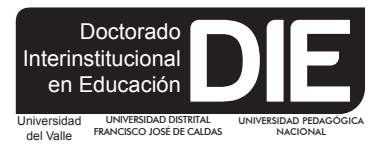




\section{UNIVERSIDAD DISTRITAL FRANCISCO JOSÉ DE CALDAS}

\section{Comité Editorial-CADE}

Adela Molina Andrade: 2006-2012 Carlos Javier Mosquera Suárez: 2013

Presidente CADE

Álvaro García Martínez Representante grupos de investigación Interculturalidad, Ciencia y TecnologíaINTERCITEC, y del Grupo Didáctica de la Química-DIDAQUIM, del Énfasis de

Educación en Ciencias.

Sandra Soler Castillo

Representante de los grupos de investigación Identidad, Lenguaje y Cultura, Moralia, Estudios del Discurso, Educación Comunicación y Cultura del

Énfasis de Lenguaje y Educación.

Olga Lucía León Corredor Representante de los grupos de investigación Interdisciplinaria en Pedagogía de Lenguaje y las Matemáticas

GIIPLyM, Matemáticas Escolares Universidad Distrital-MESCUD, del Énfasis de Educación Matemática.

Rigoberto Castillo

Representante de los grupos de investigación Formación de Educadores, del énfasis de Historia de la Educación, Pedagogía y Educación Comparada.

José Javier Betancourt Godoy Representante de los estudiantes del DIE-UD

\section{Comité Editorial Interinstitucional-CAIDE}

Rosalba Pulido de Castellanos

Directora Nacional

\section{Germán Vargas Guillén}

Coordinador DIE, Universidad Pedagógica

Nacional

\section{Carlos Javier Mosquera Suárez}

Director DIE, Universidad Distrital Francisco José de Caldas

Jaime Humberto Leiva

Coordinador DIE, Universidad del Valle

Inocencio Bahamón Calderón

Rector

Universidad Distrital Francisco José de Caldas

\section{Boris Bustamante Bohórquez}

Vicerrector Académico

Universidad Distrital Francisco José de Caldas

Primera edición, 2013

(c) U. Distrital Francisco José de Caldas

\section{Preparación Editorial}

Doctorado Interinstitucional en Educación

Sede U. Distrital Francisco José de Caldas

http://die.udistrital.edu.co

\section{Elban Gerardo Roa Díaz}

Asistente editorial

eventosdie@udistrital.edu.co

\section{Fondo de publicaciones}

U. Distrital Francisco José de Caldas

Cra. 19 No. 33-39. Piso 2.

PBX: (57+1) 3238400, ext. 6203

Diseño, Diagramación e impresión

Fundación Común Presencia

Prohibida la reproducción total o parcial sin permiso escrito de la Universidad Distrital Francisco José de Caldas. 
AGRADECIMIENTOS

INTRODUCCIÓN

1. LA ESCRITURA COMO OBJETO DE REFLEXIÓN 15

1.1. Modelos de aproximación a la escritura $\quad 15$

1.1.1. La teoría de la gran división y el modelo autónomo 15

1.1.2. Nuevos estudios sobre literacidad y modelos ideológicos 17

1.2. Escritura y poder. Una reflexión para el caso latinoamericano 19

1.3. Políticas educativas, interculturalidad y discriminación 22

1.3.1. El contexto latinoamericano 22

1.3.2. La discriminación en la escuela 23

1.3.2.1. Formas de discriminación en la escuela 24

1.3.2.1.1. Las acciones del sistema educativo 25

1.3.2.1.2. Las acciones de los docentes, interacción en el aula y currículo oculto 26

1.3.2.1.3. Las acciones de los administradores y la gestión escolar 27

1.3.2.1.4. Las acciones de los estudiantes 28

1.3.3. En torno a la desigualdad e inequidad en la escuela 28

1.3.3.1. Estadísticas de desigualdad en el sistema educativo en América Latina $\quad 28$

1.3.3.2. El caso colombiano 33

1.4. La escritura académica en el contexto latinoamericano 35

2. REPRESENTACIONES DE LA ESCRITURA ACADÉMICA DE ESTUDIANTES AFRODESCENDIENTES E INDÍGENAS DE LA UNIVERSIDAD DISTRITAL 39

2.1. El diseño metodológico 39

2.2. El instrumento $\quad 40$

2.3. El análisis $\quad 41$

2.3.1. Fase preliminar 41

2.3.2. Fase de análisis $\quad 41$

2.4. La muestra 42 
2.5. Las políticas de acceso a la Universidad Distrital 42

2.5.1. Normatividad vigente para el proceso de acceso a la UD 42

2.5.2. El Acceso a la Universidad Distrital 44

2.5.3. Permanencia de los estudiantes afrodescendientes e indígenas en la U.D. $\quad 47$

2.5.4. Logros 48

2.6. ¿Con quiénes conversamos? Elementos contextuales 49

2.6.1. Estudiantes indígenas $\quad 49$

2.6.1.1. El ingreso al sistema escolar $\quad 50$

2.6.1.2. ¿Y la escritura? Primeras letras $\quad 60$

2.6.1.3. La escritura en la universidad. La relación oralidad-escritura 61

2.6.1.4. Funciones de la escritura 66

2.6.1.5. Las prácticas de la escritura académica $\quad 77$

2.6.1.6. La metacognición. Estrategias de producción de textos escritos 84

2.6.2. Estudiantes afrodescendientes 87

2.6.2.1. El ingreso al sistema escolar 88

2.6.2.2. ¿Y la escritura? Primeras letras $\quad 91$

2.6.2.3. La escritura en la universidad $\quad 94$

2.6.2.4. Funciones de la escritura académica 96

2.6.2.5. Las prácticas de la escritura académica 100

2.6.2.6. La metacognición. Estrategias de producción de textos escritos $\quad 109$

3. SISTEMATIZANDO LOS DATOS: ELEMENTOS PARA UNA DISCUSIÓN 115

3.1. Algunas salvedades 115

3.2. Primera discusión: la escritura en la universidad, un problema de contexto 118

3.3. Segunda discusión: Repensar la dicotomía oralidad y escritura 120

3.4. Tercera discusión: Repensar las funciones de la escritura 123

3.5. Cuarta discusión: Las prácticas de la escritura académica en la universidad 127

3.6. Quinta discusión: El saber sobre la escritura 129

4. CONSIDERACIONES FINALES 131

4.1. Habría que pensar 132

4.2. Reflexividad 132

$\begin{array}{ll}\text { REFERENCIAS BIBLIOGRÁFICAS } & 133\end{array}$ 


\section{ÍNDICE DE TABLAS}

Tabla 1. Tasa neta de matrícula en educación primaria

Tabla 2. México: Porcentaje de población de 6 a 14 años que asiste a la escuela en localidades por densidad de población indígena (2000)

Tabla 3. Brasil: asistencia a la escuela por rango de edad y características raciales

Tabla 4. México: Población de 15 años y más por grado de alfabetismo en localidades según densidad de hablantes lengua indígena (2000)

Tabla 5. Porcentaje de personas por nivel educativo alcanzado según el color de la piel (1998)

Tabla 6. Brasil: Nivel de escolarización de la población mayor de 25 años por características raciales

Tabla 7. Rendimiento en castellano de alumnos de tercer y cuarto grado de educación primaria por porcentaje de estudiantes indígenas en el aula en Bolivia, Perú y México

Tabla 8. Condiciones socioeconómicas de la población afrocolombiana

Tabla 9. Distribución de cupos especiales en la Universidad Distrital

Tabla 10. Requisitos específicos para cupos especiales

Tabla 11. Número de estudiantes matriculados por facultad

Tabla 12. Estados académicos y de inscripción aplicados a los estudiantes de la Universidad Distrital Francisco José de Caldas

Tabla 13. Estado de los estudiantes de la UD por Facultad

Tabla 14. Egresados de los programas especiales

Tabla 15. Relación oralidad-escritura para los y las entrevistados

Tabla 16. Funciones de la escritura 



\section{Agradecimientos}

A los estudiantes indígenas y afrodescendientes, por su paciencia y colaboración. Ojalá sus voces encuentren eco en estas páginas.

A Doris Santos, por introducirme en esta aventura. 

En el siglo XVI, los misioneros españoles juzgaron y clasificaron la inteligencia y la civilización humana en función de si los pueblos poseían o no una escritura alfabética. Éste fue un momento inicial en la configuración de la diferencia colonial y en la construcción del imaginario atlántico, que se convertiría en el imaginario del mundo moderno, colonial. (Mignolo, 2003: 61)

Con estas palabras Walter Mignolo introduce su texto Historias locales, diseños globales y para esta investigación resultan de vital importancia pues ponen sobre la mesa el tema de la escritura como una de las primeras formas de exclusión en América.

En Colombia, en la actualidad, según las estadísticas, de un total de población afrodescendiente de 10.5 millones, sólo el $2 \%$ accede al nivel universitario y de un total de 702.000 indígenas, el 29.3 por ciento (IESALC, 2004). Sin embargo, su permanencia y logros en el sistema son aún más bajos. Para citar tan sólo el caso de los estudiantes que ingresan a la Universidad Distrital, de un total de 714 estudiantes indígenas y afrodescendientes inscritos entre los periodos 1997-2008, sólo 23 estudiantes culminaron con éxito sus estudios. Los demás se retiraron, se encuentran en prueba académica o continúan repitiendo materias y semestres por largos periodos. Las causas se desconocen, las universidades sólo se preocupan por cubrir las cuotas de ingreso que les impone el Estado y lo que posteriormente ocurra con estos estudiantes, a casi nadie le interesa. Quizá una causa tenga que ver con las prácticas académicas propias de la Universidad, en las que la escritura ocupa un lugar central y el español es la lengua oficial, en detrimento de otras prácticas como la oralidad o el uso de lenguas indígenas como lenguas maternas.

Escritura, poder y exclusión se convierten así en el hilo conductor de esta investigación que se inició en el marco de reflexión sobre la educación superior y la escritura académica propuesto por el profesor John Elliot desde el Centro de Investigación Aplicada a la Educación de la Universidad de East Anglia en el Reino Unido, y quien invitó a miembros del grupo Estudios del Discurso a vincularse a esta iniciativa.

Se trata de una red de investigación de carácter internacional en torno a lo que este autor denomina la geopolítica de la escritura. Para el caso de los países angloparlantes participantes en la investigación, como es el caso de Inglaterra, 
Estados Unidos y Australia, la preocupación gira en torno a los procesos de escritura en inglés de los estudiantes provenientes de otras nacionalidades y con otras lenguas maternas. Como lo señala Santos:

Se hizo referencia al dilema que enfrentan estos estudiantes al escribir para audiencias y agendas que entran, en muchas oportunidades, en conflicto en el proceso de escritura (escribir en y para el país anfitrión, y escribir en y para sus comunidades en los países de origen). Igualmente, se presenta este reto de escribir en una segunda lengua como el inglés, con un sentimiento de pérdida e impotencia en el proceso de construcción del conocimiento desde una lengua que no es la propia. (2010: 5)

A esta agenda se sumaron países como México, Perú y Colombia, que si bien compartían algunas de estas preocupaciones presentaban características particulares, al ser países en los que en su interior conviven diversos grupos étnicos y culturales, cuyos miembros deben ingresar en instituciones educativas que poco o nada reconocen sus particularidades, saberes y formas de trasmisión cultural.

En Colombia, el grupo de investigación Estudios del Discurso, que integra investigadores de la Universidad Distrital, la Pontificia Universidad Javeriana y la Universidad Nacional de Colombia, se vinculó a esta iniciativa en el 2006 cuando inició el macroproyecto de investigación "La escritura académica en contextos de bilingüismo e interculturalidad: un estudio descriptivo en tres universidades de Bogotá-Colombia". Investigación que ya entregó resultados en la Pontificia Universidad Javeriana y la Universidad Nacional y que presenta aquí el segundo informe en la Universidad Distrital.

En la Universidad Distrital el proyecto se dividió en tres sub proyectos, con objetivos particulares y progresivos. Si bien el objetivo general lo constituye la caracterización e interpretación de las situaciones de inclusión-exclusión presentes hoy en los procesos sociales y culturales involucrados en la escritura académica de un grupo de estudiantes, hablantes nativos de lenguas indígenas y pertenecientes a las comunidades afrodescendientes del país, estudiantes de la Universidad Distrital Francisco José de Caldas. El primer subproyecto se llevó a cabo a partir de la realización del análisis crítico de documentos de política educativa a nivel internacional, regional y nacional ${ }^{1}$. El segundo, busca describir las representaciones sociales sobre la escritura que tienen estudiantes afrodescendientes, indígenas y docentes de la Universidad, sus intereses, necesidades y expectativas. El tercero, se enfoca a desarrollar un programa de intervención a través de la realización de seminarios de reflexión y debate entre profesores y estudiantes sobre la escritura académica.

1. Los resultados de este subproyecto pueden leerse en Soler (2011). 
Con estos objetivos específicos en mente, esta investigación recurrirá al Análisis del Discurso para dar cuenta de las situaciones de inclusión y exclusión presentes en los procesos de escritura académica en el contexto universitario seleccionado. Propone además la investigación-acción para transformar el status quo. Se espera hacer un aporte en la elaboración teórica de la noción de escritura académica y así ofrecer ideas para la formulación de políticas educativas nacionales más acordes a la complejidad del objeto de estudio. 



\section{La escritura como objeto de reflexión}

El único fenómeno que ella [la escritura] ha acompañado fielmente es la formación de las ciudades y los imperios, es decir, la integración de un número considerable de individuos en un sistema político y su jerarquización en castas y en clases. Tal es, en todo caso, la evolución típica a la que se asiste, desde Egipto hasta China, cuando aparece la escritura: parece favorecer la explotación de los hombres antes que su iluminación. [...] Si mi hipótesis es exacta, hay que admitir que la función primaria de la comunicación escrita es la de facilitar la esclavitud.

Lévi-Strauss, Claude (1970)

Si bien la escritura y la oralidad han sido temas importantes de reflexión a lo largo de la historia, lo que implica leer y escribir, sus significados y su trasmisión a través de la escuela poco interés ha tenido dentro de los académicos. Durante siglos la alfabetización ha sido el estado que da cuenta de las personas que saben leer y escribir, incluso llegó a implicar simplemente que la persona pudiera firmar. Sin embargo, este término que señalaba meramente los aspectos técnicos del proceso, asociado siempre a la escuela, en las últimas décadas ha sido objeto de profundas reflexiones y debates. A partir de los años ochenta los especialistas han optado por remplazar el concepto de alfabetización por el de literacidad, vista como una práctica social y cultural, en la que intervienen relaciones de poder (Street, 1995). Implica el rechazo a entender la escritura y la lectura sólo como habilidades técnicas y neutrales, y aunque no las niega, las entiende incorporadas a sistemas culturales y estructuras de poder. En esta investigación se adopta este concepto por lo que nos detendremos un poco más en su comprensión.

\subsection{Modelos de aproximación a la escritura}

\subsubsection{La teoría de la gran división y el modelo autónomo}

Los orígenes modernos de la discusión se remontan a 1968, cuando Goody y Watt escribieron un ensayo muy influyente -en el campo de las ciencias sociales- que analizaba la oralidad y la escritura en lo que denominaron sociedades letradas y sociedades iletradas. Analizaron las características de las tradiciones no letradas y mostraron como en éstas la trasmisión cultural se realizaba de modo personal, en relaciones cara a cara y con la memoria como fuente principal, la cual se regulaba y moldeaba de acuerdo al presente. Según los auto- 
res, con la aparición de la escritura alfabética esto cambió. Estudiaron el caso de la antigua Grecia, primera cultura en la que se generalizaron los procesos de escritura, y concluyeron que este tipo de práctica permitió la aparición del pensamiento lógico, al establecer un tipo de relación particular entre la palabra y el referente; una relación más general y abstracta y menos centrada en las particularidades de la persona, el espacio y el tiempo, como sucedía en la comunicación oral. Con la aparición de la escritura se desarrolla formalmente el sentido del pasado humano como una realidad objetiva y aparece la distinción entre mito e historia (Goody, 1996: 54). Para Goody, el desarrollo de la lógica y la categorización permitió el avance del conocimiento, y el desarrollo de mentalidades más subjetivas y reflexivas, y estaría asociado con el surgimiento de formas políticas de organización superior, como la democracia, pues la escritura implicó una mayoría de ciudadanos libres que podían leer las leyes y tomar parte activa en las elecciones y la legislación (65).

De esta manera se dio inicio a la teoría conocida como la "gran división", que establece profundas diferencias entre sociedades letradas y no letradas, que, en últimas, difieren en el tipo de pensamiento que alcanzan. Unas primitivas, otras desarrolladas. Unas civilizadas, otras bárbaras. Posteriormente autores tan influyentes como Havelot (1963), Ong (1987) y Olson (1998) presentaron sendas teorías que apoyaron estas ideas. En resumen, se habla de la escritura como tecnología que se relaciona con formas de pensamiento abstracto y elaborado, que desarrolla habilidades cognitivas superiores, procesos lógicos y, en general, operaciones complejas versus la oralidad que, por el contrario, es dependiente de los contextos, es menos abstracta, menos crítica y menos reflexiva. Olson llega incluso a señalar que fue la escritura la que permitió el desarrollo de la ciencia moderna al favorecer los procesos de clasificación y el ordenamiento del conocimiento y al facilitar los procesos hermenéuticos que contrastaban los textos y sus interpretaciones (1998: 218). La escritura se consideró instrumento necesario para el progreso y la modernización de las sociedades.

Esta postura divisionista, sin embargo, afrontó duras críticas. Primero, la noción de escritura alfabética fue cuestionada por considerársela etnocéntrica y excluyente, dadas las limitaciones y restricciones que implicaba para lenguas cuya escritura no era alfabética, como el caso de las lenguas orientales. Segundo, para algunos autores, celebrar la cultura escrita con todas sus posibilidades implica de manera soterrada considerar que las sociedades que no la poseen son inferiores, y se encuentran en estados que deben superarse. Por último, se critica el hecho de que los autores de la gran división atribuyen a los letrados habilidades cognitivas particulares, que, sin embargo, estudios recientes han encontrado en sociedades ágrafas; de igual manera atribuir a las comunidades 
letradas altos grados de desarrollo, es cuestionable. Los autores de las teorías de la gran división han salido al paso a estas críticas introduciendo conceptos y justificaciones que no se apartan sin embargo de sus ideas originales. Así han hablado de "cultura escrita restringida" (Goody), o de "oralidad residual" (Ong).

Según Street, lo que se haya detrás de estas teorías es lo que él denomina un Modelo Autónomo de Literacidad (MAL). Un modelo que busca interpretar la escritura desde sí misma. Señalando sus bondades en las comunidades que la tienen y limitaciones en el proceso de adquisición de aquellas que no la poseen. Es un modelo sobre la naturaleza de la escritura y sus consecuencias cognitivas y sociales para los pueblos, en el que se le atribuyen cualidades intrínsecas y efectos inexorables: el progreso o el atraso de las sociedades. En él se destaca el carácter técnico de la escritura y su desprendimiento de todo contexto social. Lo que implica considerar la escritura como una serie de habilidades técnicas y procesos cognitivos universales que pueden ser aprendidos sin importar los contextos sociales y culturales, lo que implica que lo que la escritura por sí misma puede lograr es lo mismo en todos los tiempos y lugares (Street, 1995: 75). Concepción imperante en nuestros días y que ha permeado ampliamente los modelos de enseñanza y aprendizaje y sobre la cual volveremos más adelante.

\subsubsection{Nuevos estudios sobre literacidad y modelos ideológicos}

El origen de lo que se conoce como Nuevos Estudios de Literacidad (NEL) radica en la crítica a quienes consideran que la escritura crea y desarrolla habilidades cognitivas superiores a las de la oralidad, y a la falta de estudios prácticos que así lo demuestren. Para rebatir estas ideas, un grupo de estudiosos de diversas áreas de conocimiento se ha dedicado a realizar estudios cualitativos y cuantitativos mediante el empleo de diversas técnicas en las que se destacan las experimentales y etnográficas aplicadas en diversas comunidades.

Scribner y Cole (1981) realizaron un detallado estudio de una comunidad de Liberia para comprobar, entre otras cosas, si era la escritura o la educación la que afectaba, si lo hacía, el funcionamiento mental. La comunidad estudiada, los Vai, era particular porque presentaba diversos tipos de literacidad: la población aprendía a leer y escribir en inglés en la escuela; poseía un sistema indígena de escritura silábica que no se aprendía en la escuela, y dominaba un sistema árabe de escritura. Estas diversas escrituras se usaban en contextos diferentes. No toda la población dominaba los tres tipos de escritura, algunos dominaban uno; otros, dos y otros, tres. Lo que posibilitó el aislamiento de variables. Los investigadores concluyeron que en ninguno de los grupos había diferencias en la realización de tareas de razonamiento abstracto o categorización. Señalaron 
además que los grupos que asistían a la escuela presentaban algunos niveles superiores de abstracción pero sólo en tareas referidas a "hablar de las tareas", es decir en términos metacognitivos. Procesos que se desarrollan con mayor frecuencia en la escuela que en otros contextos. En general, concluyeron que no había grandes diferencias por el uso de la escritura en inglés, en vai o en árabe, sino dependientes de los contextos en los que se usaba cada una de ellas. Resaltaron la importancia de crear marcos en los cuales situar las habilidades cognitivas en prácticas que han sido organizadas culturalmente.

Los hallazgos de esta investigación fueron claves para poner en duda los Modelos Autónomos de Literacidad. Desde entonces son numerosos los trabajos que intentan ir más allá de este modelo. Entre los más destacados se encuentra el denominado Modelo Ideológico propuesto por Street en su libro Literacy in theory and practice (1984), que parte de la idea de que la literacidad depende del contexto y está estrechamente relacionada con las estructuras de poder y las tradiciones culturales. Plantea la necesidad de describir los espacios sociales en los que se producen los eventos de escritura, en particular aquellos en los que las instituciones promueven determinados patrones y formas de escritura, a fin de contextualizar usos y funciones. Para Street la escritura se relaciona con todas las instituciones sociales a través de las cuales se lleva a cabo el proceso, sin limitarse exclusivamente a la escuela. En este modelo, las habilidades cognitivas implicadas en la adquisición de la escritura no se deben a características intrínsecas de la misma sino que son parte de las ideologías construidas socialmente y, en consecuencia, hacen que varíen los modos de atribuirle significado y vivenciarla de acuerdo con los procesos de adquisición.

Lund (1997) sostiene que si bien la literacidad es dependiente de los contextos, un factor determinante para tener en cuenta en su estudio es la interpretación que los letrados den a esta práctica; interpretación que en muchos casos depende del grupo social y las instituciones involucradas en esta actividad. Gee, otro de los autores más influyentes en el tema, señala que más que insistir en las clásicas dicotomías, lo que habría que buscar es la existencia de diversas prácticas culturales, que en ciertos contextos requieren determinados usos del lenguaje y no insistir en diferencias tajantes intrínsecas a cada tipo de comunicación (1986).

Como lo señala Ames (2002: 82), los estudios de la NEL, en general suponen:

- Una preocupación por la continuidad entre oralidad y escritura antes que una oposición.

- Cuestionan la idea de que las sociedades progresan a lo largo de una secuencia universal que va de la oralidad a la escritura. 
- Resaltan la existencia de múltiples literacidades, dependientes de diferentes dominios sociales y de los usos y funciones que las personas den a la comunicación escrita.

- Enfatizan la necesidad de comprender cada literacidad en su propio contexto y a través de las prácticas letradas de las personas.

Desde este enfoque, en el contexto latinoamericano, resultan fundamentales las investigaciones realizadas en países como Perú, Bolivia y México donde la educación intercultural bilingüe tiene una mayor tradición, y donde la escritura y la lectura han sido objeto de amplios debates y cuestionamientos por autores como Vigil (2006), Ames (2002), Zavala, (2000, 2002), Zavala et al. (2004), Marí (2005) y Kalman (2003), Biondi y Zapata (1994, 2006a, 2006b), entre otros.

\subsection{Escritura y poder. Una reflexión para el caso latinoamericano}

En la actualidad leer y escribir hacen parte de las actividades diarias de la mayoría de las personas; sin embargo, no siempre fue así, durante mucho tiempo las sociedades permanecieron ágrafas y la gente de los pueblos que la desarrollaron era mayoritariamente analfabeta. La escritura, surgida por motivos políticos y administrativos, era manejada tan sólo por unos pocos, generalmente pertenecientes a las élites políticas o religiosas. Los escribas gozaban de alto estatus social y económico. Con el paso del tiempo y el contacto entre culturas, la escritura se convertiría en uno de los criterios de división y clasificación de las sociedades. Los pueblos que no la desarrollaron fueron considerados bárbaros. Aunque es importante resaltar que no se trataba de cualquier tipo de escritura; la clasificación de civilizado, incivilizado, estaba dada por el desarrollo de la escritura alfabética. Otros tipos de representación no eran tenidos en cuenta o eran valoradas como incipientes o limitados. El etnocentrismo y el logocentrismo han controlado el concepto de escritura desde su aparición. Incluso, en la actualidad es considerable el número de historiadores que se han negado a concebir las representaciones de las culturas orientales o prehispánicas como escritura.

Como lo señala Mignolo, citado al inicio de este trabajo, la primera gran valoración que hicieron los misioneros españoles al llegar a América, la realizaron a partir de la posesión o no de la escritura alfabética. Lo que determinaría gran parte de nuestra historia sangrienta y cruel. La escritura entró a América como una forma de poder y exclusión y así se ha mantenido a lo largo de la historia.

Durante la colonia, los escribas se convirtieron en sujetos indispensables para la Corona, eran quienes a través de documentos escritos impedían los constantes 
fraudes económicos de la población. También la evangelización encontró en la escritura su gran aliada, pues ésta era la forma más adecuada para trasmitir el mensaje de Dios. Los escribas poco a poco se convirtieron en una élite en América con mayor autonomía al irse institucionalizando a partir de funciones específicas en cargos en las audiencias, la administración, los seminarios, los colegios y las universidades. La escritura adquirió tanta relevancia que se convirtió en elemento ordenador del mundo físico; normativizando la vida de la comunidad, oponiéndose a cualquier tipo de particularismo. La razón instituye el orden, pareció ser la consigna de la época. Durante la Colonia se establecieron profundas jerarquías, y entre ellas se encontraban los letrados quienes constituían una selecta minoría, y una vez en el poder no escatimaron recursos para su perpetuación, a través entre otras, de la creación temprana de universidades (1538), que propendieron por la educación superior de los letrados. Como lo señala Ángel Rama "en territorios americanos, la escritura se constituiría en una suerte de religión secundaria, por tanto pertrechada para ocupar el lugar de las religiones cuando éstas comenzaran su declinación en el XIX" (2004: 65).

Durante la independencia los letrados continuaron siendo la élite en el poder. La independencia política corrió paralela a la independencia de las letras. En este contexto la educación entró a ocupar un lugar importante de debate, la lengua y su relación con la nación se constituiría en el centro de profundos debates. Se discutió entonces en qué lengua debía escribirse, cómo debía hacerse y qué debía enseñarse. El latín dejó de ser la lengua del imperio, y el español pasó a ocupar su lugar. Otro centro de atención se orientó a las reformas ortográficas, asunto clave para el buen uso de la escritura y para lo que se denominó independencia letrada, que propendía por el alejamiento de las normas y los cánones españoles.

Sin embargo, durante esta misma época se dieron las primeras críticas al tipo de educación que se ofrecía en las escuelas. Simón Rodríguez señaló que las repúblicas no se hacían con doctores, literatos, ni escritores, sino con ciudadanos. Rodríguez propendía por una educación social, que incluyera a todo el pueblo y no sólo a unos cuantos elegidos. Sus ideas sobre la educación iban más allá de una educación alfabeta; reclamaba el establecimiento de un "arte de pensar" que fuera universal pero a la vez particular del hombre latinoamericano. Sin embargo, las reformas propuestas fracasaron. La educación continuó siendo un asunto de élite; leer y sobre todo escribir, se antepusieron a cualquier otro tipo de enseñanza, incluido el cálculo, la lógica o la oratoria.

Durante la modernización la letra se constituyó en el principal medio de ascenso social. Se crearon mitos sociales en torno a las letras como mecanismo para ob- 
tener altas posiciones sociales y respetabilidad. Se dio un proceso de regulación de la escritura implementado por el surgimiento de las primeras academias de la lengua; entre ellas la colombiana, pionera en América Latina. Para ese entonces, América estaba dominada por letrados; escritores, pensadores, lingüistas, poetas y ensayistas ocuparon altos cargos públicos, incluidas varias presidencias.

La modernización introdujo nuevos paradigmas: los aspectos culturales perdieron su ímpetu frente a los asuntos políticos y económicos que llevaron a una rígida división del trabajo que, como señala Rama, se tradujeron en diversificados planes de estudio en una universidad de corte positivista, inmersa en una sociedad con complejas demandas de conocimiento (2004: 132). Los letrados dejaron de ser aquellos individuos que sabían de todo un poco y que dominaban el mundo de las letras. Con el surgimiento y resurgimiento de nuevas y viejas disciplinas, como la sociología, la historia, la economía, el panorama cambió. Lo que originó la aparición de clases sociales emergentes que ocupaban las grandes ciudades recientemente desarrolladas por la expansión de la industria y el comercio, ampliándose así los círculos del poder.

Con las sucesivas revoluciones americanas, nuevas ideas movieron la población: dejar atrás el enriquecimiento y la concentración desmedida de capital y el universalismo de las ideas para adentrarse en nuevos ideales como la educación para todos y el nacionalismo, promovidos por los recién formados sectores emergentes que propendían por un ensanchamiento de las bases sociales. Sin embargo, la des-centralización de los letrados con la irrupción de estos nuevos intelectuales, no impidió que el poder se siguiera ejerciendo y que éstos continuaran "legislando" o imponiendo sus ideas en diversos escenarios como las casas editoriales, las universidades y los medios de comunicación.

Durante las últimas décadas, fundamentalmente a partir de la crisis petrolera de 1973, asistimos a una transformación y cambio de paradigmas en la que son las grandes transnacionales las que gobiernan el mundo. Las distancias entre "centro" y "periferia" se acrecentaron a pasos agigantados. Los países latinoamericanos son cada vez más dependientes no sólo política y económicamente, sino intelectualmente.

En la actualidad, son los organismos internacionales los que deciden qué es bueno y malo para los países "en vía de desarrollo". Si durante, el siglo XX, la lectura y la escritura fueron de la mano de la democracia, el crecimiento económico y la armonía social, en nuestros días, son la clave para poder ingresar a los competitivos mercados mundiales, y la escuela ha sido la encargada de formar esos nuevos lectores-escritores que una vez alfabetizados adquirirán las 
competencias necesarias para ingresar a los mercados laborales. Se continúa presuponiendo que "saber leer y escribir es consonante con el desarrollo económico, social y político de los pueblos; inalcanzable mediante otros métodos" (Graff, 2008, citado en Kalman, 2008). De ahí que organismos internacionales como el Banco Mundial, la ONU, la OIT o la UNESCO, hayan centrado su interés en esta tarea. En las últimas décadas la educación ha sido objeto de incontables debates, foros, encuentros, congresos que han quedado registrados en sendos documentos que trazan los lineamientos que los países deben seguir. Importante resulta entonces analizar estos documentos de política educativa, para determinar qué supuestos ideológicos le subyacen, qué cualidades y funciones le atribuyen a la educación, qué señalan respecto a las composiciones sociales de los pueblos, cómo se refieren a los actores involucrados en ella: maestros, estudiantes, directivos ${ }^{2}$.

\subsection{Políticas educativas, interculturalidad y discriminación}

Con la aprobación de la Declaración Universal sobre la Diversidad Cultural en el 2001 en París y de la Convención Internacional sobre la Protección y Promoción de la Diversidad Cultural en el 2005, la diversidad cultural se constituyó en la clave para la generación de políticas públicas tendientes a recomponer los tejidos sociales profundamente afectados por la intolerancia y la discriminación. Estos documentos señalan que los modelos de desarrollo han conducido a una fractura de la convivencia pacífica que hace imperiosa la necesidad de una "ética global" basada en la aceptación de las diferencias culturales, y tendiente al pluralismo. La educación sería una de las responsables de tal tarea. Su función se orienta a "ayudar a comprender el mundo y a comprender a los demás para comprenderse a sí mismo" (Informe Delors, 1996). A partir de entonces, la UNESCO tomará como bandera la defensa de la diversidad cultural en sus programas de educación. Se propone entonces un cambio de las políticas homogeneizantes por aquellas que favorezcan la diversidad. La cultura se constituye en la fuente primaria para los procesos de transformación y la base para el mejoramiento en la calidad de los aprendizajes. El reconocimiento del otro y sus prácticas adquiere relevancia internacional.

\subsubsection{El contexto latinoamericano}

Latinoamérica es una de las regiones con mayores desigualdades en términos económicos y políticos. La pobreza generalizada y las desigualdades cada vez mayores entre ricos y pobres limitan las oportunidades educativas de la mayor

2. Véanse los resultados del Subproyecto Uno, en Soler (2012). 
parte de la población. Unido a esto, Latinoamérica acumula una amplia tradición de procesos de exclusión y discriminación que han llevado a la población blanca a subvalorar a las personas por aspectos raciales, étnicos o culturales. Como lo señala el informe de Políticas educativas de atención a la diversidad cultural de la UNESCO.

[...] los niveles de acceso a la educación, escolarización y logros educativos de los sectores pobres, de los indígenas, de la población negra, de los habitantes de las zonas rurales, y en algunos casos, de las mujeres, son consistentemente los más bajos en comparación con los otros grupos sociales. (2004: 21$)$

Sin embargo estas formas de discriminación en la educación no son más que reflejo de la discriminación existente en la sociedad. Así, las prácticas discriminatorias deben entenderse en el marco de las extremas desigualdades sociales y educativas de la región latinoamericana. Existen grupos sociales que han sido sistemáticamente excluidos de las políticas educativas, lo que muestra que hay discriminación hacia ellos. Se hace entonces necesario profundizar en estos conceptos y analizar qué implicaciones tienen en el campo educativo.

\subsubsection{La discriminación en la escuela}

La escuela ha sido a lo largo de la historia escenario de discriminación. En ella confluyen diversos actores con diversa procedencia social, diversas ideologías, conocimientos y creencias, pero no todos en las mismas condiciones y posibilidades. Pero antes de avanzar es importante detenernos en el concepto de "discriminación" para facilitar su comprensión y luego centrarnos específicamente en la discriminación en la escuela.

EI DRAE ofrece algunas pistas para comprender el concepto. Como primera acepción señala que discriminar es "seleccionar excluyendo". Se trata de, frente a un grupo de elementos, seleccionar unos por $x$ o y razón y excluir o sacar de dicho grupo otros. Para realizar este proceso se requieren procesos cognitivos que van desde la clasificación simple a la diferenciación. La segunda opción que presenta el DRAE hace referencia al "trato de inferioridad a una persona o colectividad por motivos raciales, religiosos, políticos etc." (DRAE). Piénsese entonces en la discriminación como un doble proceso en el que primero se identifican particularidades por medio de la comparación y luego se le agrega el factor social a partir de juicios y valoraciones.

Cuando la discriminación obedece a cuestiones étnicas o raciales algunos autores hablan de discriminación étnica. Por el contrario, autores como Van Dijk 
prefieren dar a cada fenómeno un nombre, así a la discriminación por cuestiones étnicas o raciales la denomina Racismo. Este autor sostiene que:

[...] racismo, discriminación y prejuicio son nociones relacionadas dentro de una teoría general del racismo como un sistema social de dominación racial-étnica, es decir, es un sistema de poder. Ese sistema del racismo está compuesto por dos sistemas: uno de prácticas sociales racistas, que llamamos discriminación, y otro, un sistema sociocognitivo que llamamos prejuicios, más específicamente, ideologías racistas. Esas ideologías racistas son la base de las prácticas de discriminación, y se usan también para su legitimación. (2008)

Resulta importante entonces distinguir por una parte el sistema sociocognitivo compuesto de prejuicios y estereotipos y por otra, la práctica concreta en sí, producto de ésta, la discriminación.

Los prejuicios y los estereotipos son formas de conocimiento que las personas adquieren por diversos medios desde que nacen: la familia, los medios de comunicación, las experiencias propias o la escuela, entre otros. Los prejuicios a la vez tienen una doble caracterización: cognitiva y afectiva. La dimensión afectiva se refiere a sentimientos como el miedo, el odio, el disgusto o cualquier otra forma de sentimiento negativo. La dimensión cognitiva se refiere a la manera como se piensa, se categoriza o se generaliza respecto a un grupo social. Cuando se generaliza o se simplifica acudiendo a clichés, frases hechas se está frente a estereotipos. Los estereotipos son fuente de prejuicios y pueden conducir a acciones discriminatorias.

Según Van Dijk, el racismo es uno de los más evidentes y difundidos prejuicios en la mayoría de las sociedades; y en él el discurso tiene un papel fundamental: es la práctica social con la cual aprendemos y reproducimos las ideologías racistas. En ese sentido el discurso es una especie de interfaz entre discriminación y prejuicios.

1.3.2.1. Formas de discriminación en la escuela. La escuela tiende a reproducir los patrones generales de la sociedad. La discriminación en la escuela puede estar referida a estereotipos y prejuicios de género, etnia, clase social, raza, preferencias sexuales, desarrollos cognitivos, limitaciones físicas, lengua, etc. Las formas más corrientes de discriminación están dadas en el currículo, la administración, la gestión y las prácticas de aula. Entre los agentes discriminadores están las directivas, los profesores y los mismos estudiantes. Ernesto Treviño (2005) presenta un panorama de las diversas formas de discriminación que se dan al interior de la escuela, y se reseñan a continuación. 
1.3.2.1.1. Las acciones del sistema educativo. Este tipo de discriminación se relaciona con los estereotipos incluidos en los contenidos del currículo formal. Pueden darse al menos de dos maneras: por exclusión de temas o por los contenidos mismos. En el primer caso, se trata de elisiones totales o parciales de determinadas temáticas que tienden a minimizar la historia, las tradiciones o los aportes de determinados pueblos o personas. Como lo demuestra, por ejemplo Soler (2009) al señalar que en los textos escolares de ciencias sociales de dos de las editoriales de mayor circulación en Colombia poco o nada se menciona a los afrodescendientes y a los indígenas; la referencia a sus aportes a la historia y desarrollo del país son escasos y se da una clara tendencia a la homogeneización de la población con el blanco como figura predominante. Otro ejemplo, citado por Treviño, muestra como en México, en el libro oficial de lecturas de español, en primer grado sólo una de 39 lecturas hace referencia a las tradiciones indígenas, por lo que se deja de lado una larga tradición de mitologías de estas culturas.

En el segundo caso, referido a los estereotipos y prejuicios culturales trasmitidos por los contenidos, existe una amplia gama de estudios que muestran cómo los textos escolares representan las poblaciones indígenas y afrodescendientes de manera estereotipada, atribuyéndoles características negativas como la ignorancia, la subordinación o incluso rasgos no humanos (Silva, 2002, citado en Treviño: 45), o como señala Soler, convirtiéndolos en problemas al relacionarlos siempre con pobreza, marginación, desempleo o violencia (2009).

Los estereotipos de género también son otras forma de discriminación en la escuela y han sido objeto de varias investigaciones en las que se muestra que durante décadas e incluso siglos, las mujeres estuvieron asociadas a labores domésticas y casi nunca se les relacionó a actividades con poder (Kelly \& Nihlen, 1982, UNESCO 1983a, 1983b, 1983c, citado en Treviño: 46).

Otra forma de discriminación de este tipo está dada por la existencia de currículos diferenciados: para ricos y pobres, hombres y mujeres. La denominada educación técnica o tecnológica versus la educación formal, en la que normalmente los estudiantes más pobres o provenientes de sectores marginados son encausados hacia una educación para realizar trabajos con poco estatus social y baja remuneración.

Señala Treviño que otras formas de discriminación dentro del currículo se dan cuando se realzan los valores de un grupo, casi siempre el dominante, en prejuicio de los demás. En este campo una de las áreas más estudiadas es el uso del lenguaje, ya sea el empleo de las lenguas oficiales o los dialectos hegemónicos 
contra aquellos de las clases bajas o las minorías étnicas y raciales (Bernstein, 1971; Bourdieau \& Passeron, 1970, Mandujano, 2001, citado en Treviño: 47).

\subsection{Las acciones de los docentes. Interacción en el aula y currícu-}

lo oculto. Treviño sostiene que los maestros como agentes de la educación pero también como personas inmersas en una sociedad, en ocasiones, pueden generar prácticas discriminatorias, algunas más directas que otras. Un ejemplo concreto de este tipo de discriminación lo constituye el trato diferenciado por cuestiones de género. Estudios demuestran que los profesores suelen prestar mayor atención en las intervenciones a los hombres que a las mujeres (Kelly \& Nihlen, 1982; Cronin \& Roger, 1999; y Rockwel, 1995, en Treviño: 47). También se ha hablado de la existencia de un currículo oculto para hombres y mujeres en el que los docentes tienden a orientar a las niñas hacia las humanidades y a los niños hacia las matemáticas, lo que explicaría la diferencia en el desempeño de niños y niñas en las evaluaciones de lenguaje y matemáticas (LLECE 2001, PISA 200, citado en Treviño: 47).

Otra forma de discriminación se da de los docentes hacia los estudiantes de clase baja y de sectores marginados. Los profesores tienden a culpar por los bajos desempeños a los padres y a los estudiantes y a las bajas condiciones económicas y de capital cultural de las familias (Avalos, 1982; Levinson, 2001; Román, 2000, citado en Treviño: 47). Lo que también desemboca en que algunos profesores fijen criterios de evaluación diferenciados entre estudiantes, estableciendo objetivos académicos mínimos para algunos (Assael \& Newman, 1989, citado en Treviño: 48). Los maestros también asignan etiquetas denigratorias a los niños y las niñas por diversos motivos, ya sea por cuestiones físicas, por el olor, por los comportamientos o por el uso del lenguaje. Etiquetas que afectan la autoestima de los estudiantes y que tienden a permanecer por largos periodos en la mente de los niños e incluso pueden afectar las relaciones interpersonales de los estudiantes y sus logros académicos (Rist, 1970; Weinstein, 2002; Román, 2001, citados en Treviño: 48). La clasificación de los estudiantes y la organización de grupos por rendimiento académico también podría ser otra forma de discriminación. Distinguir entre los "buenos" y los "malos" estudiantes es una práctica frecuente en las aulas. La subjetividad y el sesgo de los maestros al realizar este tipo de evaluaciones son bastante cuestionables.

La procedencia étnica y racial de los estudiantes también es objeto de discriminación. Sea porque provienen de otros países, o porque dentro del mismo país vienen de sectores más pobres y de culturas distintas a la dominante. Hay casos documentados en los que los docentes tratan a los estudiantes indígenas de estúpidos (Avalos et al. 1982, citado en Treviño: 48). Las investigaciones 
señalan que los estudiantes indígenas están sobrerrepresentados por sus docentes como personas con habilidades más bajas (Ballantine, 1997; Brint, 1998; Neukom, 1991; Oakes, 1995, citado en Treviño: 48). Lo más problemático de estas clasificaciones es que la movilidad de estos grupos hacia los colectivos con "mayores habilidades" es muy poca, pues los maestros suelen prestar menor tiempo afectivo y menor calidad en la atención a estos estudiantes. En Estados Unidos, por ejemplo, los estudiantes de las minorías étnicas son enviados a valoraciones psicológica con mayor frecuencia, alegando cualquier tipo de discapacidad (Losen \& Orfield, 2002, citado en Treviño: 49). Y, en el Reino Unido, hay estudios que muestran como los profesores suelen criticar a los estudiantes afrodescendientes por sus comportamientos y descalificarlos por su vestimenta y peinados (Pilkington, 1999, citado en Treviño: 49).

Para el caso de Latinoamérica y a pesar de los pocos estudios de las formas de discriminación en la escuela, señala Treviño que: "Los valores de las culturas indígenas son considerados como inferiores (Guzmán 1991, en Treviño: 49); se discrimina a los estudiantes que hablan lenguas indígenas (Zúñiga, 2002: 49); se tienen menores expectativas en aulas con mayores porcentajes de estudiantes indígenas (Treviño 2002, en Treviño, 2005: 49); se cree que los estudiantes indígenas no deben aprender en su idioma materno, sino en la lengua dominante (Kuykx 1999, Schmelkes, 2000 en Treviño: 49), y el origen racial y la lengua materna son vistos como determinantes de fracaso escolar (Ávalos, 1982, en Treviño, 2005: 48). Señala Treviño que estas consideraciones no son muy diferentes al referirse a las poblaciones afrodescendientes. Llama la atención este autor que la ausencia de investigaciones al respecto no debe confundirse con la ausencia de fenómenos discriminatorios en las aulas.

1.3.2.1.3. Las acciones de los administradores y la gestión escolar. Una de las formas más frecuentes de discriminación ejercidas por la administrativos de la escuela está dada por la selección de los estudiantes que ingresan al sistema educativo. Aunque se supone que la educación pública es para todos, sin distingos de ningún tipo, esto no se lleva a cabo así. Las instituciones aplican sistemas de selección que perjudican a los más pobres y a las minorías. En ciertos planteles la asignación de cupos en las diversas jornadas está determinada por factores económicos, procedencia y pertenencia a grupos no marginados. Otras formas de discriminación que obedecen a las políticas de los planteles se relacionan con la expulsión de estudiantes embarazadas o por preferencias sexuales. Otras escuelas discriminan por edad, negando el acceso a personas mayores o estudiantes que podrían estar por encima de los estándares. Y la mayoría, discrimina por las condiciones físicomotoras, dejando por fuera estudiantes con limitación visual, auditiva o motriz. 
1.3.2.1.4. Las acciones de los estudiantes. La discriminación entre los estudiantes también es muy frecuente. Los niños y jóvenes tienden a establecer categorizaciones de distinto orden, por apariencia física, habilidades, pautas de comportamiento o género. Con frecuencia utilizan apelativos negativos para referirse a sus compañeros. En las escuelas donde hay mayor diversidad de población suelen ser más frecuentes estas formas de discriminación. La población afrodescendiente es una de las que más padece este flagelo (Soler, 2012). En ocasiones las agresiones pueden llegar a la violencia física, convirtiéndose en uno de los problemas más frecuentes en las escuelas en la actualidad.

\subsubsection{En torno a la desigualdad e inequidad en la escuela}

Como lo señala Treviño (2005), los conceptos de desigualdad e inequidad tienen significados diversos para distintos autores. La desigualdad se entiende como el modo de distribuir un bien en la sociedad entre diversos grupos (Farrel, 1999: 158, citado en Treviño: 27); la inequidad tiene en su origen una valoración moral en la que se aprecia una situación como justa o no. Estos términos son muy importantes en el análisis de la educación y suponen al menos dos modelos de interpretación. Los basados en las desigualdades y los basados en las oportunidades educativas. El primer modelo considera que la educación es un sistema de selección que favorece el status quo y en su camino deja siempre los grupos marginales por fuera. Los indicadores de igualdad incluyen los siguientes términos: a) acceso, b) supervivencia, c) logros en el aprendizaje y d) resultados en el desempeño social.

\subsubsection{Estadísticas de desigualdad en el sistema educativo en América}

Latina. Algunos datos respecto a las desigualdades en América Latina muestran estadísticas bastante preocupantes:

Acceso. En Latinoamérica, en términos de acceso, las poblaciones indígenas, afrodescendientes, los habitantes de zonas rurales y en algunos casos las mujeres, tienen menor acceso a la educación.

Como lo muestra la Tabla 1, los porcentajes de acceso a la educación primaria de las comunidades rurales son bastante más bajos que los de las zonas urbanas. Igual sucede con las comunidades indígenas. En México, para tomar tan sólo un ejemplo, las estadísticas muestran que existe menor acceso a la educación en aquellas localidades en las que la mayoría de la población es indígena. Como lo indica la Tabla 2. 
Tabla 1. Tasa neta de matrícula en educación primaria*

\begin{tabular}{|c|c|c|c|c|c|c|c|}
\hline País & Periodo & \multicolumn{3}{|c|}{ Primer año de periodo } & \multicolumn{3}{|c|}{ Último año del periodo } \\
\hline & & Total & Urbana & Rural & Total & Urbana & Rural \\
\hline Bolivia & $1990-1990$ & 57,4 & 76,2 & 33,3 & 61,6 & 75,2 & 39,1 \\
\hline Colombia & 1997 & -- & -- & -- & 77,4 & 83,4 & 65,1 \\
\hline Ecuador & $1990-1998$ & 78,8 & 92,2 & 64,6 & 90,4 & 99,8 & 77,8 \\
\hline Guatemala & $1992-1998$ & 68 & 74,1 & 64,2 & 77,7 & 74,3 & 79,8 \\
\hline Honduras & $1990-1999$ & 83,8 & 104,3 & 74,2 & 85,7 & 105,2 & 76,5 \\
\hline Panamá & $1990-1998$ & 91,4 & 89,7 & 92,9 & 93,7 & 95,6 & 91,9 \\
\hline Paraguay & $1990-1997$ & 91,1 & 93,7 & 89 & 91,4 & 86,3 & 96,9 \\
\hline
\end{tabular}

Total niños matriculados en primaria y con edad de cursar el nivel como porcentaje de la población del grupo de edad correspondiente.

La tasa neta urbana superior al $100 \%$ se debe probablemente a estimaciones de población bajas o bien a datos de matrícula muy altos.

Fuente: OREALC/UNESCO (2000): Informe Subcategorial de América Latina: Evaluación de Educación para Todos en el año 2000.

Tabla 2. México: Porcentaje de población de 6 a 14 años que asiste a la escuela en localidades por densidad de población indígena (2000)

\begin{tabular}{|c|c|c|c|c|}
\hline $\begin{array}{c}\text { Asistencia a } \\
\text { eventos }\end{array}$ & \multicolumn{4}{|c|}{ Densidad de población indígena } \\
\hline & $70 \%$ y más & $30-69 \%$ & $1-29 \%$ & Total \\
\hline Asiste & 85 & 88,7 & 92,9 & 92,3 \\
\hline No asiste & 15 & 11,3 & 7,1 & 7,7 \\
\hline
\end{tabular}

Fuente: INEGI: XII Censo General de Población y Vivienda 2000 INI: Dirección de Investigación y Promoción Cultural, IBAI.

Para el caso de los afrodescendientes, la situación es similar. Miremos el caso de Brasil.

Obsérvese como los índices más bajos de acceso a la educación están entre la población afrodescendiente.

Permanencia La permanencia es un indicador muy importante porque nos muestra qué avances puede lograr el individuo cuando ha entrado al sistema educativo y cuánto tiempo logra mantenerse. 


\section{Tabla 3. Brasil: asistencia a la escuela por rango de edad y característica raciales}

\begin{tabular}{|l|c|c|}
\hline Rango de edad y raza & 1998 & 1999 \\
\hline Población total & & \\
\hline Personas de 7 a 13 años que no asisten a la escuela & 4,6 & 3,6 \\
\hline Personas de 14 a 17 años que no asisten a la escuela & 20,1 & 18,3 \\
\hline Personas de 18 a 25 años que no asisten a la escuela & 70,1 & 68,4 \\
\hline Blancos & & \\
\hline Personas de 7 a 13 años que no asisten a la escuela & 2,9 & 2,4 \\
\hline Personas de 14 a 17 años que no asisten a la escuela & 17,1 & 15,6 \\
\hline Personas de 18 a 25 años que no asisten a la escuela & 67,7 & 66,7 \\
\hline Negros & & \\
\hline Personas de 7 a 13 años que no asisten a la escuela & 6,2 & 4,8 \\
\hline Personas de 14 a 17 años que no asisten a la escuela & 23,3 & 21 \\
\hline Personas de 18 a 25 años que no asisten a la escuela & 72,9 & 70,4 \\
\hline
\end{tabular}

Fuente: Henriques, R. (2001): Desigualdad racial en Brasil: Evolución de condiciones de vida en la década de 90. Textos para discusión- Ipea N 807. Río de Janeiro.

Tabla 4. México: Población de 15 años y más por grado de alfabetismo en localidades según densidad de hablantes de lengua indígena (2000)

\begin{tabular}{|l|c|c|c|c|}
\hline \multirow{2}{*}{ Población por alfabetismo } & \multicolumn{2}{|c|}{ Densidad de población indígena } & \multirow{2}{*}{ Total } \\
\cline { 2 - 4 } & $70 \%$ y más & $30-69 \%$ & $1-29 \%$ & \\
\hline Población de 15 años y más alfabeta & 60,8 & 77 & 92,9 & 91,2 \\
\hline Población de 15 años y más analfabeta & 39,2 & 23 & 7,1 & 8,8 \\
\hline
\end{tabular}

Fuente: INEGI: XII Censo General de Población y Vivienda 2000 INI. Dirección de Investigación y Promoción Cultural, IBAI. Base de localidades y comunidades indígenas, 2002.

Las cifras muestran cómo las comunidades indígenas presentan igualmente los menores grados de permanencia en el sistema educativo. Véase por ejemplo el caso de México, en la Tabla anterior.

Igual sucede con las poblaciones afrodescendientes. 


\section{Tabla 5. Porcentaje de personas por nivel educativo alcanzado según el color de la piel (1998)}

\begin{tabular}{|l|c|c|c|c|c|c|c|c|c|}
\hline \multirow{2}{*}{ Educación } & \multicolumn{3}{|c|}{ México } & \multicolumn{3}{c|}{ Costa Rica } & \multicolumn{3}{c|}{ Chile } \\
\cline { 2 - 11 } & Blanco & Moreno & Mulato & Blanco & Moreno & Mulato & Blanco & Moreno & Mulato \\
\hline Primaria (1 a 6 años) & 22 & 36 & 53 & 50 & 54 & 54 & 35 & 38 & 50 \\
\hline Secundaria (7 a 12 años) & 32 & 38 & 30 & 26 & 22 & 23 & 38 & 38 & 40 \\
\hline Superior (13 y más años) & 41 & 24 & 11 & 18 & 10 & 7 & 26 & 24 & 9 \\
\hline
\end{tabular}

Fuente: Basañez, M y Parás, P. (2001): Color and democracy in Latin America. En Camp, R. (editor): Citizen views of democracy in Latin America University of Pittdbourg Press. Basado en los resultados de la Hewlett Poll, 1998.

Aunque el tipo de distinción entre blanco, moreno y mulato resulta problemático, los datos son muy dicientes. La población blanca es la que presenta mayores porcentajes de permanencia en el sistema educativo, con porcentajes que duplican o incluso triplican el de las demás poblaciones.

El caso de Brasil resulta paradigmático en este sentido:

\section{Tabla 6. Brasil: Nivel de escolarización de la población mayor de 25 años por características raciales}

\begin{tabular}{|l|c|c|}
\hline Rango de edad y raza & 1998 & 1999 \\
\hline Población total & & \\
\hline Personas de 7 a 13 años que no asisten a la escuela & 35,8 & 35 \\
\hline Personas de 14 a 17 años que no asisten a la escuela & 65,5 & 64,8 \\
\hline Personas de 18 a 25 años que no asisten a la escuela & 8,9 & 9 \\
\hline Blancos & & \\
\hline Personas de 7 a 13 años que no asisten a la escuela & 27 & 26,4 \\
\hline Personas de 14 a 17 años que no asisten a la escuela & 58,1 & 57,4 \\
\hline Personas de 18 a 25 años que no asisten a la escuela & 12,8 & 12,9 \\
\hline Negros & & \\
\hline Personas de 7 a 13 años que no asisten a la escuela & 48,2 & 46,9 \\
\hline Personas de 14 a 17 años que no asisten a la escuela & 76,1 & 75,3 \\
\hline
\end{tabular}

Fuente: Henriques, R. (2001): Desigualdad racial en Brasil: Evolución de condiciones de vida en la década de 90. Textos para discusión-Ipea No. 807. Río de Janeiro.

Nótese cómo, para 1999, el nivel de personas negras con menos de cuatro años de estudio asciende casi a la mitad de la población negra en Brasil, y tan sólo el $3.3 \%$ de esta población logra el ingreso a la universidad. Cifras verdaderamente alarmantes. 
Estas estadísticas están igualmente relacionadas con el poder adquisitivo de la población. Así en Colombia, por ejemplo, la población perteneciente a los estratos bajos tiene un promedio de educación de 3.6 años, mientras que los estratos altos tienen un promedio de 11.8 años (Sarmiento, 2000, citado en Unesco). En México las estadísticas muestran cifras similares, para 1996, el $90 \%$ de la población con ingresos bajos tenía la primaria completa o menos años de escolarización. Las clases altas alcanzaban por el contrario niveles postbásicos o superiores (Bracho 2000, citado en UNESCO).

Calidad y logros. De igual manera la calidad de los establecimientos educativos y los logros de los estudiantes son desiguales en el contexto latinoamericano. Los estudiantes de las regiones rurales, pertenecientes a comunidades indígenas o a poblaciones afrodescendientes asisten a la escuela con peores condiciones, ya sea en términos de infraestructura o de calidad en la formación del profesorado. Lo que hace que los niveles de aprendizaje sean menores.

El Laboratorio Latinoamericano de Evaluación de la Calidad de la Educación (LLECE) de la UNESCO, ha señalado que en Latinoamérica las escuelas están segregadas de acuerdo con el nivel socioeconómico de la población que atienden. Los estudiantes ricos y pobres asisten a escuelas bien diferenciadas, con recursos dispares. La diferencia entre las escuelas privadas y públicas es notoria, al igual que entre las escuelas ubicadas en los sectores urbanos y rurales. Los estudiantes que asisten a escuelas privadas de clases medias y altas cuentan con más y mejores recursos logísticos y los profesores suelen tener mayor preparación, lo que se ve reflejado en los logros de los estudiantes. EI LLECE, al comparar el rendimiento de los estudiantes en lenguaje y matemáticas de escuelas privadas urbanas y públicas urbanas identificó mejor desempeño en las primeras (UNESCO, LLECE, 2001). Otros estudios han demostrado que existen desigualdades considerables en los logros educativos de personas de distintas etnias. Así por ejemplo, un estudio realizado en Perú, México y Bolivia mostró que los estudiantes indígenas alcanzan menores logros que los blancos. Al comparar los logros en castellano de cursos con distinto porcentaje de estudiantes indígenas se tuvo que a mayor porcentaje de estudiantes indígenas menores fueron los logros que se muestran en la Tabla 7.

Sin embargo, estas estadísticas es importante leerlas con cuidado pues pueden estar arrojando diverso tipo de desigualdades. Por una parte, la lengua en la que se realiza la prueba, y por otra, el nivel de conocimiento que tienen los estudiantes del castellano.

A partir de estos datos se muestra que la educación en Latinoamérica no es igual para todos, que existen formas de segregación de las poblaciones indígenas, 
afrodescendientes y campesinas y que la educación más que ser un factor de movilidad social se convierte en un factor de exclusión. Las políticas educativas de nuestros países son políticas que favorecen el status quo. La segregación en el sistema educativo tiene una correspondencia directa con la estructuración de la sociedad. Clases altas con poder y oportunidades; clases bajas con pobreza y exclusión.

\section{Tabla 7. Rendimiento en castellano de alumnos de tercer y cuarto grado de educación primaria por porcentaje de estudiantes indígenas en el aula en Bolivia, Perú y México}

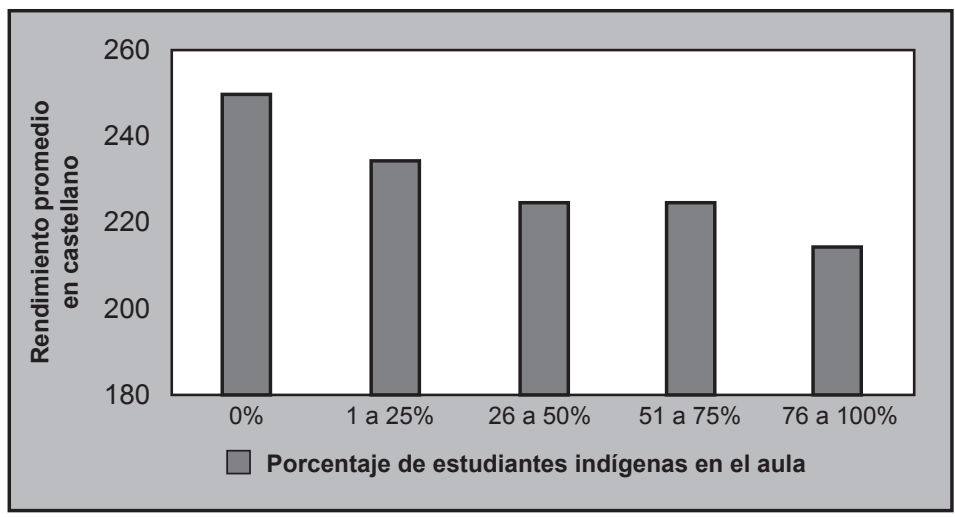

Fuente: LLECE, 2000: Cálculos propios usando la base de datos del Laboratorio Latinoamericano de Evaluación de la Calidad de la Enseñanza, OREALC/UNESCO, Santiago.

1.3.3.1. El caso colombiano. Según el censo realizado por el DANE en 1993, Colombia tiene 44 millones de habitantes de los cuales el $70 \%$ habita en zonas urbanas y el restante $30 \%$ en las zonas rurales. La mayoría de la población es mestiza. La población indígena asciende a 785.356 mil habitantes distribuidos en 83 pueblos, que hablan 65 lenguas indígenas (ONIC, CRIC, IESALC-UNESCO, 2004); los afrodescenciantes son 10.5 millones; los gitanos son 8 mil y los raizales 25 mil.

En el país existen 567 resguardos indígenas distribuidos a lo largo del territorio colombiano, principalmente en los Andes, el Caribe y la Amazonia. Las comunidades afrocolombianas se encuentran también dispersos por toda Colombia, principalmente en Buenaventura, Tumaco, Cali y Quibdó, con cada vez mayores desplazamientos hacia las ciudades de Bogotá y Medellín, producto de la pobreza, la violencia, el desplazamiento forzado y las pocas posibilidades de ascenso social o incluso a acceso a los sistemas de salud y educación, como lo demuestran las cifras del DANE. 


\section{Tabla 8. Condiciones socioeconómicas de la población afrocolombiana}

\begin{tabular}{|l|}
\hline Educación: \\
Analfabetismo: $43 \%$ de la población rural \\
Cobertura educación primaria: $60 \%$ \\
Ingreso a la universidad: $29 \%$ \\
\hline Salud: \\
Tasas de mortalidad infantil: mayor del $20 \%$ (superior al $10 \%$ del promedio del país) \\
Esperanza de vida: $20 \%$ inferior a la del promedio \\
\hline Situación económica: \\
Viven en extrema pobreza: $80 \% *$ \\
Ingreso per cápita: 3 veces por debajo del promedio nacional \\
Con salario inferior al mínimo legal vigente: $74 \%$ \\
\hline$\left(^{\star}\right)$ En 1993, el nivel de pobreza alcanzo el $76,4 \%$ de la población, frente a un promedio del $37 \%$ en todo el país. \\
\hline
\end{tabular}

Fuente: Departamento Nacional de Planeación. Procesado Oficina de Derechos Humanos, Ministerio de Relaciones Exteriores.

En cuanto al acceso a la educación, obsérvese las altas tasas de analfabetismo en la población y las bajas tasas de cobertura durante la primaria; a penas del $60 \%$, muy por debajo de los indicadores nacionales. Preocupante resulta que sólo el $2 \%$ de la población afrocolombiana alcance el nivel universitario. Reflejo, de nuevo, de las condiciones de segregación social en las que, como lo señala la tabla, el 80 por ciento de la población vive en condiciones de extrema pobreza.

La situación de los pueblos indígenas presenta características similares aunque habría que considerar aquí otros factores como la educación bilingüe o el valor que estas culturas otorgan a la educación tradicional occidental. Hechas estas salvedades, las estadísticas muestran que para 1985, últimos datos disponibles, el analfabetismo de la población indígena alcanzaba el 44\%, frente al 30.6 del sector rural nacional. En 1989, la cobertura de la básica primaria era de $11.3 \%$ y de secundaria, de $1.25 \%$ frente al $84 \%$ y $46 \%$ de los promedios nacionales (pág. 298).

Los logros educativos son también alarmantes. Según las pruebas Saber en cuanto a la evaluación de las competencias en lenguaje y matemáticas, los resultados nacionales están muy por debajo de lo esperado, así por ejemplo, en lenguaje en tercer grado sólo el $40 \%$ alcanza los logros esperados, descendiendo en los siguientes grados hasta llegar a un $20 \%$ en noveno. En matemáticas los porcentajes son aún más desesperanzadores al indicar que menos del $20 \%$ de básica primaria logran los resultados esperados y sólo el $3 \%$ de la secundaria. Descienden aún más en las zonas rurales y de mayor concentración de población indígena y afrodescendiente. 
Ante esta situación, sin embargo, el gobierno ha adoptado una serie de políticas educativas tendientes a corregir estas desigualdades o al menos a disminuirlas. En consonancia con la Declaración de educación para todos de la UNESCO, de 1990 y en respuesta al llamado de diversos sectores de la sociedad colombiana entre quienes se encontraban intelectuales, movimientos populares y algunos políticos, en la Constitución Nacional de 1991 se introdujeron cambios considerables en torno a los derechos a la educación y el reconocimiento de la diversidad lingüística y cultural, que posteriormente se implementaron en planes de acción, como el Plan de Apertura Educativa 1990-1994, el Plan Sectorial Salto Educativo, el Plan Nacional de Desarrollo 1999-2002 y el Plan Decenal de Educación, entre otros. Los objetivos incluyen una educación con calidad y equidad para todos, el avance en la universalización de la educación básica primaria, ampliar la cobertura en todos los sectores del país, disminuir la deserción y la repitencia y mejorar los resultados de aprendizaje. También a partir de la Constitución de 1991, se propuso la educación diferenciada para las comunidades indígenas a través de la etnoeducación y la implementación de la Cátedra de estudios afrocolombianos, que, sin embargo, aún no se ha implementado en la mayor parte de las escuelas y colegios. También se creó el Proyecto de educación para el sector rural y programas de atención a la población vulnerable.

Aunque es necesario aclarar que muchas de estas políticas siguen siendo excluyentes y están planteadas en términos homogeneizantes en los que predominan los valores de la clase dominante y los intereses de los grandes grupos económicos, por lo que en la práctica, en el día a día de las escuelas, la situación no parece haber cambiado; aún se siguen presentando situaciones de exclusión y discriminación en el sistema educativo. Para el caso de la Universidad Distrital, que es el tema objeto de estudio de esta investigación, si bien se aprobó una norma de discriminación positiva en la que los estudiantes indígenas y afrodescendientes tienen un determinado número de cupos de acceso a la universidad, esto no siempre se logra, pues son pocos los estudiantes que terminan el bachillerato; los que terminan no alcanzan los niveles académicos requeridos para el ingreso y los pocos que lo alcanzan no logran permanecer en la universidad y menos aún terminar sus carreras por problemas que van desde la adaptación cultural, problemas con la lengua, factores económicos y la predominancia de ciertas prácticas propias del sistema educativo, como escritura.

\subsection{La escritura académica en el contexto latinoamericano}

En Latinoamérica, los estudios de la escritura se ubican dentro de los modelos autónomos, antes mencionados. Se trata de trabajos que dan respuesta a in- 
tereses de los organismos internacionales que trazan las políticas educativas, en general, y relativas a la escritura y la lectura, en particular. La mayor parte de estas investigaciones se centra en la escritura académica, entendida ésta como una práctica dada en un espacio institucional particular: la escuela, en un contexto de aprendizaje, con fines específicos: comunicativos y epistémicos y de acuerdo con prácticas socioculturales legitimadas y altamente convencionales. Poco o nada se ha estudiado la escritura como práctica cultural por fuera de este contexto. La mayor parte de las investigaciones ha optado por centrarse en el mejoramiento de la competencia lecto-escritural en la escuela básica y media, con menor preocupación por la educación superior.

Paula Carlino, una de las mayores estudiosas del tema, señala que en Latinoamérica son escasos los trabajos investigativos en esta área y que los existentes se encuentran ubicados en el diagnóstico de las falencias de los estudiantes y en la formulación de propuestas que buscan mejorar los niveles de desempeño de los estudiantes tanto en la formación de pregrado como de posgrado (2005b: 144), tal como puede evidenciarse en los trabajos desarrollados por las redes encargadas de estos temas o por instituciones como la Cátedra UNESCO para la lectura y la escritura.

Un breve repaso por las investigaciones sobre la escritura en el nivel superior, muestra que hay una tendencia a verla como herramienta pedagógica en la que señalan aspectos como la importancia de un aprendizaje significativo, el cual está constituido por la relación que el estudiante establece entre lo que escribe y su valor frente al campo disciplinar que le interesa. Identifican que el objetivo de la escritura en la educación superior es la reformulación del conocimiento previo a través de la adquisición de nueva información, en pocas palabras, el escribir debe contribuir a "la transformación conceptual", como lo explica Vázquez de Apra (en Narváez y Cadena; 2008: 24). Hay una clara perspectiva cognitiva sobre la escritura en la universidad, que hace alusión directa a la idea de "transformar el conocimiento" (Scardamalia \& Bereiter, 1992).

Se parte de la idea de que la transformación del conocimiento del estudiante se logra si éste se apropia de la escritura como proceso. Se cree entonces, siguiendo los supuestos, ya mencionados, de los autores de los modelos autónomos de literacidad, que es en la escritura: avance tecnológico que ha marcado de forma radical el desarrollo cognitivo del hombre, el espacio donde el estudiante debe desenvolverse de modo eficaz.

Desde lo epistemológico, Daniel Cassany (1999) y sus antecesores Flower y Hayes, y Shin, entre otros, han propuesto la noción de escritura como proceso 
que plantea que la expresión escrita lleva a preguntar en relación con el escritor: ¿qué sabe?, ¿cómo lo utiliza?, ¿cómo adquiere la lengua escrita?, y ¿cómo puede mejorar su proceso? Siendo parte de la respuesta, el reconocimiento de la existencia de escritores expertos y aprendices.

Partiendo del supuesto del estudiante como un escritor inexperto o aprendiz, se hace necesario que sea orientado, incluso hasta los niveles superiores de educación; por lo que es el objeto de la intervención pedagógica y didáctica, ya que, hay que otorgarle la oportunidad de fortalecer e introducir de forma consciente las acciones necesarias para producir textos que, mientras avanza el proceso formativo, van siendo más exigentes y mejoran sus procesos comunicativos. En este sentido, el profesional en formación no sólo debe dominar su disciplina a nivel conceptual sino que "(...) para comunicar sus mensajes efectivamente (...) debe además, manejar los discursos, y por ende, los recursos formales que los tipifican o definen" (Cadario; 2008: 1).

Es así como para la incidencia en los espacios pedagógicos que se diseñan y ponen en práctica, una de las opciones, es trabajar el proceso de escritura a través de las parejas escritura-teoría y escritura-mejoramiento. Tales parejas hacen iniciar un proceso de enseñanza-aprendizaje basado en el lenguaje como objeto de conocimiento y el acto escritor como acción que se da en respuesta: "(...) a una situación retórica" (Flower \& Hayes, 1996: 76; Carlino; 2005) o a la toma de una postura, por parte del escritor, que guía la configuración simbólica de las experiencias lingüísticas del escritor (Rosenblatt, 1996). Esta línea epistemológica indica los procesos cognitivos que desde estas concepciones implica asumir la escritura como proceso. De forma básica se encuentra la propuesta de Rohman, mejorada por Shin, en la que el escribir se da en el proceso de preescribir, escribir y reescribir (Cassany, 1999).

Otra serie de investigaciones se relaciona con las convenciones discursivas de la escritura académica; parte de la idea de que el conocimiento y las formas de uso de ciertas convenciones permite caracterizar a los estudiantes y dilucidar las estrategias de acción para proponer procesos de mejoramiento de la escritura (véase: Urdaneta \& García; Méndez R.; Manrique U. en Narváez \& Cadena; 2008; Ballesteros, 2008; Jakob \& Valle, 2008). Para estos autores, para escribir un texto académico es necesario que el escritor aprendiz diferencie o conozca los requerimientos de la producción a realizar; pues, como explican Manrique y García (en Vázquez \& Cadena; 2008), la escritura tiene estrategias de escritura propias, las cuales comprenden: el uso discursivo (la noción de texto y la interacción; la coherencia y la cohesión; manejo de la macro estructura) y la organización textual. 
En el plano discursivo se requiere la acción de planear, que se relaciona con la representación mental, entendida como "(...) un conjunto de convenciones sobre la descripción de elementos" (Santa Cruz, 1985: 91, citado en Correa, 2004), la cual elabora el escritor y da cuenta sobre qué escribir y cómo ha de escribirse. La organización textual busca dar cuenta de la relación entre la organización de los textos (expositivos, explicativos y argumentativos) y los grados de dificultad que presentan los estudiantes de diversos niveles de escolaridad para comprender los textos escritos. Y, a partir de esto, lograr mediante intervenciones pedagógicas, mejorar las estrategias de comprensión y de producción textual, y, de aprendizaje a partir de los textos escritos. Piénsese por ejemplo en los trabajos desarrollados en torno a la Cátedra Unesco y publicados en sendos libros dedicados a los textos argumentativos y expositivos. (Martínez, 1999, 2001, 2005a, 2005b, 2005c; Silvestri, 2001; Colombi, 2000; Carlino 2005; Sánchez \& Álvarez, 2001; Rincón, 2005 y Pérez, 2000).

Además de las tendencias anteriormente mencionadas se encuentran propuestas que se originan en las experiencias de escritura en segunda lengua, L2 (inglés, en especial) en programas postgraduales, y escrituras mediadas por las Tics (véase: Urdaneta \& García en Narváez \& Cadena; 2008: 285-304; Pérez Abril \& Barrios 2005) que partiendo de una base de diagnóstico, caracterizan las prácticas de escritura relacionadas con usos de recursos y estrategias; en donde, para el primer caso, con base a esa caracterización se proponen talleres de trabajo para mejorar la escritura de los estudiantes y en el segundo caso se observa la potencialidad de las Tics en el mejoramiento de los niveles de compresión del texto en el campo disciplinar de formación.

En Colombia, se sigue igualmente esta línea de trabajo producto del interés de pequeños grupos de profesores preocupados por los bajos niveles de desempeño en lectura y escritura que presentan sus estudiantes universitarios. Son ejemplo de ello, las investigaciones realizadas por la Red Nacional de Discusión sobre Lectura y Escritura en Educación Superior y los trabajos de la Cátedra UNESCO para la lectura y la escritura. 


\section{Representaciones de la escritura académica de estudiantes afrodescendientes e indígenas de la Universidad Distrital}

\subsection{El diseño metodológico}

La perspectiva teórica y metodológica desde la que se hace esta investigación es el Análisis Crítico del Discurso (ACD), desarrollado en Europa a partir de 1980 por autores como Fairclough, Wodak o Van Dijk, quienes se preocuparon por las escasas relaciones que los investigadores del lenguaje establecían entre el contexto político, social y el discurso. EI ACD se relaciona con el poder y el abuso de poder y con la producción y reproducción de éstos en el discurso. Se enfoca en los grupos e instituciones dominantes y en la forma en que éstas crean y mantienen la desigualdad social por medio de la comunicación y el uso de la lengua (Van Dijk, 2004: 8).

Para el ACD, el discurso se ubica en el nivel de las acciones y los comportamientos, pero también en el de la cognición; es decir, en cómo a través de éste se crean y manipulan los conocimientos, las actitudes, las normas, los valores y las ideologías, en resumen, las representaciones sociales, RS. Según Vasilachis las RS son "construcciones simbólicas individuales y/o colectivas a las que los sujetos apelan o las que crean para interpretar el mundo, para reflexionar sobre su propia situación y la de los demás y para determinar el alcance y la posibilidad de su acción histórica" (Vasilachis, 1998: 301). Desde este enfoque, la formación de las opiniones y visiones de la realidad no es un proceso individual o idiosincrásico, sino que está determinado por la inserción de los individuos en diversas categorías sociales y su adscripción a diversos grupos. Las RS las configuran el medio cultural en que se vive, el lugar que ocupa en la sociedad y las experiencias concretas individuales.

Al estudiar las RS se busca dar cuenta de la manera como se forman las visiones de la realidad y cómo éstas orientan nuestras conductas cotidianas. Las RS son un mecanismo que permite comprender al "otro", saber cómo comportarnos ante él, y lo que es más importante, permiten asignarle un lugar dentro de la sociedad.

La forma más generalizada de acceder a las RS es a través de los discursos, los cuales se someten a diversos tipos de análisis, que van desde los típicos análisis 
de contenido, análisis de similitudes, de correspondencias semánticas o incluso técnicas experimentales. Para los analistas del discurso, las RS son parte constitutiva de los discursos y su recuperación se puede hacer desde varios tipos de análisis centrados en los aspectos formales y funcionales del discurso, que incluye las formas gramaticales, retóricas, semánticas, estilísticas pragmáticas o de interacción. No todos los aspectos del análisis lingüístico se aplican siempre, ni tampoco de la misma manera. El marco analítico depende del problema, los objetivos y el alcance de la propuesta de investigación y de la perspectiva teórica del analista. En esta investigación se privilegió el análisis semántico centrado en la determinación de los contenidos semánticos del discurso.

\subsection{El instrumento}

Para lograr los objetivos propuestos, identificar e interpretar las representaciones sobre la escritura académica de un grupo de estudiantes indígenas y afrodescendientes de la Universidad Distrital, se trabajó primero en el diseño de una entrevista semiestructurada teniendo en cuenta las investigaciones previas sobre escritura académica (Carlino, 2005; Ballesteros, 2008; González, 2006).

A partir de la identificación de contenidos relativos a la escritura académica, y de acuerdo con la experiencia de los investigadores del grupo Estudios del Discurso en el trabajo con comunidades diversas se plantearon los siguientes ejes:

- Primer eje temático: Significados atribuidos a la escritura académica.

- Segundo eje temático: Funciones asignadas a la escritura académica.

- Tercer eje temático: Prácticas de escritura académica.

- Cuarto eje temático: Dificultades de la escritura.

- Quinto eje temático: Conocimiento de la escritura.

Estos contenidos centrados en la escritura, se complementaron con otra serie relativa a los sujetos entrevistados, así:

- Sexto contenido temático: contexto sociocultural de los entrevistados: procedencia.

- Séptimo contenido temático: ingreso al sistema escolar: básica, media, universidad.

- Octavo contenido temático: adquisición de la escritura: primeras letras. 
Con base en estos ejes temáticos se diseñó una entrevista semiestructurada, en la que los contenidos se reordenaron con el fin de iniciar por aquellos más fáciles de reproducir en términos de la memoria y con menor carga "evaluativa". Véase entrevista (Anexo 1).

Una vez piloteada la entrevista, se hicieron algunos ajustes y se aplicó a un grupo de estudiantes afrosdescendientes e indígenas que se contactó siguiendo la técnica de bola de nieve o a partir de contactos con profesores que habían tenido en sus cursos estudiantes con estas características. La entrevista la realizó una recién egresada de la Licenciatura de Lengua Castellana de la Universidad Distrital; esto con el ánimo de que los estudiantes se sintieran seguros, en confianza, tranquilos y en ningún caso, evaluados. La entrevistadora tuvo varios contactos con los estudiantes previos a la entrevista.

\subsection{El análisis}

Para el análisis de las entrevistas se estableció el siguiente procedimiento:

\subsubsection{Fase preliminar}

- Primer paso: Transcripción y revisión de las entrevistas. Primera familiarización con los datos.

- Segundo paso: Lectura detallada de las entrevistas. Identificación de grandes contenidos y primeros procesos de categorización.

\subsubsection{Fase de análisis}

Primer paso: inclusión de las entrevistas en una matriz de análisis y primer análisis, codificación baja y media. Se procedió al análisis a partir de la identificación previa de contenidos temáticos, identificados en el diseño de la entrevista. Se segmentaron todas las entrevistas de acuerdo a los contenidos y se extrajeron los fragmentos que respondían a cada contenido.

Posteriormente se procedió a la codificación a partir de la identificación de la red semántica, formada por un grupo de oraciones, palabras o ítems lexicales que se reiteran en un texto, entendido como una unidad semántica (Halliday \& Hassan, 1977). De allí se redujo aun más la información hasta terminar en una macro estructura o idea central, que engloba el contenido mayor. Para este caso preferimos incluir las voces textuales de los entrevistados. Mediante este procedimiento se pudo establecer las representaciones, lo que nos llevó a una primera descripción. 
Luego estos enunciados se confrontaron con las ideas del entrevistador y se procedió a establecer categorías iniciales de análisis (véase Anexo 2).

Segundo paso: una vez analizadas la totalidad de las entrevistas, se procedió a integrar de nuevo los datos, esta vez a la luz de las teorías, codificación alta. Se intentó establecer un proceso de ida y vuelta entre los datos y las teorías para proponer algunas discusiones y puntos de quiebre a partir de los datos. Mediante este procedimiento se avanzó en la sistematización y problematización de las representaciones a la luz de las teorías.

\subsection{La muestra}

La muestra objeto de estudio de esta investigación la constituyen 28 estudiantes de la Universidad Distrital. El grupo de entrevistados indígenas lo conforman 16 estudiantes indígenas: 7 hombres y 7 mujeres, procedentes de las comunidades inga (4), kamtsá (3), pastos (1), kamkuamo (1), mesay (1), sandoque (1), pijaos (1), puinave (2), waunan (1), arawuak (1). La mayoría de estos estudiantes nacieron y se criaron dentro de sus comunidades.

El grupo de afrodescendientes lo conforman 12 estudiantes; ocho mujeres y cuatro hombres, procedentes del Chocó (5), Nariño (3), Magdalena (1), Medellín (1), Puerto Tejada (1) y Bogotá (1). Se trata de estudiantes provenientes de lugares apartados, con escasos recursos económicos.

\subsection{Las políticas de acceso a la Universidad Distrital}

\subsubsection{Normatividad vigente para el proceso de acceso a la UD}

La Universidad Distrital Francisco José de Caldas es una institución de educación superior que se reconoce, desde su fundación en el año 1948 hasta la actualidad, como una entidad de carácter público que ha tenido como criterio orientador "(...) garantizar el acceso de las capas menos favorecidas"3 de la población bogotana a la educación. Además, declara, tal y como indica el artículo 14 del Estatuto General de la Universidad, que las políticas educativas de la Institución buscan responder de forma integral a los planes y programas de desarrollo del país y del Distrito Capital.

En este sentido, al realizar un rastreo de los documentos que contemplan las políticas educativas o académicas de la Universidad Distrital en las que se integren y reconozcan los grupos afrodescendientes, indígenas, raizales y rom como

3. La Universidad Distrital Francisco José de Caldas en su página www.udistrital.edu.co en el link ¿Quiénes somos? Presenta la historia y el perfil de la institución, de allí se extrae esta cita. 
parte de la población que puede acceder a la educación superior se encuentra que sólo a partir del 2001 el Consejo Académico establece, a través del Acuerdo No. 002 del 24 de octubre del año en mención, la normatividad que permite el ingreso de esta parte de la población colombiana.

Este Acuerdo acoge leyes tales como: Ley 70 de 1993, Carta Magna Art. 7, el inciso 2 del artículo 13 del C.P.N, Decreto 1627 de 1996, y la Sentencia T-411 de 1997 de la Corte Constitucional. La alusión a estos documentos se encuentra dentro de los campos relacionados con el derecho a la igualdad y equidad para las personas que por su origen han sido históricamente discriminadas y marginadas y teniendo en cuenta que, garantizar el trato igualitario se perfila como principio funcional del estado colombiano, es deber para la Universidad Distrital formar parte del cumplimiento de este derecho fundamental, por tanto, lo acordado sobre las poblaciones ya mencionadas es la adjudicación de "cupos especiales" para las "minorías étnicas y culturales, Comunidades Negras y Beneficiarios de programas de reinserción" (Acuerdo 002 de 2001. Art. 1).

La asignación de cupos especiales se encuentra en el Artículo 1, parágrafo primero del Acuerdo y es el siguiente:

PARÁGRAFO PRIMERO: Por cada cuarenta (40) aspirantes admitidos en los Proyectos Curriculares de pregrado que ofrece la Universidad, se destinarán cinco (5) cupos en la modalidad de especial distribuidos entre los grupos y/o comunidades que se encuentran beneficiadas de acuerdo a la Ley.

Esta oferta es descrita en los instructivos de admisión como se muestra en la Tabla 9. El criterio base para la selección de los aspirantes es el puntaje en el examen de Estado aplicado por el Instituto Colombiano para el fomento de la educación superior, Icfes y las pruebas de admisión establecidas tanto por las facultades como por el programa al que se presenta el aspirante. Por estas razones, como se encuentra expresado en el instructivo (Tabla 9) y en el estatuto estudiantil (Artículo 7), se tienen en cuenta los mejores puntajes, pues se considera que la admisión a la Universidad Distrital es por mérito académico.

Por otra parte, los aspirantes que se presentan dentro de las subcategorías propias de los cupos especiales, deben cumplir con requisitos adicionales que buscan garantizar la veracidad del origen del aspirante; en el caso de las comunidades negras y minorías étnicas y culturales, en el Acuerdo 002 de 2001, Artículo 2 se indican requisitos adicionales:

ARTíCULO 2: Para el otorgamiento de los cupos especiales a que se refiere el artículo primero, debe certificarse por las Oficinas del Ministerio del 
Interior encargadas de la coordinación y dirección, previo cumplimiento de los procedimientos de acreditación por parte de ese ente gubernamental, con las respectivas autoridades de las comunidades.

\section{Tabla 9. Distribución de cupos especiales en la Universidad Distrital}

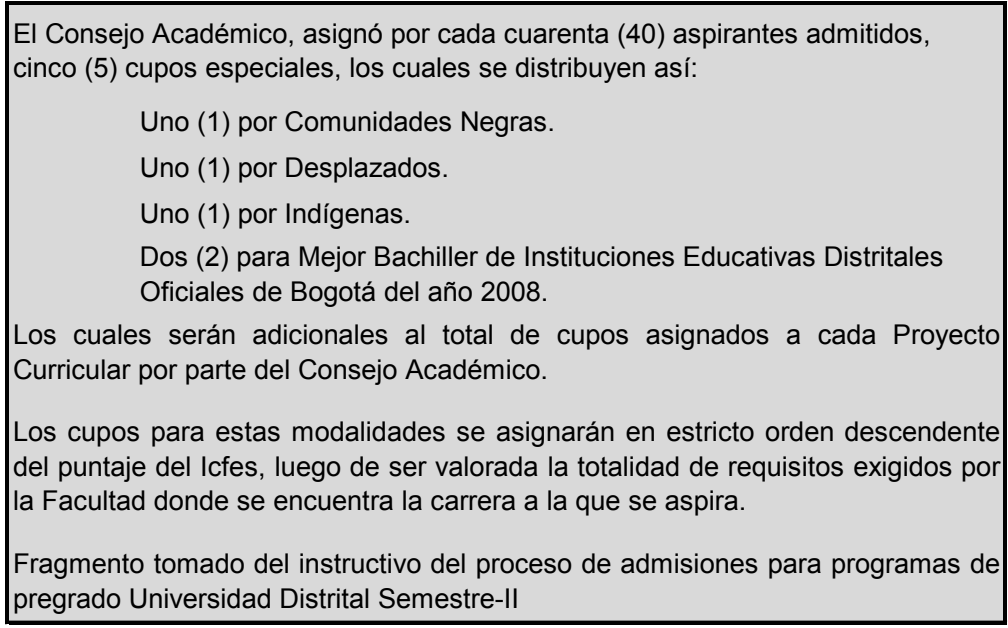

Con respecto al segundo semestre del año 2009, los documentos que están de forma explícita en el instructivo para el proceso de admisiones (Tabla 10) corresponden sólo a las subcategorías "desplazados" y "mejor bachiller" mientras que para las minorías étnicas y culturales no hay, en el literal que le corresponde, ningún requisito explícito; sin embargo, el apartado que orienta el proceso de legalización de la inscripción el literal "E" precisa que se debe presentar un certificado expedido por un Cabildo Indígena, el Ministerio del Interior o un CADEL para la inscripción especial.

Pormenorizado el instructivo en cuestión, la subcategoría "comunidades negras" no se encuentra involucrada en el texto, en consecuencia, la asignación de cupos especiales se reduce a tres subcategorías; obsérvese la siguiente Tabla.

\subsubsection{El acceso a la Universidad Distrital}

La Universidad Distrital cuenta con la Oficina Administradora de Sistemas (OAS) en la que se lleva el registro general de los tipos de inscripción que se encuentran registrados como inscripción de cupos generales y cupos especiales. Sobre este último, la dependencia posee una base de datos general que data el ingreso y estado de inscripción de los estudiantes desde 1997 hasta 2008 (excepto el año 2000). 


\section{Tabla 10. Requisitos específicos para cupos especiales}

\section{ASIGNACIÓN DE CUPOS ESPECIALES}

A) Comunidades Indígenas y Minorías Étnicas.

B) Mejor Bachiller de Instituciones Educativas Distritales Oficiales de Bogotá del año 2008 (Certificado por la Secretaría de Educación del Distrito Capital de Bogotá, a través de los CADELES y de la Rectoría de donde es egresado el aspirante).

C) Desplazados, procedimiento a seguir:

(Acreditados por la Agencia Presidencial para la Acción Social y la Cooperación Internacional). Para dicho procedimiento los aspirantes se deben presentar en la UAO* más cercana (Suba, calle 144 No. 90-62. Ciudad Bolívar, carrera 20 B. No. 63-98. Bosa, calle 65 sur No. 81C. - 16) y la UAID (carrera 36 No. $18 \mathrm{~A}-47$ ), a fin de realizar los trámites correspondientes para su acreditación ante la Universidad Distrital.

2. Realizar la inscripción a través de Internet, diligenciando la casilla en el formulario de inscripción que especifica la inscripción de población desplazada.

3. Una vez finalizado del proceso de inscripción la Universidad envía los datos a la Secretaría de Gobierno para certificar que dichos aspirantes se encuentran en el Registro Único de Población Desplazada.

4. La Secretaría de Gobierno, reenvía la Base de Datos con la información de aquellos quienes efectivamente se encuentran en el Registro Único de Población Desplazada.

5. El aspirante revisa el resultado de su inscripción a través de Internet el día 21 de Junio de 2009.

La entrega de los soportes de las inscripciones especiales (item A, B y C), se hará el siguiente día hábil posterior a la realización de la inscripción, en la carrera 8 No 40-62 Edificio Sabio Caldas, Primer Piso Oficina de Admisiones

\section{LEGALIZACIÓN DE LAS INSCRIPCIONES ESPECIALES}

A) Dos hojas del comprobante de inscripción impresas de Internet.

B) Certificado de localidad y estrato socioeconómico de residencia del aspirante, expedido por la Alcaldía Local o Planeación Distrital (Supercades).

C) Certificado de la Localidad del Colegio donde terminó estudios de bachillerato, y en el cual se indique el valor mensual de la pensión. En el caso de haber validado el estudio de educación media, la Universidad tendrá en cuenta el costo de la prueba de validación (Art. 3 Acuerdo 004 de enero 25 de 2006 del CSU). Este certificado se solicita en el Colegio Respectivo.

D) Declaración de Renta o Certificado de Ingresos y Retenciones de quien costeara los estudios. Este certificado debe ser expedido en formato de la Dirección de Impuestos y Aduanas Nacionales (DIAN). En caso de trabajadores independientes o familiares no declarantes debe presentarse certificado de no contribuyente.

E) Certificado de la condición de Inscripción Especial (Cabildo Indígena, Ministerio del Interior, CADEL) en el evento de realizar una Inscripción Especial.

Fragmento tomado del instructivo del proceso de admisiones para programas de pregrado Universidad Distrital Semestre-II.

* Unidad de Atención y Orientación a Población Desplazada 
Partiendo de esta base de datos se establece que en los diez años de registro de cupos especiales, existe la denominación "indígenas" a partir de 1997 (cuyo acuerdo normativo no ha sido localizado); sin embargo, desde el 2002 se registra la denominación "minorías étnicas y culturales" manteniéndose dentro de los listados la denominación "indígenas". Sobre estos registros la Vicerrectoría Académica de la institución reitera que sólo existe el Acuerdo 002 de 2001 que norma el ingreso de estas poblaciones. La base de datos tiene la información de las cinco facultades de la Universidad Distrital, a saber: Facultad de Medio Ambiente y Recursos Naturales, Facultad de Ciencias y Educación, Facultad Tecnológica, Facultad de Ingeniería y Facultad de Artes -ASAB- ${ }^{4}$. El número y estado de los estudiantes se registra a continuación:

\section{Tabla 11. Número de estudiantes matriculados por facultad}

\begin{tabular}{|l|c|}
\hline \multicolumn{2}{|c|}{ Estudiantes inscritos por facultad durante el periodo 1997-2008 } \\
\hline Facultad & Inscritos \\
\hline $\begin{array}{l}\text { Facultad de medio ambiente y } \\
\text { recursos naturales }\end{array}$ & 159 \\
\hline Facultad de ciencias y educación & 139 \\
\hline Facultad tecnológica & 199 \\
\hline Facultad de ingeniería & 214 \\
\hline Facultad de artes & 3 \\
\hline Total & $\mathbf{7 1 4}$ \\
\hline
\end{tabular}

Según los datos suministrados por la Universidad, la razón entre el número de cupos generales y cupos especiales es de 8:1. Sin embargo, si se tiene en cuenta que de los cinco (5) cupos especiales, dos (2) son destinados a los mejores bachilleres y uno (1) a los desplazados, la razón entre el número de cupos para los aspirantes a ingresar a un programa de pregrado en la Universidad Distrital que pertenezca a comunidades negras y minorías étnicas y culturales, corresponde a un nivel menor al anteriormente expresado; es decir, la proporción real es de 20:1. Además, la descripción que se hace en el instructivo de admisión sobre la asignación de cupos para "minorías étnicas y culturales, Comunidades Negras y Beneficiarios de programas de reinserción" se generaliza en la denominación "minorías étnicas y culturales" a través del uso de la palabra "indígenas" y la denominación "reinsertados", al parecer, se homologa con la denominación "desplazados".

4. Para la cuantificación y razón numérica de la población estudiantil referida a la facultad de artes se debe tener en cuenta que es la de más reciente constitución como parte integral de la Universidad. 
En consecuencia, en la Universidad Distrital, estaríamos frente a lo que Treviño denomina desigualdad en el acceso a la educación, pues, no todos los grupos sociales tienen el mismo grado de oportunidad de acuerdo con sus condiciones sociales. Existe un claro proceso de exclusión de las mal llamadas minorías étnicas y culturales en los procesos de ingreso a la universidad. Las proporciones de ingreso de la población indígena y la afrodescendiente, de acuerdo con el número de habitantes en Colombia, es extremadamente baja.

\subsubsection{Permanencia de los estudiantes afrodescendientes e indígenas en la UD}

Aunque para las universidades lo más importante es cumplir con la reglamentación nacional de acceso a la educación, es claro que tan importante es el ingreso como la permanencia. La Universidad Distrital posee un registro de seguimiento a sus estudiantes. Los estados de inscripción o académicos son en particular detallados según los resultados en las calificaciones, las faltas disciplinarias y las situaciones personales. Estos estados se encuentran asociados como control del aplicativo estudiantil de la siguiente manera:

Tabla 12. Estados académicos y de inscripción aplicados a los estudiantes de la Universidad Distrital Francisco José de Caldas

\begin{tabular}{|c|c|}
\hline CODIGO DE ESTADO & ESTADO ACTUAL \\
\hline $\mathrm{H}$ & Terminó y matriculó \\
\hline$E$ & Egresado \\
\hline $\mathrm{R}$ & Retirado \\
\hline $\mathrm{T}$ & Terminó materias \\
\hline A & Activo \\
\hline$S$ & Sancionado \\
\hline Z & No superó prueba académica \\
\hline $\mathrm{C}$ & Cancelado \\
\hline $\mathrm{F}$ & Prueba académica y no matriculado \\
\hline$B$ & Prueba académica y activo \\
\hline $\mathrm{J}$ & Prueba académica \\
\hline V & Vacaciones \\
\hline$M$ & No oficializó matricula \\
\hline $\mathrm{x}$ & Excluido \\
\hline 1 & Inactivo \\
\hline $\mathrm{K}$ & Sin notas prueba \\
\hline$P$ & Aplazó \\
\hline
\end{tabular}


En particular, hay dos estados que señalan la permanencia de los estudiantes dentro de los programas de formación; éstos son: Activos y Activos en Prueba Académica. El primero se aplica a quienes realizan la oficialización a través de la entrega de recibo de pago de matrícula y otros documentos exigidos cada semestre; los segundos son estudiantes que oficializan matrícula pero poseen en su haber académico la reprobación de tres materias o cursan por tercera o cuarta vez una materia, según indica el Estatuto Estudiantil (Art. 23). Veamos algunas estadísticas en la Tabla 13.

Tabla 13. Estado de los estudiantes de la UD por Facultad

\begin{tabular}{|l|c|c|c|c|}
\hline \multicolumn{5}{|c|}{ Estudiantes inscritos por facultad durante el periodo 1997-2008 } \\
\hline & Inscritos & Activos & $\begin{array}{c}\text { Prueba } \\
\text { académica }\end{array}$ & Otros \\
\hline $\begin{array}{l}\text { Facultad de Medio Ambiente y } \\
\text { Recursos Naturales }\end{array}$ & 159 & 56 & 24 & 71 \\
\hline Facultad de Ciencias y Educación & 139 & 60 & 14 & 55 \\
\hline Facultad Tecnológica & 199 & 37 & 40 & 115 \\
\hline Facultad de Ingeniería & 214 & 45 & 48 & 120 \\
\hline Facultad de Artes & 3 & 3 & 0 & 0 \\
\hline
\end{tabular}

Teniendo en cuenta lo anterior, para el caso de la población estudiantil de interés, la Universidad Distrital durante el segundo semestre del año 2008 contaba con 326 estudiantes activos, de los cuales 126 se encontraban en prueba académica. Los estudiantes que poseen este estado académico o de inscripción han sido admitidos en la institución desde el año 2002 hasta el 2008. En los restantes estados de inscripción o académicos se encuentran registrados 360 estudiantes de los 714 estudiantes en el período de referencia.

\subsubsection{Logros}

Que el estudiante culmine satisfactoriamente su proceso escolar es el objetivo de la educación en general; sin embargo, en algunos casos los estudiantes logran ingresar, se mantienen en la universidad durante largos periodos pero no logran graduarse. En este sentido las estadísticas de los estudiantes en la universidad Distrital son bastante preocupantes:

En un periodo de 11 años, el número de egresados es bastante bajo, con casos extremos como el sucedido en la Facultad de ingeniería, que cuenta con un solo egresado de 214 matriculados. Es decir que el porcentaje de egresados es del $3.1 \%$. La facultad de artes aún no registra estudiantes titulados, ya que, el primer ingreso de un estudiante perteneciente a minorías étnicas y culturales es en el 
Tabla 14. Egresados de los programas especiales

\begin{tabular}{|l|c|c|}
\hline \multicolumn{3}{|c|}{ Estudiantes egresados por facultad durante el periodo 1997-2008 } \\
\hline \multicolumn{1}{|c|}{ Facultad } & Inscritos & Egresados \\
\hline $\begin{array}{l}\text { Facultad de medio ambiente y } \\
\text { recursos naturales }\end{array}$ & 159 & 8 \\
\hline Facultad de ciencias y educación & 139 & 7 \\
\hline Facultad tecnológica & 199 & 7 \\
\hline Facultad de ingeniería & 214 & 1 \\
\hline Facultad de artes & 3 & 0 \\
\hline
\end{tabular}

segundo periodo académico del año 2006. Otras estadísticas muestran que la universidad tiene cinco (5) estudiantes que han terminado sus materias pero no han finalizado su proceso de graduación.

En términos generales, a parte de unas cuantas estadísticas, la Universidad no cuenta con un programa de seguimiento a los estudiantes que ingresan bajo la denominación de casos especiales. No se sabe cuál es la causa del alto número de estudiantes en prueba académica o qué ha pasado con los estudiantes que se han retirado. En ese sentido el trabajo que aquí se presenta pretende ser una primera aproximación a la comprensión de este fenómeno. La hipótesis que le subyace es que las prácticas académicas del contexto universitario constituyen un fuerte obstáculo para los estudiantes, más específicamente el empleo de prácticas occidentales hegemónicas como el excesivo valor otorgado a la escritura académica y, en particular, a la escritura de textos argumentativos en oposición a otros tipos de organización de la experiencia, como los textos narrativos. Por eso nos interesa conocer un poco más cuáles son las características sociales y culturales de estos estudiantes, cómo es su proceso de inserción a la educación y a la Universidad y, fundamentalmente, nos interesa saber cuáles son las representaciones que tienen frente a la vida académica, en general, y a la escritura, en particular.

\section{6. ¿Con quiénes conversamos? Elementos contextuales}

\subsubsection{Estudiantes indígenas}

Como ya se mencionó, el grupo de entrevistados lo conforman 16 estudiantes indígenas: 8 hombres y 8 mujeres, procedentes de las comunidades inga (4), kamtsá (3), pastos (1), kamkuamo (1), mesay (1), sandoque (1), pijaos (1), puinave (2), waunan (1), arawuak (1). La mayoría de estos estudiantes nacieron y se criaron dentro de sus comunidades. 
El manejo de lengua indígena es dispar; la mitad de ellos habla español y la otra mitad una lengua materna indígena y español. Las causas de la pérdida de la lengua materna se atribuyen a diversos factores como el desconocimiento de la lengua por parte de la madre, el desplazamiento de la comunidad, o la pérdida de la lengua por parte de toda la comunidad como en el caso de la estudiante Pijao y la perteneciente a los Pastos. En general, el grupo de estudiantes posee una valoración positiva de su comunidad, pero señalan que se ha venido dando un proceso acelerado de pérdida de tradiciones, aunque también señalan que hay un interés de las comunidades por rescatar las lenguas y las tradiciones de sus pueblos.

Es importante resaltar que algunos de los estudiantes entrevistados se destacaron en sus colegios como excelentes estudiantes y obtuvieron incluso los primeros puestos. También que algunos pertenecen a familias con padres profesionales, líderes comunitarios y que otros tienen padres dedicados a la docencia.

Para los entrevistados, la cuestión de la identidad es una preocupación central. Pareciera que existiera un auto cuestionamiento al respecto. Seguramente producto de factores externos a la comunidad que los obligan a identificarse o no como indígenas para obtener ciertos beneficios del Estado. Sin ir más lejos, el propio ingreso a la Universidad.

Los entrevistados señalan una relación estrecha entre lengua e identidad indígena. Quien no habla lengua indígena no es indígena o es menos indígena que aquellos que la hablan, aunque reconocen que en las comunidades se ha ido perdiendo la lengua indígena y que los jóvenes cada vez la hablan menos.

Establecen una relación entre identidad y territorio. Relación que cumple dos funciones; una cultural que implica que los pueblos se desarrollan como tal alrededor de un espacio físico vital y otra política, que les permite reclamar el derecho a la tierra. Tema fundamental que pasa hoy día por el desplazamiento forzado de que han sido víctima muchos de los pueblos indígenas del Pacífico, el Cauca, y la Sierra Nevada de Santa Marta.

También señalan una relación de identidad y vestimenta, amparada en la creencia de que quienes usan trajes típicos son más indígenas que quienes no los usan.

2.6.1.1. El ingreso al sistema escolar (La primaria: yo diferente, yo excluido). El proceso de inserción escolar de los estudiantes es diferente teniendo en cuenta la procedencia, el tipo de escuela: pública o privada, y la existencia o no de educación propia. El desplazamiento de las zonas rurales a las urbanas 
estuvo acompañado de los traumatismos propios de dejar el núcleo familiar y la comunidad para ingresar a los internados. Para algunos implicó cambios tan significativos como pasar de la selva a la ciudad, o como señala un estudiante Puinave, implicó darse cuenta de que se vivía en un país que se llamaba Colombia, que estaba en un planeta llamado Tierra, y que había otras teorías de la creación del mundo diferentes a las trasmitidas por sus abuelos:

\section{Yo ni sabía que vivía en un Estado}

INF.: Cuando llegué a la capital, todo el mundo muy diferente, ¿sí? Yo ni sabía que vivía en un Estado, que se llamaba Colombia y que estaba (RÍE) en un planeta, que se llamaba Tierra, o sea, no tenía conocimiento de nada, o sea, sólo ancestrales, sólo lo que me enseñaban mis abuelos y las teorías que tenían ellos sobre la creación del mundo, la luna, el sol y eso, o sea, yo me encontré con un mundo muy diferente [y] me interesé mucho por eso. (INDF5 $\left.{ }^{5}\right)$

La educación que recibieron provino en general de comunidades religiosas, a través de las normales, dirigidas por personas que manifestaron un profundo desprecio por los indígenas, les impusieron una forma de vestir, unos comportamientos y costumbres, y los obligaron a hablar español.

\section{Y las monjas en sí eran muy, muy duras}

ENT.: ¿Cómo fue la experiencia de ingresar al internado?

INF.: Al internado, que yo me acuerde, fue muy duro, porque igual, allá fue una imposición ¿sí? Fue una imposición de, por ejemplo, desde el uniforme, que uno, tradicionalmente se vestía con su indumentaria, en cambio ellos vinieron a imponer unas, reglas, tanto en el uniforme, como en la forma, en el comportamiento que uno debía tener frente a sus superiores, frente a las demás niñas, frente a respetar unas, unas normas, hasta de comer, y todo, y las monjas en sí eran muy duras, muy estrictas, porque no dejaban que uno se durmiera hasta tal hora, sino que tenía que ser hasta la hora de ellas; tenía que despertarse a la hora de ellas; no poder hacer algo que fuera en contra de las reglas de ellas, establecidas por ellas, entonces, fue muy duro, porque hasta me, nos prohibieron hablar en lengua, entre nosotras las niñas, ¿sí?, porque decían que eso era un insulto, que qué uno hablaba a espaldas de ellas, ¿sí?, era como, como restringirnos ese diálogo, entre nosotras. (INDF4)

El rechazo fue la práctica más generalizada; los compañeros de clase se negaban a trabajar en grupo con ellos o a establecer cualquier lazo de amistad. La violencia física también fue una constante por parte de los profesores:

5. Se indica el tipo de estudiante: indígena (IND), o afrodescendiente (AFRO), luego se señala si es hombre $(\mathrm{H})$ o mujer $(\mathrm{M})$, posteriormente el número de entrevista. 


\section{A mí no me tenían en cuenta en los grupos de trabajo}

INF. Entonces allá existía, antes, porque ahora ya no, existían lo que son los internados para mujeres, internados para hombres, entonces, eh, creo que estuve dos años, de seis y siete años estuve allá, estuve interna porque mis padres estaban aquí en Bogotá, trabajando, entonces, mi abuelita, podía ver por nosotras, pero no todo el tiempo, entonces, nos internó, pues, ahí era muy difícil, eh, porque, pues, el hecho de ser indígenas, pues nos excluía, a mí, o sea, yo me sentía excluida, a mí no me tenían en cuenta en los grupos de trabajo, ehm, siempre nos tildaban de COCHINOS, de piojosos, ¿sí?, a pesar de que eran MONJAS, las que estaban ahí, como, o sea, pendientes del cuidado de los estudiantes, eh, pues, ahí más que todo, entraban a estudiar, no INDÍGENAS, ¿sí?, y pues, el hecho de estar un indígena o dos o tres, siempre se sentía ese, RECHAZO, eh, nosotras, pues, con mi hermana, estuvimos ahí en el internado, entonces tratamos, no podíamos hablar bien el español, entonces, hablamos entre español e inga, entonces, habían cosas en español, que las podíamos pronunciar, pero más que todo se combinaba con el inga y no nos entendían, y, entonces resulta que, que cuando pasa esto, pues, habían otras compañeras inga, que eran más grandes que nosotras y nos ayudaban, nos decían, no digan así, digan ASÍ, en español, ¿si?, pero entonces, cuando ellas no estaban, entonces las monjitas nos REGAÑABAN, y nos pegaban porque ellas utilizaban lo que es la regla, eh, o digamos, el empujón, o el golpecito en la boca, que así no hable, que hable bien, ¿sí?, porque para ellos, el hecho de uno hablar en los dos idiomas, es que uno no habla BIEN, que uno es como TONTO, como bruto, que no sabe, ¿sí?, eso, cuando digamos, lo que más me acuerdo es los fines de semana, que en mi comunidad tienen la costumbres los abuelos, de llevarles cosas, bueno, a las monjitas, entonces, resulta que, entre semana, pues ellas se portaban muy feo con nosotras, ¿si?, porque no nos dejaban hablar en la lengua, a veces nos poníamos el chumbé, para amarrarnos el cabello, no' lo quitaban, nos decían que nos peináramos con otras moñas, por ejemplo, o a mí me pasó eso, y yo recuerdo, y así, otras cosas, ¿si?, entonces, eh, ahí era pues como esa exclusión, pero cuando mi abuelita llegaba, digamos con doce huevos, con una gallina, con papa, con frijol, para darles de ofrenda a las monjas por el cuidado que yo recibía, ahí sí eran diferentes, jay! que la niña, que se portó muy bien, que jay!, que ella es muy juiciosa, que no sé qué, o sea, ¿sí?, se notaba. (INDF7)

Este paso doloroso por la escuela hizo que se aislaran de sus compañeros y sólo hablaran con otros indígenas, procedentes de otras comunidades o del mismo grupo. Como lo reitera esta estudiante:

\section{No sabía que era, que había gente importante, y menos importante y MUCHO menos importante}


INF.: Eso era peor, porque ahí en ese colegio, pues resulta que, pues yo me enteré hasta cuando estaba en quinto de primaria, pero o fui consciente de esas cosas, porque ahí estudiaban hijos de senadores, de concejal, de gente importante, entonces, yo no SABÍA eso, o sea, no sabía que había gente importante, y menos importante y $\mathrm{MUCHO}$ menos importante, entonces, eh, siempre era duro, CLARO, como no lo sabía, pues siempre el rechazo era fuerte, entonces, también con ese billete de diez mil me molestaban, nos echaban a un lado, no jugaban con nosotras, NADA, o sea, en el descanso me la pasaba con mi hermana SOLA, solitas las dos a un lado, por ahí retiradas, y es cosa, son cosas que los profesores, no, no se dan cuenta, no lo miran, no miran esa situación. (INDF7)

En términos psicológicos, la violencia simbólica e incluso física, los volvió inseguros, temerosos y avergonzados de su condición de indígenas. La reiterada práctica de menospreciarlos en términos psicológicos y cognitivos, les hizo pensar incluso que estaban vetados para el conocimiento, como se señala en el siguiente texto:

\section{Cree que está VETADO las cosas que uno DICE}

INF.: Porque uno en ese medio, de los niños, a uno mismo le da por ser TIMIDO [...] tímido en el sentido de que uno no participa, y que no hace porque cree que está VETADO las cosas que uno DICE, porque yo por ejemplo desde muy pequeña me acuerdo que trataba de meter TODO lo que yo había aprendido en la comunidad, porque era casi lo ÚNICO que sabía, en cambio esto era, algo nuevo que, que yo tenía que aprender, pero no me lo hacían conocer a la forma que yo lo había aprendido, o sea, ¿sí?, con paciencia, como MIRE, con ejemplos o así, no, era USTED LEA y, eh, lea o, escuche y ESCRIBA, no más. (INDF4)

Como se observa, la diversidad de prácticas formativas también se convirtió en problema; unas basadas en el ejemplo y otras en la imposición. Lo que les implicó un doble proceso: borrar lo aprendido en la comunidad y aprender lo que la escuela les impone. Además manifiestan una desventaja frente a los demás compañeros quienes no deben aprender ciertas cosas pues son conocimientos dados por sentado.

\section{Si a él le toca estudiar esto una vez para aprenderse esto, yo tengo que estudiarlo DIEZ veces para aprendérmelo}

INF.: Y bueno, perdido porque hay muchas cosas que los chinos de acá ya saben, ah no que eso, y yo, o sea, no porque eso yo no lo SÉ, entonces uno ya viene, como que, si a él le toca estudiar esto una vez para aprenderse esto, yo tengo que estudiarlo DIEZ veces para aprendérmelo, porque esa no fue mi cultura, yo no aprendí de esa forma. (INDF1) 
Las condiciones sociales y el marginamiento regional también juegan un papel relevante en el proceso educativo. La inestabilidad de los docentes quienes generalmente vienen de otras comunidades y tradiciones, se hace evidente:

\section{Pérdida de clase y todo}

INF. Por lo que, por la alimentación, por los materiales y todo, que, que deben tener los docentes, o sea, el nivel de educación en este momento, es muy difícil porque, eh, porque recibe pocas horas de clase, ¿sí?

ENT: ¿Es decir que no hay un año escolar de los diez meses establecidos, sino depende del tiempo que dure el profesor que llega, y si no hay, nadie va al colegio?

INF. Sí, y no hay control de eso. Se supone que la Secretaría de Educación del Departamento manda al profesor allá y él, digamos, va a Inírida a hacer sus vueltas y dura una semana y esa ya es pérdida de tiempo, pérdida de clase y todo, entonces no sale igual, que a un niño que está en el municipio. (INDM1)

Quienes realizaron su primaria en Bogotá sufrieron iguales condiciones y reacciones. Los estudiantes que asistieron a colegios públicos manifiestan haber llevado su primaria de manera normal con un cierto reconocimiento de su condición de indígenas. Y quienes tuvieron la fortuna de estudiar en colegios bilingües o de educación propia manifiestan haber llevado un proceso exitoso, acorde con las tradiciones y la vida en comunidad.

\section{El bachillerato: yo me adapto}

Los estudiantes se detienen menos narrando su paso por el bachillerato. Señalan que la enseñanza se realiza toda en español, lo que hace que las diferencias vayan desapareciendo a medida que avanza el conocimiento de la lengua y se van adquiriendo ciertas dinámicas escolares. La homogenización del estudiantado muestra sus primeros frutos en la educación media.

\section{Allá sí es totalmente el castellano}

INF.: En la normal no, allá sí es totalmente el castellano, allá en NINGÚN momento se interesaron por enseñar esa parte, y eso que habían muchos proyectos, pero creo que no lo miraban viable, al final, cuando yo ya estuve terminando once, como que hicieron caso a hacer artesanías, dentro de la normal, pero muy poquito. (INDF2)

Al familiarizarse con ciertas prácticas, los procesos educativos se hacen menos traumáticos, máxime si esas prácticas además son las que también se privilegian en las comunidades, por ejemplo, el uso de la memoria: 


\section{En ese tiempo estaba el auge de la memoria}

INF.: Bien, fue muy buena, porque en ese tiempo estaba el auge de la memoria (RÍE), era muy buena para memorizar cosas, entonces era una de la niñas como APLICADAS, y a la vez de la memoria, me estimaban mucho lo profesores por esa parte. (INDF2)

El paso al colegio supone en ocasiones migrar de las veredas o pueblos a la ciudad, con mayoría de población mestiza. Cinco años de escolarización suponen un proceso de aculturación progresivo, en el que la comunidad y sus tradiciones van quedándose atrás:

\section{Nos tenían discriminados, por tener arraigos culturales indígenas}

INF.: Habían de otras etnias, ¿sí?, habían de otras etnias, básicamente la población está compuesta por un setenta por ciento de indígenas, ¿sí?, que están distribuidos en la parte eh, no en el centro de la ciudad, sino en la selva, en la parte rural, en la parte urbana, como el treinta por ciento, más que todo mestizos, o sea, tirando más a blancos, y pues en la capital, compartimos más con los blancos, y por otra parte nos tenían discriminados, por tener arraigos culturales indígenas, ¿sí?, por nuestra forma de ser, y, prácticamente, uno con el tiempo, uno va cambiando, y va perdiendo todo, ¿sí?, y ya al final, es que uno se da cuenta que eso vale. (INDM5)

Algunos estudiantes también narran experiencias positivas, centradas en los colegios privados:

\section{En un colegio privado es muy distinto}

INF.: Pues lo que pasa es que yo tuve la fortuna de ser becada, ingresé a un colegio privado, entonces, en un colegio privado es muy distinto, la educación pública, nosotros por ser un grupo muy pequeño, entonces fue algo personalizado; en mi curso no eran más de veinte personas, por lo tanto era algo MUY personalizado, los profesores tenían una paciencia increíble además que llevaban años manejando ese colegio; es uno de los pocos colegios privados que hay, entonces, ya llevan una trayectoria bastante arraigada; fue algo muy personalizado, por lo tanto nos dedicaron mucho tiempo. (INDF6)

Los estudiantes que realizaron el bachillerato en colegios de las mismas comunidades resaltan positivamente las experiencias, el hecho de que tengan currículos diferentes a los de las escuelas tradicionales:

No sólo se centra, en la enseñanza como tal

INF.: Entonces, no sólo se centra, en la enseñanza como tal, sino si hay que hacer varias actividades y suspender la clase, académica, se suspende, y 
eso funciona si de pronto un día toca ir, hacer un ritual, un trabajo tradicional a nivel general, entonces el colegio se cierra y hasta nueva orden uno está ahí esperando qué pasa. (INDM4)

Para algunas comunidades, terminar el bachillerato es el grado máximo al que debe aspirar un estudiante. Se espera que ellos regresen a las comunidades y se vinculen a las diversas actividades.

\section{Tú te vas a poner viejo estudiando}

ENT.: Bueno, este es un cuento largo, allá hay una concepción de que si uno ya es un bachiller, ya está uno apto para enseñar, así lo miran allá a uno, en la Sierra, entonces a uno le proponen, ¿y tú porque no te vas a dar clase a tal pueblo, a tal colegio?, independientemente de si me pagan o no me pagan, porque uno está contribuyendo a la comunidad, así se mira allá, entonces, cuando uno tiene ya una mentalidad de que uno tiene que tener plata, y yo no, a mí no me sirve estar enseñando ahorita, yo quiero prepararme más, entonces eso dije yo, yo quiero estudiar más, no quiero quedarme en un bachillerato porque con un bachillerato, o sea, no me siento, ya SÉ lo que me enseñaron, pero no sé más, como que quiero estudiar MÁS, saber más, y, prepararme más, (...) en la casa sí me decían, no, ya, tú qué más, que vas a estudiar, tú te vas a poner viejo estudiando, vas aprender, o sea, qué quieres, y allá, uno no puede estar mucho tiempo solo, o sea, si uno cumple veinte, veinticuatro años, ya uno, tiene que estar casado, tiene que tener su pareja, y empezar a hacer su propia vida, entonces a mí me dicen, tú ya tienes veintitrés años, conformar tu hogar, y organizar, sí, y hacer una familia, que te vas a poner a estudiar, te vas a poner VIEJO, me decían, y yo decía a mí no me IMPORTA, puedo llegar aquí de cuarenta años, lo que sea, pero yo quiero saber cosas, más cosas, y mi 'amá, nunca quiso, nunca (...) (INDM4)

\section{La universidad: yo diferente, yo incluido}

El ingreso a la Universidad Distrital fue bastante difícil para casi todos los estudiantes. La mayoría llegó directamente de su comunidad, lo que implicó adaptación a nuevas costumbres, espacios y hábitos. La ciudad fue una nueva experiencia. Viajar desde la comunidad a Bogotá, una travesía. El ingreso a la universidad supuso diversas expectativas personales, familiares y de la comunidad, pues si bien el interés personal es importante, también los son el familiar y el comunitario. El estudiante llega cargado de expectativas y responsabilidades:

\section{Estudiar, pues para conocer ese otro mundo}

INF.: Bueno, pues, el incentivo es, desde mis papás, que ellos sí desde el principio que, que nos mandaron a traer acá, era estudiar, estudiar, pues 
para conocer ese otro mundo, para entenderlo, para replantear lo que nosotros somos, lo que vinimos a hacer, y sí, es el incentivo de allí, de mis papás, de la primaria al bachillerato, de bachillerato a la universidad, entonces es como, seguir la línea de mi mamá, más que todo, pues mi papá y mi mamá, eh, también empezaron hacer carreras, pero mi papá se quedó por nosotras, por la situación económica, y mi mamá sí terminó la carrera, es lingüista de la Nacional, entonces viendo a mi mamá, también trasnochar y que nos pedía ayuda para eso, pues yo a veces decía, no, eso es muy duro para mí, estar leyendo, y uno que no está acostumbrado a leer, sino que es la generación de nuestro conocimiento es hablar con los mayores, entonces ERA muy difícil, pero no, en el bachillerato ya me incentivaron mucho más, pues a escribir y TODO, es pues, por las profesoras mismas; yo digo que uno el valor más importante de una profesora o alguien que lo oriente, es que le ayude a tener esa iniciativa, como ese QUERER, a las cosas, ¿si?, porque si uno no, o sea, si no lo incentivan a uno a eso, pues uno lo deja de paso, de lado, entonces, mi mamá también, apenas salimos del colegio fue directo a la universidad, entonces, se abrieron convocatorias y todo, primero (RÍE) presentarnos a la Nacional, y yo, no pasé, entonces, yo dije, a no pues la Nacional, era lo que MÁS, pues querido, porque se habla mucho de la Nacional, pero segunda opción fue la Distrital, entonces qué más que la Distrital para poder uno ejercer como profesor, como alguien que guiará procesos para poder fortalecer algo que es nuestra cultura, AQUÍ en Bogotá, y más que todo aquí, donde los niños han perdido una identidad muy grande, y que el reconocimiento de ser indígenas no es, ay! yo visto y medio hablo indígena, entonces, soy indígena, es como apropiarse también de la identidad para también darse a conocer. (INDF4)

La ciudad se les presenta enorme, violenta y ajena. Las diferencias entre la vida en las comunidades y la vida en Bogotá resulta determinante: la percepción del dinero: todo hay que comprarlo; la concepción del tiempo: todo rápido y a una hora determinada; las distancias: todo lejos y la gente: cada uno por su lado.

\section{Bogotá es muy cerrado ¿sí?, la gente es muy cerrada}

INF.: Bogotá es muy cerrado, ¿sí?, la gente es muy cerrada, no en conocimiento sino en relación con las demás, tal vez por el mismo ambiente que se maneja, por la inseguridad; yo me estrellé mucho acá en Bogotá por eso, ¿si?, no sé, allá en mi tierra, las cosas se manejan diferente, uno saluda, o sea, así no lo conozcan uno arma conversación, en todo el camino, ¿si?, y no pasa NADA, ¿sí?, no hay un mal pensamiento, que me quiere hacer algo, o a éste qué le pasa, entonces uno llega acá y todo el mundo lo mira raro, pero yo que hice (RÍE), o sea, qué pasa, sí, uno se estrella muy feo, yo me he estrellado muy horrible acá en Bogotá, entonces como que uno se va volviendo muy rígido; uno ni saluda, uno va perdiendo muchas cosas. (INDM5) 
Al ingresar a la universidad estos elementos se convierte en desventaja frente a los compañeros:

\section{Tú tienes una desventaja más}

INF.: Con mis compañeros se dio un proceso distinto, pues lo que pasa es que cuando tú vienes, tú tienes claro que vienes a algo, entonces, el proceso ya de familiarización, se da distinto, entonces tú llegas como si nada a un lugar donde no conoces a nadie, no perteneces a esta ciudad, o sea, tú tienes una desventaja más, tú sabes que vienes a algo claro y inicias eso y ya el resto de compañeros se va llevando en el proceso. (INDF6)

Los procesos académicos universitarios también se complejizan:

\section{Fue duro el cambio}

INF.: No fue duro el cambio, porque yo, más que todo era, yo extrañaba mucho, extrañaba a mis papás, siempre yo como que, yo nunca había salido de mi casa y, y fue triste todo eso, ¿sí?, además que yo vine aquí y me sentía triste en muchas cosas, en matemáticas, jay!, no Dios mío, yo estaba viendo música, y el profesor de música, pues, ahorita yo me río con él y estoy volviendo a ver música con él, pero en ese entonces, yo lo MIRABA y del susto, que le tenía, yo empezaba era a llorar, no LLORABA pero se me caían las lagrimas, qué, me decía, va a LLORAR, va a LLORAR, yo estaba estudiando técnica vocal y el señor nos exigía al máximo que debes cantar soprano, así, pues, excelentes, y yo, pues, nos pasaba así que las partituras, y yo en la vida no sabía qué era una partitura, yo sabía que a mí me gustaba cantar pero ahí en el baño nada más, saber cantar como tal es, muy COMPLICADO, y ahora tengo las bases que afortunadamente las aprendí, entonces por eso yo, jay! Dios mío ya no más, y bueno (INDF1).

La interacción con los estudiantes se percibe positiva; los compañeros manifestaron bastante interés y preocupación por ellos, por su integración al sistema:

\section{Me siento muy acogido}

INF: Me siento muy acogido, primero que todo empezando por la coordinación del proyecto, que desde el primer día que vine a legalizar la matrícula, me sentí muy apoyado, que no conocía prácticamente a nadie, acá, en la universidad yo no conocía a nadie, empecé a conocer gente ya después, empecé a conocer a unos profesores, de pronto a la gente de salud, a la gente de la institución, del bienestar institucional, que también es de Valledupar, ya nos hicimos amigos, y no mira que yo soy de Valledupar, yo te conozco, yo he visto arawakos, allá en Valledupar, muchos, bueno, y ahí nos fuimos haciendo amigos y siento que de pronto, me han, me han sabido respetar, y me han aceptado, en el contacto social de la universidad. (INDM4) 
Los estudiantes indígenas asocian la acogida con la curiosidad y el deseo de conocerlos:

\section{Les da como curiosidad saber de uno}

INF.: No, bien, yo me he dado cuenta, que, les da como curiosidad saber de uno, ¿no?, pues, ah, los compañeros, que a preguntarte del pueblo, y de las cosas que hay allá, qué hay por allá, (( )), pero sí, yo me he sentido bien, en esta universidad en ese sentido, los profesores también son bien, bien, interesados por uno, de pronto, llama la atención preguntarle, cómo es que le está yendo a uno, el rendimiento académico, lo AYUDA, no, pues hermano, póngase a estudiar, no, o sea, sí, mis compañeros, yo llegué acá, y pues al principio, pues, $\mathrm{mm}$, sin conocer a nadie y todo, pero, después ya, la gente, los compañeros del salón, lo hacen a uno sentirse bien, y uno se siente en confianza y empieza ya, a hacer amistad con gente. (INDM7)

Sin embargo, para algunos las prácticas académicas generan tensiones; las representaciones de la figura del profesor generan un choque cultural:

\section{Yo los miraba como extraterrestres (a los profesores)}

INF: Pues le cuento que... fue muy duro por el lenguaje, ¿no?, que uno utiliza, pero de resto los compañeros, fueron bien, muy bien, yo casi con profesores, en el primer semestre no me relacionaba, porque yo venía con esa CONVICCIÓN, de que los profesores son un nivel más alto (...) y en mi pensamiento, yo decía, yo no puedo llegar hasta allá, para HABLARLES, entonces cuando yo llegué acá, les preguntaba a mis compañeros, pero ustedes cómo hacen para hablar con el profesor, y me dicen, pues normal, él es una persona normal, pero (a mí), pero ellos son, o sea, de pronto yo los miraba como extraterrestres (RÍE), porque siempre nos mantenían de que nosotros éramos allá, y nosotros éramos ahí (INDICA CON LA MANO POSICIÓN SUPERIOR E INFERIOR RESPECTIVAMENTE) o sea si eran capaces de colocarse una tarima, se la colocaban (RÍE). (INDF2)

La timidez sigue siendo una constante en algunos indígenas, quienes se sienten inseguros frente a sus conocimientos. Existe cierto complejo de inferioridad producto de años de rechazo y subvaloración por parte de compañeros de clase y profesores; sin embargo, ya en la universidad las cosas parecen cambiar, el tan anhelado deseo de ser incluido en los grupos, finalmente se logra:

\section{Me da mucha pena preguntar}

INF.: Dentro del aula en clase, no hay problema, incluso mucha gente ha tratado de ayudarme, porque yo era muy tímido cuando llegué, inclusive, MÁS que tímido, yo no sabía, muy, me da mucha pena preguntar, de pronto la gente ya entiende, ahí normal, y yo ahí preguntando, cómo me van a 
mirar, cómo me van aceptar, o sea, como complejos que yo tenía, cuando llegué acá, pero mucha gente sí pudo entender eso y me colaboraban, nunca me rechazaron para trabajo en grupo. (INDM4)

La aceptación hace que ellos cambien su autopercepción. Se sienten más orgullosos de su identidad indígena, más seguros y capaces de interactuar con el otro como iguales:

\section{Ya llegué ya con una imposición}

INF.: Lo que pasa es que yo me crié con mi abuelo, ¿no?, eh, y al criarme con mi abuelo, mi abuelo, me decía, me llevaba, me traía, me (explicaba); de repente, por qué eso, entonces yo era muy viajero, muy andariego, estaba yendo constantemente a Venezuela, igual venía constantemente para Bogotá, a donde mi tío, a Medellín a donde mi tía, y así, de allá para acá; de repente eso me dio una ventaja, ¿no?, de que yo tengo una hermana, en Venezuela, ¿no?, pues, es mi prima, pero nosotros nos criamos con mi abuelo, entonces, nos llevaba a trabajar en diciembre, entonces yo ya era más familiarizado con la ciudad y cuando entré al primer semestre a la Distrital me salté el primer paso, que es el de la primiparada, ya había pasado por eso, entonces, dije no, llegué a los quince días después, pero entonces, ya llegué ya con una imposición, ¿si?, buenas tardes, mi nombre es Oscar Bastidas Jacanamijoy, soy indígena de Putumayo, y en cualquier cosa que le podamos servir ¿sí?, entonces, ya TODO el mundo me iba relacionando, yo en la carrera, (teniendo) relación de CUÁNTOS, indígenas habían en primero, y me encontré con DIEZ indígenas, pero que a NINGUNO lo conocían ahí, al único indígena que relacionan en el Vivero es a mí, en algún evento, comunidad indígena, todo evento, Oscar, comunidad indígena, Oscar, ¿si? (INDM3)

2.6.1.2. ¿Y la escritura? Las primeras letras. Las primeras letras se aprendieron en casa con la familia o algún otro miembro de la comunidad. En términos generales la madre es la encargada de iniciar los procesos de escritura y lectura, casi siempre en español pues la mayor parte de la población no conoce los sistemas de escritura de la lengua indígena.

\section{La educación principal uno la adquiere en su hogar}

INF.: Pues básicamente la educación principal uno la adquiere en su hogar, ¿no?, en su casa con su papá y su mamá, yo creo que con ellos fue con los que primero aprendí a dar ese primer PASO, a saber cómo son las letras, que qué me van a enseñar, pero, digo, el español, en el colegio ya lo aprendí por parte de mis profesores que tienen una licenciatura. (INDF1)

Los recuerdos de los estudiantes de las primeras clases de escritura en la escuela se limitan a señalar que se empezó con palitos y bolitas, y se pasó a la 
identificación de letras y luego a los silabarios. Quienes estudiaron en colegios religiosos recuerdan que se empleaba mucho la memorización, la reescritura de textos, y la elaboración de planas y en general señalan que aunque el trato fue duro, se obtuvieron resultados positivos y hubo un buen proceso de adquisición. Recuerdan el empleo de cartillas como Coquito y el uso de la letra cursiva.

\section{El bachillerato}

Al pasar al bachillerato la escritura se limita a la toma de apuntes, a la elaboración de resúmenes y a la escritura de textos, casi siempre de tipo narrativo. Señalan que se escribe sobre lo que los profesores piden pero no lo que los estudiantes quieren, además resaltan el poco interés de los profesores por los textos, y la poca comprensión de los textos, pues el profesor tiene una interpretación y es esa la que desea que los estudiantes le escriban, no otra. Aunque también señalan que durante el bachillerato se les permitió hablar un poco más de sus tradiciones y costumbres y en algunos casos se les invitó a escribir sus mitos y leyendas. Señalan mucho el trabajo autónomo como garante de un buen aprendizaje.

2.6.1.3. La escritura en la universidad. La relación oralidad-escritura. A continuación presentamos algunas de las representaciones que se evidencian en las entrevistas de los estudiantes en cuanto al tema de la escritura académica en la universidad.

La relación oralidad escritura es uno de los primeros temas que aparecen al cuestionar a los estudiantes por la escritura. Destacan su condición de pueblos tradicionalmente orales, y terminan relacionándola con la educación y los procesos de aprendizaje.

\section{La oralidad es vida}

Para esta investigación este es un tema de suma relevancia pues estamos frente a la cuestión de la tradición cultural. Las comunidades indígenas, en general, se han mantenido ágrafas y la oralidad es la práctica más generalizada; a través de ella se transmiten los conocimientos de generación en generación y la palabra oral adquiere carácter sagrado. Por el contrario, en la universidad, y en general en las sociedades occidentales, en el ámbito académico prima el discurso escrito.

Los estudiantes indígenas entrevistados señalan esta situación dentro de sus comunidades: 


\section{La palabra está en constante movimiento}

INF.: Todo es oral, todo se maneja a través de la oralidad, ahí le da mucho valor a lo que es la palabra, la palabra juega un papel muy importante, digamos en la transmisión de TODO ese conocimiento, porque ellos dicen, la palabra es VIDA, la palabra está AHÍ, la palabra no es algo inerte, no, la palabra está en constante MOVIMIENTO, lo mismo que el pensamiento, entonces el pensamiento, la palabra y la ACCIÓN; porque usted como persona no puede PENSAR y DECIR y hacer otra cosa, usted no puede pensar, no puede hablar otra cosa de lo que usted está pensando, y después ir a decir otra cosa, o hacer otra cosa, ¿ya?, entonces siempre hay una unión entre el pensamiento, la palabra y la acción. Entonces ellos siempre... eh, por eso, digamos, el hombre, eh, digamos, en el mambeadero, en la maloka, cuando utilizan el espacio de la maloka, entonces ellos dicen, vamos hacer amanecer esa palabra, esa palabra que es, un poco el pensamiento, y, esa palabra se convierte en acción. Al otro día cuando la mujer, es una palabra que ellos endulzan cuando con la coca, con el tabaco, para que esa palabra se convierta en una ACCIÓN, y esa acción es cuando la mujer acompaña a la mujer, digamos, en la chagra, que esa palabra que ellos le trasmiten, es igual el hombre, es la energía y la mujer es la TRANSFORMADORA de esa energía y cómo lo transforma, en el trabajo diario que hace digamos en la chagra, cuando lleva a sus hijos en la chagra, y les explica en ese espacio los cuentos, cuando les está contando un mito y todo eso, digamos es un forma de educar, es así como nos educan a nosotros, no?, es como nosotros, es como nosotros nos educamos, porque entonces ellas dicen, llevamos a los niños, eh, llevamos a los niños, es para que empiecen ellos, vean, miren, y nosotras le vamos diciendo, siembra, digamos, siembre la papa, siembre la yuca, siembre el ají, siembre la coca, siembre el tabaco y usted en TODO lo que usted vaya sembrando, entonces va sembrando un poco el corazón suyo, está sembrado algo, y entonces eso es lo que te va a permitir, tener como un asentamiento, como una base, no?, tuya, entonces, ese es tu espacio, eso es tuyo, ya, porque ya lo sembraste, es tu CORAZÓN lo que estás sembrando, entonces perteneces allí, ya tienes un lugar de pertenencia. (INDF 5)

Esta estudiante manifiesta con vehemencia el sentido que la palabra oral tiene para su comunidad; la vitalidad y fuerza que posee. Pero también nos introduce otra relación.

\section{Oralidad y conocimiento}

Hablar y pensar, pensar y hablar son acciones que van de la mano, se entrelazan; son inseparables. Tal como lo reitera, otra entrevistada:

Habla lo que sabe 
INF: [En la oralidad] Como que uno se posesiona de lo que está diciendo (RÍE), en verdad, habla lo que sabe y no hay la tentación de copiar. (INDF2)

La estudiante justifica la predilección de la oralidad manifestando la relación de ésta con el conocimiento que difiere de otras prácticas menos originales.

\section{Problemas de interferencia}

Sin embargo, en la relación oralidad-escritura parecen existir ciertos problemas relacionados con la interferencia de una en la otra. Las características propias de la oralidad, como la repetición y la reiteración de ideas, suelen terminar haciendo parte de la escritura.

\section{Estoy diciendo lo mismo}

INF.: En los escritos, sí, un poco, es poner la posición mía, porque es que redondeo mucho, mucho; entonces yo explico una cosa, y yo digo, jay!, no, es que se me olvidó otra cosa, entonces, vuelvo, y cuando leo, y yo, ay, no, estoy diciendo lo mismo, entonces, ese es mi problema, es como la redundancia que le hago a un texto, aunque, por ejemplo, los profesores me dicen, no, pues qué bueno, pero otros me dicen, no es que eso está... ¡especifique, especifique! (RÍE). (INDF4)

El circunloquio propio del discurso oral se manifiesta dentro del discurso escrito y se convierte en un problema. Siguiendo a Ong, estaríamos frente a una de las características que él atribuye a las psicodinámicas de la oralidad: la redundancia, debida a la lentitud con que trabaja la mente.

\section{Diferencias entre registro oral y escrito}

Para los estudiantes entrevistados el paso de un registro a otro también implica dificultades:

\section{Un lenguaje diferente}

INF.: No logro porque es como otro lenguaje, ¿sí?, y eso mismo me lo dijeron en el anteproyecto, la profesora me dijo, yo pasé su anteproyecto Sandra, muy bien y todo, dijo, pero cuando yo lo empecé a leer, no lo entendía, me tocó, leerlo TRES veces, me dijo ella, me dijo, porque ustedes utilizan un lenguaje diferente. (INDF7)

La idea de otro lenguaje, en la cita anterior, aunque proviene de la profesora, es interesante, pues la estudiante la asume de esta manera y supone enormes diferencias en el paso de la oralidad a la escritura, y quizá como veníamos señalando, de una forma de pensamiento a otra. 
Las diferencias en los registros suponen diferencias en el grado de complejidad:

\section{La escritura es muy concisa}

ENT.: Lo que pasa es que lo oral a ti, te permite defenderte más, la escritura es muy concisa; si a ti te piden, exponga lo que piensa el autor Hegel, de acuerdo a tal, tú tienes que exponer eso, mientras que a si te dicen, de acuerdo a lo que piensa Hegel, cómo podrías aplicarlo, entonces eso te permite defenderte mucho MÁS, aunque en el momento no esté segura... (INDF6)

La escritura supone una mayor dificultad al requerir mayores procesos de elaboración; la oralidad supone repetir o recitar un conocimiento y da la posibilidad de defender una idea, incluso si no se está muy seguro de ella.

\section{La memoria histórica de los pueblos}

Algunos estudiantes indígenas han ido interiorizando el discurso occidental de la primacía de la escritura frente a la oralidad en cuento al mantenimiento de las tradiciones:

\section{Usted habla bonito, pero entonces si no está escrito es como si no valiera}

INF.: Entonces ella me motivó MÁS, ¿sí?, ella me decía, usted está, ya entró a sexto de bachillerato, usted tiene que pensar en cómo va a hablar de su comunidad, por ejemplo, un día me dijo, chévere que usted escribiera todo lo que hace, lo que usted hizo en su COMUNIDAD, todo lo que hace aquí en Bogotá, con sus papás, no sé qué, no sé cuando, y yo le decía, ¿sí?, sí, eso es bueno, porque, digamos, me decía, de aquí a unos años, eh, de pronto a usted se le vaya olvidando, entonces, si usted escribe, pues, eso le sirve como un DIARIO, donde usted va recordar, todo lo que usted habla, todo lo que usted dice de su comunidad, porque a ella le gustaba que yo hablara, y hablaba BIEN bonito, pero si no está escrito es como si no valiera, ¿sí?, entonces, desde ahí empecé a entender que como de muchas comunidades indígenas no hay nada escrito, entonces se va perdiendo TODO, ¿sí? (INDF7)

Esta estudiante señala la diferencia entre las dos prácticas y la validez de una sobre la otra; la expresión "usted habla bonito, pero entonces si no está escrito es como si no valiera", resume claramente la idea.

\section{La escritura, un problema de memoria}

En la relación oralidad y escritura, los estudiantes atribuyen características es- 
peciales a la escritura. La escritura se relaciona con la memoria y la acumulación de conocimientos:

\section{Se le acumulan tantas cosas}

ENT.: En las evaluaciones escritas, al principio de la carrera, ¿cómo has visto qué ha cambiado tu desempeño?

INF.: De pronto en el colegio es como una debilidad, pues, podría llamarse así, tenía muy poca capacidad de MEMORIZAR, ¿si?, no sé por qué, pero yo para memorizar algo tenía que estudiarlo muchísimo, pero lo memorizaba, yo era responsable y lo sigo siendo, entonces respondía a mis posibilidades, y ya una vez en la universidad, como a uno se le ACUMULAN TANTAS COSAS, o sea, que TIENE que estudiar esto, pero también esto, pero no es una sola cosa de dos hojas, no, el libro para mañana, pero también el ensayo de cien hojas; ya no le queda a uno como de estudiar TANTO tiempo una sola cosa, entonces la mente le va trabajando a uno más rápido, para estudiarlo dos veces, y que ya se lo haya aprendido; hay cosas que sí necesita uno estudiarlas varias veces. (INDF1)

Esta estudiante manifiesta primero que todo el cambio de la cantidad de conocimientos para memorizar en el colegio y en la universidad que hace que la memoria deba esforzarse mucho más. Así lo ratifica otro estudiante que relaciona escritura y memoria, como si se tratara de escribir lo que está en la memoria, lo que supondría no una elaboración sino un producto, reflejo de la oralidad:

\section{Entonces falta un poco de memoria}

ENT.: En las evaluaciones escritas, ¿qué tipo de dificultades has tenido?

INF.: Pues, en la parte de memoria.

ENT: ¿De memoria, de recordar información?

INF.: Sí, de recordar así mucha información.

ENT.: ¿Por la cantidad o por lo que falla un poco lo de la lectura?

INF.: Por la cantidad, a veces dejan mucho tema, dictan mucho tema en especial y entonces uno no está estudiando todos los días, de lo que le han explicado, de lo que han visto en clase. Entonces falta un poco de memoria. (INDM 2)

\section{La escritura, cuestión de práctica}

La escritura es una práctica académica que genera costumbre y los resultados dependen de haber adquirido el hábitus. 


\section{La costumbre}

ENT.: ¿Y cómo te iba en las evaluaciones escritas, en relación al proceso de escritura?

INF: Ah!, claro, el que estudia sabe, ¿no?, yo pensé que no.

ENT.: Sí...

INF.: Yo te digo, después de once, doce, años de estar en lo mismo, se convierte en cotidianidad, ¿no?, pues ya usted lee en español, escribe en español, de repente es por eso, ¿no?, porque yo conozco casos de COMPAÑEROS, que REALMENTE, les queda GRANDE el español, pero realmente ellos sí inician pero cuando se encuentran con la realidad, en los primeros semestres, son mortales para ellos, mientras se adaptan a la ciudad. (INDM3)

La idea de hábitus es bastante frecuente, nos lo recuerda el refrán popular: "La práctica hace al maestro". Pero también depende de la familiaridad que se tenga con el código, en este caso el español. Conocer la lengua resulta básico para el éxito escolar. La idea de inicio planteada por el estudiante es importante porque señala diferencias con los estudiantes que ingresan a la universidad directamente de sus comunidades, y vienen con un conocimiento del español limitado, además del desconocimiento de las costumbres de la ciudad.

\subsubsection{Funciones de la escritura. Para qué sirve la escritura académica.} Bajo este apartado se agrupan las respuestas de los estudiantes al interrogárseles por las funciones de la escritura académica en la Universidad.

\section{Función comunicativa}

Para algunos estudiantes la escritura sirve para comunicarse. Se da una analogía con las funciones del lenguaje, en las que la función comunicativa es recurrente y primordial. Sin embargo, el desarrollo de esta representación es simple, se refiere a expresar un punto de vista y hacerlo de manera correcta.

\section{Expresarme bien escritamente}

INF.: Principalmente en la carrera que yo estoy haciendo, en las materias de química y biología, piden muchos informes, como expresarse bien escritamente, eh, utilizar las palabras correctas, para, expresar lo que uno quiere decir, y como (unir) en la práctica esa parte. (INDM2)

Se trata de conocer un código y poder utilizarlo de manera correcta, en ocasiones la escritura se equipara a la redacción, como lo señala el informante siguiente: 
ENT.: ¿Cuáles crees que son los propósitos que tienen los trabajos escritos, cuando los solicitan los profesores?

INF.: Que nosotros aprendamos a leer BIEN, y, de ahí que aprendamos a redactar, ¿no?, aprender a escribir, con sentido, pues, y sin tanta palabra. (INDM7)

\section{La escritura sirve para evaluar}

Como ha sido señalado por la literatura, una de las funciones que mayormente se le atribuye a la escritura es la evaluación, en la que se busca básicamente comprobar la adquisición de conocimientos; es en esencia un dispositivo de control por parte de los docentes. El tema de la evaluación es complejo y presenta varias aristas que sería importante tener en cuenta. En la universidad existen dos tipos de evaluación: escrita y oral, cada una con características y funciones diferentes. Para la mayoría de los estudiantes, la evaluación escrita tiene un fin de comprobación y poco influye en el replanteamiento de las estrategias docentes en el aula:

\section{El profesor va a mirar qué tanto ha captado uno}

ENT.: ¿Cuáles crees que son los propósitos de los trabajos escritos?

INF.: Yo pienso que es como una evaluación de la capacidad que tiene un estudiante, el profesor va a mirar qué tanto ha captado uno, de lo que él ha hablado, y de las direcciones de lo que están enseñando ahí, y por un lado evaluar, qué tanta capacidad tiene uno, para hacer un análisis de un texto, digamos, entonces yo siento que es una forma que hace parte de la metodología que usa el DOCENTE, pero, lo más chévere sería que si alguien está cometiendo un error, pues, que el profesor cambie el método pedagógico, que busque otras alternativas, si eso no se da, la cosa como que no funciona mucho, ¿no?, aunque eso no me ha pasado todavía, puede que pase eso, no sé, uno piensa. (INDM 4)

La escritura de textos también sirve para que el profesor indague por los puntos de vista de los estudiantes, como lo señala esta estudiante:

Para ver el punto de vista de uno

INF.: Siempre los trabajos escritos, es decir como ensayos, en cuanto a las materias que no son tanto de relleno, sirven para ver el punto de vista de uno, de las ideas que uno tiene sobre cómo se puede enfrentar a tal tema, equis o ye tema que el profesor tenga en la clase y ya no sé qué otra cosa... (INDF3)

Existe la idea de que se escribe para medir, ya sea los conocimientos adquiridos o el interés por la materia: 


\section{Es como medir la parte académica}

ENT.: Ejemplos así de esos propósitos, que ellos tienen.

INF.: Es como medir la parte académica, o medir como la parte de INTERÉS a la materia, o otros yo creo es por calificar algo, que me ha pasado porque hay profesores que dicen, ah, no, en todo el semestre vimos tal cosa y tal cosa, entreguen un ensayo como final, y ya, entonces no le veo el sentido a la clase como a la materia. (INDF4)

En el proceso de medición, para los entrevistados lo que más se valora es la reproducción de una idea: la idea que el docente supone es la idea del autor del texto:

\section{¿Usted por qué?, ¿de dónde sacó eso?}

ENT.: ¿Cuáles crees que son los propósitos que tiene el profesor cuando pide un trabajo escrito?

INF.: También yo siempre me preguntaba eso, que si uno lee a un autor de alguna forma u otra, uno dice, NO, pero cómo dice eso, si desde mi lenguaje uno le enseña OTRA cosa, y si uno habla desde el lenguaje de uno, y dice, no, esto está mal, o de pronto el autor, o de pronto el autor no se acerca a nada a lo que YO ENTENDí, y entonces el profesor le dice bueno pero es que eso no era lo que yo quería que usted dijera, del autor, entonces uno queda perdido, a mí me pasó en casi todos los semestres, porque teníamos que hablar de cierta pedagogía, y teníamos que decir lo que el autor estaba diciendo, TAL CUAL, y meter lo de nosotros, pero entonces yo hacía un SANCOCHO, pero yo lo ENTENDÍA, o sea, yo decía, yo lo entiendo, imposible, que un profesor no, pero él me decía, no, porque el autor no está diciendo eso, usted por qué de dónde sacó eso, y yo, pero cómo así, si yo lo entendí así, y yo metí lo que está bien pa' mí, lo que está mal, o bueno, lo refuté ¿si?, pero por qué, no, eso no es así, eso está mal, vuélvalo hacer. (INDF7)

\section{La escritura sirve para aprender}

Escribir para aprender también es una idea generalizada, como se señaló anteriormente. Supone procesos de relacionar contenidos e ideas:

\section{Uno aprende mucho escribiendo}

ENT.: ¿Qué piensas de esas indicaciones que el profesor da cuando manda a hacer trabajos escritos?

INF.: A mí me parece que es buena metodología, a pesar de que mis compañeros hacen mala cara, cuando dicen que hay que hacerlo a mano, todo 
el mundo, ino Profe!, computador, computador, control ce, control uve; entonces ellos dicen que no, entonces yo pienso que este, es muy buena metodología así, porque igual como dije anteriormente, uno aprende mucho escribiendo, cuando yo leo y saco la idea, yo no escribo lo que estoy viendo en el texto, de pronto se me viene otra cosa, o le puedo agregar otros conectores, o algo así, pero me parece buena metodología. (INDF3)

Para otros estudiantes, la función de la escritura es poder entender e interpretar los fenómenos:

\section{Nos ayudan como que a mejorar nuestro nivel de pensamiento}

ENT.: ¿Qué propósitos crees, que tienen los trabajos escritos que tú presentas?

INF.: Evidenciar la parte que hacemos con la parte de práctica, confrontarlo con una parte teórica, porque a veces podemos manejar, hablando de la parte de laboratorios de química, todo eso, manejamos ciertos reactivos, pero nos pueden dar, otras cosas que nos hablan en una teoría, porque de pronto un reactivo no estaba puro, estaba contaminado, porque la temperatura no era esa, porque esa no era la cantidad exacta que debíamos agregar de sustancia, entonces, confrontamos todo eso, con la parte teórica, y eso nos ayuda como a entender mejor, y a ver qué es lo que está pasando y a interpretar más las cosa que nos están enseñando, en la parte pedagógica; creo que nos ayudan como que a mejorar nuestro nivel de pensamiento, a cómo argumentar nuestras ideas, a cómo estamos viendo las cosas desde nuestro punto de vista. (INDM6)

La escritura permite adquirir conocimientos declarativos de las carreras, que luego se evidencian en un mejor desarrollo profesional:

\section{Al mismo tiempo que uno va escribiendo, va aprendiendo cositas}

ENT.: ¿Te ha gustado la experiencia de escribir acá en la universidad?

INF.: Pues, sí, muchísimo.

ENT.: ¿Por qué?

INF.: Es que ese escribir le sirve a uno para formarse como persona, para aumentar su vocabulario, para aumentar el contexto en el que uno va hablar, porque uno al momento de escribir va buscando sinónimos, así yo uso esa palabra, pero cuál es el sinónimo, qué palabra le puedo poner, entonces uno va aprendiendo. Mucho me ha servido, muchísimo, es muy interesante, al mismo tiempo que uno va escribiendo va aprendiendo cositas, y todo eso se le va acumulando como para que en algún momento que una persona o alguien le pregunte, bueno, usted qué hace en su carrera, usted 
qué va hacer, entonces, todos esos ensayos y esos resúmenes, le sirven a uno para dar una respuesta completa, bueno, yo SOY ingeniera y tal, yo voy hacer esto, estoy en capacidad de hacer esto, bueno usted ESTÁ en capacidad de hacer esto, eso se CONSTRUYE a medida de la formación académica y profesional que tenemos hasta este momento. (INDF1)

\section{La escritura da seguridad}

Es una manera de testimoniar, dado que la oralidad es pasajera, la escritura queda y sirve para respaldar lo dicho.

\section{Es como más para sentirme más seguro}

ENT.: ¿Tienes costumbre de tomar notas en clase?

INF: Sí.

ENT.: ¿Cómo tomas esas notas, tienes alguna forma particular para hacerlas, y para qué las usas?

INF.: Yo soy de los (RÍE) que escribe casi TODO lo que dice el profesor, el fin de esas notas es como para sentirme más seguro, por ejemplo en alguna sustentación, yo por ejemplo puedo tomar las notas que tomé en cierta clase y leerlas y si mi profesor, por equis motivo, me contradice, yo le puedo decir, MIRE, eh, según lo que nos explicaba la anterior clase, y según lo que tengo entendido, esto es así, y así, y así, y se lo puedo sustentar, y si está errado, y me enseñó MAL (RÍE), entonces, pues es como más para sentirme más seguro, como más respaldado de las cosas que tengo ahí anotado, pues, trato de copiar, lo más que pueda. (INDM.6)

Para qué debería servir la escritura en la universidad. Una vez que se han identificado algunas de las funciones que los estudiantes reconocen como los objetivos que los docentes del escribir, resulta interesante conocer qué expectativas tienen ellos frente a la escritura y qué función podría cumplir.

\section{Evaluación consciente}

Los estudiantes señalan que los profesores piden los trabajos y no se vuelve a saber de ellos, excepto quizá cuando se pone la nota, pero no hay ningún grado de discusión sobre los resultados del escrito. Lo que sugiere pensar que la función atribuida al trabajo por el profesor es la simple toma de notas:

\section{No se hace un debate después}

INF.: Uno no sabe si verdaderamente lo que uno piensa es eso, no se hace un debate después, de lo que se hizo, ¿sí?, ni entre los mismos alumnos, 
sino que el profesor recoge los trabajos, se los lleva y chao, usted no vuelve a saber más nada de él (RÍE).

ENT: No hay retroalimentación, y ahora va la siguiente pregunta que sería: ¿qué otro propósito te gustaría que tuviera los trabajos escritos?

INF.: En general, mjm, pues más que todo sería retroalimentación, por ejemplo, los ensayos de los laboratorios de calidad de agua y de química... El profesor le da a uno el libro donde uno puede conseguir las fórmulas y uno las aplica como uno las entiende, y el profesor da una nota y YA, uno no sabe si esa vaina quedó bien, o dónde falló, ¿sí?

ENT.: En dónde falló

INF.: Sí, porque no hay retroalimentación, no hay evaluación de lo que se hizo, ¿sí? más que todo en los laboratorios de química y calidad de agua, y en los ensayos también me parecería interesante, pues, poquito tampoco se va echar una clase completa, sino veinte minutos. (INDM5)

\section{Escritura como generadora de cambio}

En ese mismo sentido los estudiantes piden que sus escritos sean tomados en serio por los profesores:

\section{Cómo generar alternativas}

ENT: ¿Y cuáles consideras que deberían ser los propósitos?

INF.: Generar alternativas, de solución, frente a algunos temas que se quieren cambiar, que se tomen en serio, porque muchas veces, YO VEO, que sólo se presentan como trabajos, más de sacar notas, mas no por ver QUÉ es lo que de verdad aprenden, y cuáles, y qué es lo de verdad la síntesis del estudiante. (INDF2)

Se resalta entonces la idea de que el escrito debe servir más que para sacar una nota, para dar cuenta de lo que sabe el estudiante y de esta manera generar soluciones a los problemas.

\section{La escritura debe permitir establecer procesos de individualización}

Mediante la escritura, el profesor debe identificar las particularidades de los estudiantes. Reforzando la idea de la falta de retroalimentación, también se propone que los docentes desarrollen estrategias pedagógicas como el ejemplo para mejorar la escritura y para que los estudiantes no sean vistos como una masa uniforme: 


\section{Parece que todos somos iguales}

INF.: Pero, ellos, lo cogen, y se lo llevan, pero no vienen acá y no dicen, vamos a compartir este trabajo, que me pareció excelente, MIREN una idea que se propuso aquí, NO, ellos no nos comparten qué dijeron nuestros compañeros, que por qué pusieron eso, y me parece que debiera hacerse; cada uno aporta muchas cosas, ideas, palabras, oraciones, que muchas veces decimos, UY! hasta interesante, hasta uno dice, UY! se le ILUMINÓ, pero todos tenemos nuestro, entonces para esa complementación, DEBIERAN, los profesores revisar y mirar, UY!, me pareció interesante esta persona, MIRE lo que dijo ACÁ, o si no, pues, PARECE que todos somos iguales (RÍE). (INDF2)

\section{Escritura para aportar conocimiento}

Los estudiantes no son sólo actores pasivos del proceso escolar, ellos también poseen conocimientos que pueden aportar:

\section{Aportar conocimiento}

ENT.: ¿Cuáles te gustarían que fueran los propósitos de los trabajos que se presentan aquí en la universidad?

INF: Pues, más que todo de los míos es como, que yo, yo quisiera es como APORTAR todo ese conocimiento que yo tengo para que otros lo puedan leer y discutir, un aporte más de conocimientos, que igual aquí yo sé que algunos compañeros se interesan por lo indígena, pero no le dan el valor, o sea, como el sentido de pertenencia que uno lo tiene, no lo hay. (INDF4)

Pero en ocasiones no se trata sólo de aportar si no de la necesidad de que se den espacios para otros aprendizajes, como señala este estudiante:

\section{La gente debe aprender cómo viven y cómo pueden ayudar los pue-} blos indígenas del país

ENT.: ¿Te gustaría agregar algo sobre lo que me has contado, sobre tu experiencia de escritura, sobre lo que significó o significa para ti escribir en la universidad?

INF: HAY que enseñarle a la gente de la situación REAL, si es por medio de la escritura, de la escritura, ¿no?, había una cosa muy bonita, que hacía el taita Víctor Jacanamijoy; él escribe sus poemas en inga y los traduce al lado siguiente en español, y se los da a la gente, ¿sí?, (sitaspui) sembrar, $((\quad)$ ) aquí vamos a cantar, (( ) ) vamos a danzar, (( )), yo creo que la gente debe aprender cómo viven y cómo pueden ayudar los pueblos indígenas del país, a partir de nuestra reflexión, nuestro análisis, nuestra VIVENCIA, a través de nuestro equilibrio natural ancestral, ¿sí?, que la 
gente aprenda, y a mí sí me gusta que las universidades, que es DONDE SE DEBE APRENDER, porque ellas, mal o bien van ayudar al desarrollo, y al manejo del país en un futuro, pero que conozcan, a mí sí me gustaría proponer, en la universidad, que se HAGA, y más que todo en la facultad de Medio Ambiente, que se haga, una electiva, que se haga una CÁTEDRA, sobre, sobre legislación especial indígena, porque como ambientalistas van a ejercer después y no van a conocer cómo hacerle una consulta previa a los pueblos indígenas, ¿sí?, son ellos los que van a incidir en QUÉ mega proyecto se va hacer, ¿sí?, que el PLAN de manejo AMBIENTAL que manejamos los indígenas, es sin el exterminio de nuestra especie, de nuestra biodiversidad de nuestros pueblos, ¿sí?, y el ministerio que es el encargado de realizar y de dar permisos ambientales, ¿sí?, que mire, que realmente sea claro, porque de no ser así después de dar los permisos debemos demandar, ¿sí?, como pasó con el Estatuto de Desarrollo Rural, lo que pasó con la Ley Forestal, se cae, porque sencillamente no consultan a los pueblos indígenas, y es un derecho para nosotros los pueblos indígenas, entonces sí, es eso y cualquier cosa que le podamos colaborar, aquí estamos a la orden. (INFM3)

Este cuestionamiento del alejamiento de los contenidos curriculares de la realidad del país y de sus gentes lo sintetiza muy bien este mismo estudiante cuando señala que "uno tiene que ser realista a la hora de escribir".

\section{Escritura para reconocer al otro y sus saberes}

En consonancia con el tema anterior, los estudiantes plantean que haya un mayor reconocimiento de sus conocimientos, experiencias y contextos y que no se limite solo a lo que dicen autores extranjeros:

\section{Comprender el saber que traen los estudiantes}

ENT.: En esa medida, ¿cuáles te gustaría que fueran los propósitos de los trabajos escritos?

INF: Bueno, yo creo que comprender el saber que traen los estudiantes, porque así uno sea, o no sea de una comunidad, todos los estudiantes vienen de un ambiente, de un contexto, de una forma de vida muy diferente, ¿sí?, y pues chévere que uno pudiera decir y hablar con los autores desde la experiencia de uno, de vida, ¿sí?, no de lo que ellos nos quieran VENDER, porque muchos autores nos venden es de lo que ellos han visto en su experiencia de vida en otro mundo, digamos, en otros continentes, en otros países, donde no pasa eso acá, ¿sí?, o sea, digamos, de equis problema, en Brasil, no lo va a pasar igual aquí en Colombia, ¿sí?, y uno viene de otros contextos, si ha visto a los niños sufrir, ha visto a los jóvenes en unos ambientes ¿sí?, en dónde no está la realidad propia, de nosotros, 
entonces a mí me gustaría eso por ejemplo, que si hay un saber indígena, o sea, no saberlo entender, pero saberlo escuchar y PREGUNTAR por qué lo estoy HACIENDO, por qué lo estoy escribiendo, mas no que me digan, no, eso está mal, por ejemplo. (INDF7)

Resulta interesante el señalamiento que hace la estudiante: el reconocimiento de la existencia de saberes otros no implica que se tengan que entender tan sólo que se escuchen, se trata de un llamado al reconocimiento del otro.

\section{Escritura para la libertad}

La libre expresión es un reclamo generalizado en los estudiantes indígenas. Se pide poder disentir de los textos y poder establecer relaciones con la cultura propia.

\section{Que uno tuviera libertad}

ENT.: ¿Y te gustaría que esos trabajos tuviesen otro tipo de propósitos?, ¿otros fines aparte de los que mencionaste?

INF.: Que uno TUVIERA como esa LIBERTAD, de coger un texto y decir, no me gusta, por esto y por esto, y por eso no me gusta, o sea, desde mi punto de vista, siendo yo de otra CULTURA digamos, de otro modo de pensar, pero no, uno siempre como que está limitado a algo, tiene que escribir algo que el PROFESOR está pidiendo, ¿no?, no lo que, en cierta forma, tú QUIERES, hacer con ese texto. (INDF5)

Los estudiantes plantean poder fijar su lugar de enunciación, como indígenas que pertenecen a unas culturas y que poseen conocimientos.

\section{La escritura como indicador del aprendizaje}

Centrar el proceso de escritura en el aprendizaje y no en las notas es un reclamo generalizado:

\section{Mirar la capacidad del estudiante en cuento aprendizaje}

ENT.: Ya mencionaste los que crees que son, ¿ahora cuáles te gustaría que fueran?

INF.: A veces yo pienso, una nota no es importante para mí, porque el hecho de yo sacar, un tres o un dos, o un dos cinco, no significa que yo no he aprendido nada, lo que para mí significa es que me falta complementar muchas cosas, que todavía no lo sé, y yo a veces miro esa nota, como que, el estudiante no sabe nada; entonces yo esperaría que con esos trabajos escritos se MIRE la capacidad del estudiante, ¿no?, en cuanto al aprendizaje, y de ahí mirar, si algo está fallando. (INDM4) 
A partir de esa nueva mirada, resultaría más fácil evaluar los procesos de aprendizaje y generar estrategias de mejoramiento de los procesos.

\section{Una escritura más humana}

Se plantea la necesidad de ir más allá de los contenidos, el aprendizaje y las notas hacia la condición humana del estudiante para que así haya una mayor motivación de éste por la escritura:

\section{Mirar la parte más humana}

ENT.: ¿Qué propósitos te gustaría que tuvieran los trabajos escritos?

INF.: No sé, los propósitos a los que va enfocado cada trabajo me parece muy bueno, pero también sería, como que, deberíamos ver la parte más humana de una persona, o sea, no a raíz de, MIREN, el estudiante es tal cosa, entonces, hagamos esto, hagámosle tal trabajo, hagámosle tal cosa, para que aprenda más, y de pronto vemos en ocasiones que el estudiante no rinde, en una clase, en una vaina, entonces no se ponen a ver, QUÉ ES lo que le pasa, sino como que, MIRE, si usted no hace, ya tiene cero, mire si usted no hace, se tira la materia, de pronto, la persona tiene problemas, entonces esos trabajos, eh, como tratar de ver en esos trabajos, como tratar con el estudiante, como motivar a un estudiante, de una forma que a él le dé ganas de hacer ese trabajo, como con el corazón, con la mente, con todo, porque es lo que vamos hacer, cada día de nuestra vida, es lo que ELEGIMOS para hacer cada día de nuestra VIDA, para hacer cada día que nos levantemos, hoy, nos toca trabajar en esto, y me siento bien, o, digamos, hoy me siento mal, tengo que trabajar, y no quiero ir (RÍE), NO, entonces como ver, más que todo enfoquen al estudiante cómo te digo, cómo aclarar sus ideas, cómo decir si esto es de ellos, que vean si con esto va estar bien, porque eso es importante, sentirse bien con lo que uno está haciendo. (INDM6)

Se hace necesario entonces un mayor compromiso del profesor que implique la consideración del otro, sus gustos y sus necesidades.

\section{Otras representaciones}

Otra serie de representaciones aparecen pero con menor desarrollo.

\section{Escribir para aprender a leer}

En la relación lectura-escritura, ésta podría ayudar a mejorar los niveles de lectura, aunque se trate de la creación de fórmulas que ayuden al mejoramiento de la escritura a través del proceso de lectura: 


\section{Aprender a leer bien}

ENT.: ¿Qué propósitos te gustaría que tuvieran los trabajos escritos?

INF.: Aprender a leer BIEN, me gustaría eso, porque yo de todas formas, sé que todavía no sé leer muy bien, no sé, que se inventaran como una fórmula, que uno se dé cuenta de los errores, que uno comete al leer. (INDM7)

\section{Escribir para comprender más fácil}

La escritura debe ser una herramienta para facilitar la comprensión, no para complejizarla:

\section{Comprender de una manera más fácil}

ENT.: ¿Qué esperas de tu escritura aquí en la universidad?

INF: Yo espero, que esto me ayude MUCHO, cuando ya esté laborando, que yo tenga la capacidad de mostrar a mis estudiantes, un texto donde ellos puedan comprender de una manera más fácil lo que les estoy explicando, que no sea tan complicado como llegar y, miren muchachos vayan a tal libro, le sacan fotocopia y se ponen a leer, no, entonces, yo pueda leer eso y lo escriba de una forma que ellos lo entiendan, y le sea más divertido aprenderlo, porque para muchas personas, no es muy agradable que le digan, qué estudia, química, y todos, auchh! (RISAS).

ENT.: ¡Qué dolor!

INF: Sí, entonces, como que no, hacerla más atractiva a diferentes personas, que en esos escritos se refleje que la química no es difícil sino fácil, y es más chévere. (INDM6)

\section{Escritura y placer}

El goce estético también es una función que se manifiesta en estos estudiantes, como lo señala esta joven citando a su maestra:

No hay cosa más deliciosa que tener una hoja de papel y un lapicero y ir (armando) una letra, una frase, un cuento, un texto

ENT.: ¿Te gustaría agregar algo acerca de tu experiencia de escritura frente a las preguntas que te he hecho? ¿Qué consideras que me puedes decir o que me debes decir?

INF.: De pronto, diciéndote todo esto me he dado cuenta que ESCRIBIR y leer, y expresarse en una hoja es bien importante, más IMPORTANTE que yo estar frente a un computador programando, porque sí, puede que sea la 
carrera, y bueno, y yo me exprese, pero no hay cosa más deliciosa como dice una profesora aquí, en la universidad, que tener una hoja de papel y un lapicero y ir (armando) una letra, una frase, un cuento, un texto, TODO, y luego leer lo que uno ha escrito: eso me parece, muy chévere. (INDF3)

2.6.1.5. Las prácticas de escritura académica. El objetivo de este apartado se centró en las prácticas de escritura académica, durante el desarrollo de clase, en trabajos asignados fuera del aula y la escritura por interés propio. También interesó identificar las dificultades más frecuentes de esta práctica.

\section{Toma de notas}

El total de los estudiantes manifestó tomar notas en clase. Notas que emplean con diferentes fines; fundamentalmente para recuperar información y estudiar para las evaluaciones. Aunque también algunos señalan su función cognitiva y de establecimiento de relaciones:

\section{Para relacionar cosas, teorías}

ENT:: ¿Tú tomas notas escritas en clase?

INF.: Sí, trato de tomarlas todas (RÍE), para poder entender y comprender cosas que después cuando vaya a hacer un trabajo, yo, ah! es que tal cosa, lo vi en tal lado, entonces, tratar de argumentar desde allí, porque es que aquí es muy, es mucha teoría, le votan tanta teoría que pues, yo digo, al salir al mundo laboral uno qué va hacer con esa teoría, o sea, pues para Mí, pues yo no sé, es que yo ir a la comunidad, imponer cosas que me dicen acá es como difícil no?

ENT.: Mjm.

INF.: Pero me ha servido es como para relacionar cosas, teorías, tanto lo occidental como lo mío, para reforzarlo en los niños. (INDF4)

Aunque resaltan que se trata de aprender, también señalan su carácter mecánico:

\section{Por aprender}

ENT.: ¿Y qué usos le das, con qué propósito lo haces?

INF.: Pues, a veces para recordar, a veces uno no escucha, entonces, como que uno es mecánico (RÍE), y escribe, eso me ha pasado, a ver... ¿y por qué más escribo?, no, pues, por aprender y a veces yo sé llevar mi agenda a mi comunidad, y hay algunos interesados en leer lo que yo escribo por acá. (INDF2) 
Los estudiantes desconocen el uso de las notas, recalcan su carácter mecánico:

\section{Hay veces que ni siquiera sé para qué}

ENT.: ¿Tú tomas notas en clase?

INF.: Pues mire que yo SIEMPRE, desde primaria siempre he tomado notas, pero hay veces que ni siquiera sé para qué, porque lleno los cuadernos, pero volverlas a leer es muy raro; de pronto leía era cuando había algún taller o un trabajo que nos hubieran dejado y se me había olvidado, entonces, lo retomaba para ver; pero leer las notas que yo hacía así exactamente era muy poco, ¿si?, digamos, eh, que si en tercer semestre anoté algo, y logro otra vez volver a esa nota, pues uno dice, uy! yo escribí esto (RÍE), pues a mí me pasa así, juy!, mire yo escribí de este autor, jay! vea yo no me acordaba, así eso me ha pasado. (INDF7)

La manera de tomar notas es similar y responde más o menos al patrón "lo que me llama la atención":

\section{Me llama la atención algo que el profesor ha dicho}

ENT.: Bueno, ¿eso en los parciales escritos, en clases tienes la costumbre de tomar apuntes?

INF.: Sí.

ENT.: ¿Cómo realiza las notas y para qué las usas?

INF: Cuando tomo notas, digamos, es porque me llama la atención algo que el profesor ha dicho, y que de pronto más adelante cuando lea otro texto me pueden servir, ¿ya? (INDF5)

La cuestión de la memoria se retoma aquí, persiste la idea de que las palabras se las lleva el viento y lo que está escrito permanece, pervive:

\section{Como para reafirmar o recordar}

ENT.: ¿Qué clase de prácticas de escritura tenías en clase, cómo tomabas apuntes, para qué crees que te servían tomar esos apuntes?

INF.: Bueno, la práctica era la de tomar apuntes, que yo creo que es la práctica con la que iniciamos y la que aún se conserva, ahora ¿qué pasa?, ¿para qué me servían?, yo creo que por más apuntes que tú tomes en el momento, que tú tienes que hacer un trabajo, o tienes que refrescar lo que has visto en clase es necesario retomarse, o remitirse a algo que lo sustente; entonces yo creo que los apuntes nos sirven para eso, como para reafirmar o recordar, pequeñas cositas que se nos escapan, porque de por sí, la memoria es amplia, siempre hay cositas que se le escapan y es mejor ESCRIBIRLAS, que quede el testimonio plasmado. (INFF6) 
Resulta interesante la metáfora del computador en la que el apunte conduce en forma de enlace a otro conocimiento:

\section{Como un LINK, ¿sí?, es un enlace}

ENT.: ¿Qué tipo de notas tomas, y para qué crees que te sirven esos apuntes?

INF.: Todo depende, ¿no?, o sea, que quiere uno aprender, entonces uno RELACIONA cositas como SOPORTE para después poder acordarse, como un LINK, ¿sí?, es un enlace, para que tú después puedas seguir y acordarte, palabras claves que tú consideras importantes, a la hora de repasar o de retomar. (INFM3)

\section{Prácticas de escritura dirigidas fuera del aula}

Sin lugar a dudas, el escrito tipo ensayo es el más solicitado en la universidad; otros menos frecuentes los constituyen los informes, especialmente para quienes estudian ingenierías o ciencias; también los protocolos y las actas.

\section{Ensayos, ensayos, ensayos}

ENT.: ¿Aquí en la universidad, qué tipos de textos comenzaron a solicitarte, comenzaste hacer y has hecho hasta el momento?

INF.: ENSAYOS, muchos ensayos; yo creo que aquí, tuve la oportunidad de reafirmarme en la escritura; me acuerdo que el primer texto que nos tocó fue la típica hoja de tus vacaciones, qué has hecho; después empezamos ya con textos referentes a la carrera, a la escritura, a la educación. (INDF6)

El ensayo como práctica académica de escritura es también la más valorada por los estudiantes, fundamentalmente porque les permite establecer su punto de vista:

\section{Me gustan mucho los ensayos, sí, por lo que investiga}

ENT.: ¿De esos trabajos que has elaborado cuál es el que más te gusta?

INF.: Me gustan mucho los ensayos, sí, por lo que se investiga, porque además de tener una referencia bibliográfica, que apoye lo que uno está escribiendo, lo que haya leído, ¿sí?, que uno deja como un dato, como una hipótesis, como una conclusión personal, de lo que piensa uno, de lo que entendió, me parece interesante, además, respaldada por otras investigaciones que se han realizado... Me gusta mucho eso más que los informes de laboratorio. (INDM5)

La preferencia también se debe a que son más abiertos o dialógicos: 
Que son como más abiertos a la discusión... uno puede igual dialogar

ENT.: ¿Qué cosas te gusta escribir, qué tipos de textos y, digamos, si hay uno en especial que te guste escribir?

INF.: Los textos argumentativos.

ENT: ¿Por qué?

INF.: Son como más abiertos a la discusión, ¿sí?, pues uno se puede extender, uno puede igual dialogar, sí, en cambio los analíticos son muy superpuestos a reglas, yo creo, no sé, como MUY específicos, como de aquí no pasa, algo así. (INDF4)

Los estudiantes manifiestan que es frecuente está práctica en la universidad pero que en general los profesores dan por sentado lo que es un ensayo, prevalece la idea de conocimientos previos atribuidos a la enseñanza secundaria o a los profesores de lenguaje:

\section{¿Cómo es un ensayo? ¿Cómo así tipo ensayo?, ya se supone que uno lo sobreentendió}

ENT.: Bien, digamos que esas son las áreas del saber, digamos que en instrumentos te piden ensayos, informes, reseñas, resúmenes, ¿cuál?

INF.: Depende del área, ya es normal que le digan a uno, bueno para mañana necesito un resumen de la lectura que le envié, necesito un ensayo, eh, eh, para esta salida, necesito que me entregue un informe tipo ensayo, y ya uno no le va a preguntar pero ¿cómo es un ensayo?, ¿cómo así tipo ensayo?, ya se supone que uno lo sobreentendió. (INDF1)

Como señala la siguiente estudiante, las instrucciones para la elaboración de textos están más orientadas a los formatos de los computadores que a las características académicas:

\section{Mucho arial doce}

ENT.: Y ¿qué indicaciones les daban los profesores cuando les pedían los trabajos?

INF: Que sea la letra legible, que sea un color oscuro preferiblemente, que la portada, si va TODA en mayúscula, no importa el (( )), y que buena ortografía,, y ahorita, lo que se ve es mucha arial doce (RISAS). (INDF2)

\section{Dificultades en la práctica de escritura}

Aunque, en general, los estudiantes entrevistados manifiestan gusto por la es- 
critura y consideran que sus resultados son buenos o regulares -en ningún caso malo-, algunos identifican dificultades como las siguientes:

\section{No sé cómo expresarlo}

ENT. : ¿Pero alguna vez has tenido alguna dificultad, que te hacen una pregunta, y tú sabes que tienes el conocimiento, tú sabes eso, has tenido alguna dificultad en el momento de escribir eso que tú conoces?

INF.: Sí

ENT.: ¿Sabes cuál es la respuesta? ¿Cómo identificas que tienes esa dificultad?

INF.: Yo creo que esa dificultad surge a partir de que yo todavía no sé enseñar, entonces, cuando alguien me pregunta algo, yo lo SÉ, yo siento que sé, pero no sé cómo expresarlo, entonces lo mismo va a ser en el papel (RÍE), pues, creo que no.

ENT.: ¿Es por ese lado?

INF.: Por ese lado, a veces se me dificultan mucho o NO ME GUSTAN, las palabras técnicas. (INDF2)

Esta dificultad tiene que ver con el paso del orden del pensamiento a la escritura y se asocia con el desconocimiento de la práctica de explicar lo que se sabe. Problemas de concentración o distracción también son identificados:

\section{A veces me distraigo con mucha facilidad}

ENT.: ¿Qué dificultad encuentras al escribir, aparte de no tener la frase que funcione?

INF.: De pronto, (RÍE) distraerme, a veces me distraigo con MUCHA facilidad, y pues, es por (RÍE) gracias a veces, porque estoy con mis primitos, porque vivo con primos muy pequeños, como a mí me encanta trabajar con niños, y ellos empiezan, van a la habitación, y empiezan a armarme juego, y yo como que ¡uf!, entonces sí, de pronto la distracción. (INDM6)

Los temas disciplinares representan cierto grado de dificultad para los estudiantes, ya sea por la terminología propia del tema o como en este caso por la exigencia de escribir con las propias palabras sin copiar de los textos:

\section{Escritos de química}

ENT.: ¿qué tipos de trabajos no te gusta hacer?

INF.: Qué tipos de trabajos, la parte ya como, la parte como escritos de química, es muy difícil escribir, créeme. Que este semestre nos tocó hacer 
un trabajo, donde nos tocaba, teníamos como límite, cuarenta palabras, escribir de un texto, de resto, teníamos que escribir con, nuestras propias palabras, y no le podíamos hacer, je, algún engaño al profe, porque él había escrito un libro y se manejaba TODOS esos libros, porque los había leído y los había consultado, entonces era MUY difícil escribir, o sea, eran como cinco renglones y yo no sabía qué escribir más, no sabía CÓMO decirle, mire esto se hace ASÍ y esto, o sea, si yo lo podía escribir, como YO lo pensaba, yo, jm, jm, jm «ACOMPAÑA LA EXPRESIÓN CON EL GESTO DE ESCRITURA», pero si me tocaba implementar, eh, ciertas palabras, claves, a veces se me dificultaba mucho porque tenía que leer MÁS, más allá de lo que estábamos acostumbrados a leer, era como que, ponernos a identificar palabras, y palabras, y palabras, entonces son como los trabajos «HACE GESTO DE NEGACIÓN», que no. (INDM6)

Otra de las dificultades señalada por algunos estudiantes es poder empezar a redactar el texto a partir de una idea central. Y aunque, en ocasiones se tiene, es difícil llevarla al texto, como señala este estudiante:

\section{Encontrar una idea para arrancar}

ENT.: ¿Qué otras dificultades has visto que tienes?

INF.: A veces a mí se me dificulta, como encontrar una idea para arrancar a escribir, ¿sí?, o sea, muchas cosas se me ocurren pero no las puedo organizar, ¿sí?, esa es una de las dificultades, y hay veces que me extiendo mucho, me pongo a tratar de que el profesor, aclararle tanto, que a veces termino enredado, me ha pasado que he tenido la idea CLARA y bien, y el profesor no me ha entendido por la forma en que la escribo, y me ha puesto, mal (RÍE). Sí, pero he tenido la idea bien, porque el profesor me dice, es que usted no sabe explicar bien, o sea, HÁGASE entender, no tanto la letra, sino la idea, eso me pasa a mí, en un parcial de física, que el profesor nos hizo escribir, nos lo hizo teórico, más que, entonces, uno sabe y tal, pero entonces se pone de pronto hablar, mucho lo que no es, y de pronto el profesor se termina confundiendo. (INDM7)

\section{Escritura por interés propio}

En términos generales, los estudiantes escriben poco por fuera de la academia, aunque manifiestan interés y gusto por la escritura. En todo caso, prefieren temas relacionados con la comunidad, que representen un apoyo para ella y que se consideren de interés. Como lo señala esta estudiante:

\section{Escribir de lo que a uno le gusta}

INF.: Escribir de lo que a uno le gusta. 
ENT.: Exacto.

INF.: Sí, a mí sí me gusta, yo siempre trabajo, o sea, más que todo mis escritos, y lo que yo hago porque YO QUIERO, es en pro de la problemática de mi comunidad, ya hago, o sea, que tenga tiempito, yo hago eso para incluirlo en mí proyecto, ¿para qué?, para el día que yo vaya a vacaciones, reúno mi comunidad y cuento, bueno, esto se está viendo, ta, ta, y yo, frecuentemente visito el periódico de allá, de Nariño, y yo digo, bueno, en tal vereda pasó esto, y entonces, lo voy asociando más con lo de mi carrera, entonces, yo quiero que, por ejemplo, yo miraba ayer que hicieron los sistemas de riego para el pueblo de la Dorada en Pasto, entonces, yo digo, ah, mire sistema de riego, CÓMO LO HICIERON, entonces yo miro, sistema de riego, a mí (( $\quad$ )), ay!, mire esto se podría hacer . (INDF1)

Al escribir sobre las temáticas indígenas los estudiantes manifiestan alto interés y buenos resultados, como se evidencia enseguida:

\section{Escribí una vez sobre desplazamiento forzado de la comunidad indí- gena kankuama}

ENT:: Tú me dices que has elaborado ensayos, que eras un ejemplo en el bachillerato, que AQUÍ te llaman y te dicen, ven ayúdame hacer el ensayo, por favor!, dos horas, trabaja conmigo, ¿te gusta particularmente algún escrito que hayas elaborado?

INF.: Sí, un ensayo que escribí una vez sobre desplazamiento forzado de la comunidad indígena kankuama, fue MUY bien en ese ensayo, saqué buena nota ese día, todavía lo tengo en la casa, yo no me lo creía que yo hubiera escrito eso (RÍE)

ENT.: ¿Sí?

INF.: Era MUY vacano ese ensayo. (INDF3)

En esa misma lógica, pero cambiando de género algunos estudiantes tienen la práctica de escribir textos narrativos:

Cuentos, leyendas, de la región o de la cultura de nosotros

INF.: [Yo], fuera de todo, escribo, digamos... escribo, cuentos.

ENT.: Mhm.

INF.: Cuentos, leyendas, de la región o de la cultura, de nosotros, de pronto no me ha quedado tiempito, en vacaciones me pongo yo a escribir cuentos... Ya llevo como cinco cuentos, y son buenos (RíE). (INDM1) 


\subsubsection{La metacognición. Estrategias de producción de textos escritos. Al} reflexionar sobre las prácticas de escritura académica como la toma de notas y la realización de ensayos, informes reseñas y otros textos propios del aula de clase y su planificación, los estudiantes logran dar cuenta de procesos, unos más elaborados que otros, que demuestran la ritualización de estas prácticas y que suponen un manejo de las convenciones y los aspectos técnicos de la escritura.

\section{Tipologías textuales}

Dentro de las estrategias de escritura se habla de las formas y los tipos de texto y sus partes:

\section{Depende de qué trabajo}

ENT.: ¿Cuando elaboras un trabajo escrito qué pasos sigues?

INF.: Pues eso depende de qué trabajo sea, si es un trabajo de investigación como tal, siempre su hoja blanca, siempre trato de utilizar un solo color, esfero negro, si es base de datos, un ejemplo, lo que estaba viendo, si se tienen que utilizar muchos colores, porque se manejan tablas, se manejan atributos, ciertas cosas que hay que especificar, en cuanto a los ensayos, pues, eh, siempre que lleve su introducción, de lo que se va a tratar todo el ensayo, que sea engomador para la persona, y trato de poner todas las ideas en un solo párrafo y después irlas desglosando, a medida que uno va escribiendo, y también teniendo en cuenta los parámetros de las reglas ICONTEC.

ENT.: ¿Cuando elaboras los trabajos de investigación o los ensayos, tienes algún paso, o hay algún paso al que le prestes mucha atención?

INF.: Sí, le pongo mucha atención a la conclusión.

ENT:: ¿Por qué?

INF.: Porque se supone que la conclusión es lo que YO aprendí, en todo el proceso, que LLEVÉ escribiendo. (INDF3)

De a cuerdo con las tipologías textuales, reconocen por ejemplo los pasos de redacción de artículos:

\section{El artículo}

ENT.: ¿Y ese esquema cómo es?

INF.: Ese es un esquema general, por ejemplo, primero tiene que empezar uno, hacer el resumen de lo que se hizo, hay que hacer de pronto, unas palabras CLAVES, de lo que vaya en la introducción, luego el marco teórico, 
el TEMA que va, después siguen los materiales, todo eso, y luego sigue el procedimiento, que nos hacen hacer un diagrama de flujo, y luego si uno quiere le agrega gráficas, luego vienen, datos y cálculos, y las conclusiones. (INDM7)

O de la elaboración de comentarios de textos:

\section{Comentar trabajos}

ENT.: Cuando tú estás elaborando un trabajo escrito, ¿qué pasos sigues?

Inf.: Lo primero que hago, depende de lo que me pidan, si es una reseña, un comentario, un ensayo...

ENT.: Escoge uno de esos, de los tres, el que más te llame la atención, ¿qué pasos sigues para elaborarlo?

INF.: Me gusta más comentar los trabajos, tratar de tener toda la idea del texto en la cabeza, y de acuerdo a eso, plantear mi punto de vista acerca del texto, de lo que he leído, es siempre lo que yo trato de hacer, no es transcribir el texto, sino darle un análisis al texto, y opinar respecto de eso. (INDM4)

Hay identificación de la necesidad de planeación textual y de convenciones como las citas. En el fragmento de entrevista se perciben claros los procesos de planeación-redacción-revisión, desarrollados desde las perspectivas psicocognitivas de la enseñanza y el aprendizaje:

\section{Primero... después}

ENT.: Cuando estas escribiendo un trabajo, ya me dijiste que uno de tus recursos es leer, mirar, qué es lo que vas hacer, ¿qué otros pasos sigues para ir haciendo tu trabajo?

INF.: ¡Ah!, pues mientras leo saco conclusiones, o trato de tomar apuntes y de ahí, de MIS apuntes saco, OTROS apuntes (RÍE), o sea, LEO, escribo como conclusiones del libro, de las conclusiones del libro saco conclusiones mías.

ENT:: ¿Cuál de esos pasos que me has comentado y complementaste ahorita, a cuál de esos pasos le pones mayor atención, mayor cuidado?

INF.: A mis conclusiones, o sea, primero leo, saco conclusiones de las copias, o de la lectura, después saco mis conclusiones y después de MIS conclusiones, empiezo la redacción, o sea empiezo a transcribir lo que yo pienso y todo eso, y después empiezo como a compararlos con las copias, otra vez a ver, en qué fallé, qué me hace falta o cómo argumentar desde el mismo autor, o meter otros autores, para poder complementar, porque eso 
es, lo que a uno le piden acá también, o sea exigen que, sea de diferentes autores, una posición que uno tome, ¿ya? (INDF4)

Incluso se plantean diversas formas para la elaboración de los escritos, como en el siguiente testimonio que se propone el método deductivo:

\section{A raíz de una frase}

ENT.: ¿Qué pasos sigues cuando haces un trabajo escrito?

INF: Siempre tomo una frase que encierre $\mathrm{MUCHO}$, la mayoría de mi trabajo, a raíz de esa frase, empiezo a sacar todas mis ideas, a botar ideas, y con eso empiezo como a tratar de darle forma a mi trabajo, a darle como lo que sea más entendible ante una persona, ante las personas que lo estén escuchando, que lo lean, para que ellos vean lo que está reflejado en ese escrito, entonces, como algo importante, saber ciertas cosas, o las cosas que uno siente.

ENT.: De esas normas que sigues para hacer tus trabajos escritos, ¿a cuál es la que más le pones atención?

INF.: La frase.

ENT.: ¿De ahí surge todo?

INF.: Sí, de ahí surge todo, si yo no escojo la frase precisa, créeme que me embolato, yo, es lo que MÁS me demoro, es, mirando la frase, que me encierre todo un trabajo, que lo diga, de pronto en cuatro renglones, o en tres renglones, pero que me encierre MUCHAS cosas, y de las cuales yo pueda hablar y ahí sí, REGARME como, lo que más pueda. (INDM6)

Otros estudiantes restan importancia a la forma y resaltan la importancia del contenido, el punto de vista y la función de la escritura, a la que le otorgan una función política:

\section{Uno tiene que ser REALISTA a la hora de escribir}

ENT.: ¿Cuando escribes sigues algunos pasos en especial? ¿A qué paso le pones mayor atención cuando estás escribiendo?

INF.: Bueno, ahorita, estamos haciendo una tarea, que es la organización de mi pueblo como tal, ¿sí?, tenemos una dificultad grande que es de comunicación, y de entendimiento, y eso a veces es la función que cumple el gobierno, ¿sí?, dividir a las comunidades, entonces en ese momento estamos trabajando en ese proceso de conciliación, de unificación, para tener una representatividad a nivel local, REGIONAL, y de pronto nacional. 
ENT.: Y digamos, cuando escribes, si estás pensando en resolver ese problema de comunicación... Cuando uno escribe quiere que lo entiendan, ¿cierto?, cuando estás sentado frente al computador, frente a tu hoja, cuaderno, ¿qué pasos sigues?

INF.: Sencillamente usted va a escribir la realidad, usted no va a escribir pa' que le digan que escribe bonito, no hace mucho tuve la oportunidad de hacer el documento para la ONIC, sobre conocimiento tradicional y propiedad intelectual...

ENT.: Mhm.

INF.: Y estuvimos en Bolivia en Cochabamba, y, claro, mi propósito era realizar un diseño para un observatorio de conocimiento tradicional, a nivel de la CAN, la Comunidad Andina de Naciones, y uno realmente cuando escribe, uno, primero tiene que conocer la realidad, por la que afrontan los pueblos, ¿sí?, o sea, no como los periodistas y los escritores, ¿sí? de algunos periódicos, de algunos medios, de algunos canales, que sencillamente hablan, porque miran desde acá las cosas, cuando ni sencillamente no han ido a una base, no han ido a un territorio, no conocen la situación real de los pueblos, ¿no? Tú te basas sencillamente en la realidad que vive tu pueblo, cuando a nosotros no nos parece una garantía lo que nos ofrece el gobierno, en la medida del conocimiento tradicional, no nos satisface, no nos ofrece mecanismos de protección, ¿sí? para nuestros conocimientos, ancestrales, no tradicionales, porque lo tradicional lo conoce en sí el gobierno, por eso nosotros lo decimos, milenarios, ¿sí?, uno sencillamente hace el análisis con la realidad, que pasa en nuestros pueblos, ¿sí?, o sea mirar el sufrimiento de los pueblos, ¿sí?, de acuerdo a eso uno escribe las cosas, uno no tiene que ser romántico, ni sentimental, uno tiene que ser REALISTA a la hora de escribir. (INDM3)

\subsubsection{Estudiantes afrodescendientes}

¿Con quienes hablamos? Estudiantes afrodescendientes. Se entrevistó un grupo de 12 estudiantes: ocho mujeres y cuatro hombres, procedentes de Chocó (5), Nariño (3), Magdalena (1), Medellín (1), Puerto Tejada (1) y Bogotá (1). Se trata de estudiantes provenientes de lugares apartados, con escasos recursos económicos. Los proyectos curriculares a los que perteneces son: licenciaturas en Pedagogía Infantil (2), Lengua Castellana (2), Inglés (2), Educación Artística (1), Química (1), Ingeniería Ambiental (2), Industrial (1) y Tecnología en Sistematización de Datos (1). Se encuentran cursando diversos semestres pero casi todos apenas inician o se encuentran hacia la mitad de la carrera. Uno de los estudiantes no ingresó por comunidades afrodescendientes sino por población desplazada. 


\subsubsection{El ingreso al sistema escolar}

Los estudiantes del Chocó y Nariño estudiaron en escuelas apartadas, pequeñas y con escasos recursos como bibliotecas, infraestructura o tecnologías. Los otros estudiaron en escuelas públicas o privadas con mejores condiciones. Los recuerdos de sus escuelas y lugares de origen son vagos pues muchos de ellos viajaron temprano a ciudades como Cali o Bogotá.

Quienes vivieron el proceso de estudiar en sus lugares de origen y en Bogotá establecieron diferencias del tipo recursos y calidad de la educación:

\section{No lo pedían por la misma economía de las personas}

ENT:: Aquí en Bogotá tenías tus recursos, tus cuadernos, tus lápices, los libros de texto que pedían en el colegio, ¿cómo cambió cuando llegaste a Tumaco?

INF.: Acá por lo general siempre le pedían o le han pedido a uno, y hay que saber que la economía siempre es diferente, entonces, pues, mi mamá siempre nos cubría lo que venía siendo, aquí en Bogotá, los libros, hay colegios, que también le regalaban a uno las fotocopias, o sólo con los libros se basaban, allá la mecánica no es de un libro por persona, pues, antes, no sé ahora cómo esté, la profesora solamente se encargaba de dar las clases, y nosotros, pues, seguir el ritmo que ella llevaba, de vez en cuando pedían un libro pero no era utilizado, pues, es siempre diferente, porque mientras acá se especializaban mucho como por seguir, lo que el libro expresa como guía, simplemente no lo pedían por la misma economía de las personas, que les alcazaba, y pues en ocasiones tampoco era utilizado, ¿sí? (AFROF1)

O, como lo señala esta otra estudiante, al resaltar la falta de capacitación de los docentes, y las irregularidades en la contratación que implicaron cambios continuos de docentes:

\section{Vi como un, un déficit}

INF.: Eh, mi nombre es María Ersita Perea Mosquera, yo vengo de Condoto, Chocó, estudié en el colegio Luis Lozano (Ciprión), era un colegio con énfasis en la agricultura, en lo ambiental y en lo ecológico, eh, ¿cómo fue la enseñanza?, pues, me pareció muy buena, aunque al llegar a la universidad, vi un déficit en algunas materias, como que la enseñanza que me brindaban era muy básica, y tuve algunas dificultades en materias como cálculo y química, dado que a las comunidades en el Chocó, normalmente en los colegios, los recursos son muy escasos, y hay colegios, por ejemplo el caso mío, en química nunca tuvimos laboratorio. La primera vez que estuve en un laboratorio fue cuando llegué aquí a la universidad, y en cuanto a los profesores de cálculo, normalmente en mi colegio, siempre pasaba 
que nos quitaban los profesores, se demoraban seis meses, a veces en el año nunca volvían los profesores, entonces los que nos daban clases eran personas que medio estudiaban el tema, pero en sí no estudiaban el tema. (AFROF3)

Una característica importante para tener en cuenta es la movilidad frecuente de estas poblaciones lo que implica cambios de costumbres y adaptación o no a los nuevos sistemas:

\section{Depende del lugar donde estaba viviendo}

INF.: Soy Nelvis Ardila, soy del Banco Magdalena, pero me crié en dos lugares, como quien dice simultáneamente, mis padres son de San Martin de Loba, Bolívar; entonces un año estudiaba en San Martin, otro año en el Banco y los fines de semana, depende del lugar donde estaba viviendo, pasaba en el lugar contrario. (AFROF5)

La discriminación aunque no es un tema recurrente en los estudiantes entrevistados, sí aparece, sobre todo, en los relatos de los estudiantes provenientes de Chocó:

\section{La gente que es igual a mí}

INF.: Mera necesidad, para mí es una necesidad, bueno, yo por ejemplo, a mí nunca me ha gustado Bogotá, la verdad, si cuando yo me fui, fue porque me sentía mal, porque desde la escuela uno siente el rechazo, siente la discriminación, porque es que todos los días salía llorando, era algo, es algo traumático; cuando me fui a Tumaco, pues obviamente me sentía a mi nivel con la gente, que es igual a mí. Al regresar acá, no quería regresar, quería quedarme en Cali, pero entonces vi que era la única forma de yo poder estudiar lo que quería, enfatizar más, aprender más, y pues, lo único que yo quiero es prepararme para ir a dar clases a mi pueblo. (AFROF1)

Quienes iniciaron sus estudios en Bogotá o Medellín resaltan lo poco que se acuerdan de sus escuelas y comienzan sus relatos de manera directa en el aprendizaje de la escritura.

\section{El bachillerato}

Durante el bachillerato, la dinámica descrita por los estudiantes es similar a la narrada para la primaria, pero resaltando la necesidad de hacer cambio de colegios con desplazamiento a las capitales; lo que a su vez llevó a cambios en las interacciones:

\section{Un colegio súper inmenso, súper grande}

ENT.: ¿Cambiaste de colegio, para terminar primaria y en ese mismo continuaste bachillerato? 
INF: No, después en Cali, mis papás, consiguieron trabajo allá, entonces nos fuimos y terminé la primaria allá, que fue de tercero a quinto, en un colegio qué se llama Ceprocom; también era un colegio muy pequeño, los dos colegios han sido privados, en la primaria, eh, pues sí era un poco más grande que el primero, ya básicamente la enseñanza, ya uno, pues en esa época, se suponía que ya tenía que aprender a escribir, leer; allá sí me acuerdo que la letra cursiva era importante, o sea, la profesora escribía y pues, yo recuerdo que uno imitaba; si ella hacía la be de cierta forma, uno también la hacía. El choqué de pronto, el colegio, no, porque también era pequeño, eh, sucede que me devolvieron otra vez para Buenaventura y entonces allá sí estudié el bachillerato en un colegio público, y el colegio era SÚPER inmenso, SÚPER grande, los salones eran aproximadamente de treinta y cinco, cuarenta estudiantes y CLARO! yo sí choqué, ehm, es interesante pero a la vez es como que uno se reprime un poco, porque uno está acostumbrado a estar con poquitas personas, uno conoce a TODO el salón, en cambio acá es como, iuy! no, quién será tal, también como que uno se acostumbra ya al ambiente, en Cali, yo ya tenía mis AMIGOS, bla, bla, bla, y como que llegar a un colegio NUEVO otra vez, con otras PERSONAS, (( )), yo pensé que iba a ser el fin del mundo. (AFROF8)

Al tratarse de contextos en los que la mayoría es población afrodescendiente no hablan de discriminación racial, pero sí de dificultades en las relaciones por la procedencia rural:

\section{El de la ciudad te mira así por encima del hombro}

ENT:: ¿Cuándo llegaste a Quibdó tuviste compañeros de la misma comunidad?

INF: No, para nada. Fue un cambio así, súper drástico. Llegué al colegio, casi nunca había ido a la capital, no conocía prácticamente a nadie, venía del campo, como que el de la ciudad te mira así por encima del hombro, el campesino, el tal, pero igual, como que siempre uno se adapta al lugar y al medio. (AFROM1)

Los contenidos curriculares también son resaltados al señalar que en el contexto bogotano, a pesar de seguir el punto de vista eurocéntrico, ofrece más posibilidades:

\section{En el colegio nunca me hablan de África}

ENT:: Me dices que cambió el modelo, ¿cómo era ese modelo más o menos en Quibdó?

INF.: En Quibdó era un modelo más tradicional, no te dejan avanzar mucho, ¿ves?, el modelo de educación siempre lo he cuestionado, o sea, tenemos por nuestras condiciones sociales y étnicas, llamémoslo así, un modelo 
de educación que nos imparten, es el mismo modelo eurocentrista, que está en todas partes, entonces, fue como reafirmar acá, más eso, o sea, te olvidas de ti mismo, porqué nunca me enseñan historia, mi propia historia, ¿sí me entiendes?, en el colegio nunca me hablan de África, pero sí me apalean con todo lo de Europa ¿si ve?, y acá mucho más, fue un cambio pues ahí como total.

ENT.: Me dices que la educación en Quibdó fue así como tradicional, ¿cómo cambió aquí en Bogotá?

INF.: Era un poco, por lo que te digo, por lo que no se tenían muchas herramientas el profesor no tenía mucho de donde escoger, entonces, como que la misma secuencia nos enseñan año tras año, (( ) ), en cambio acá, no es que haya sido un cambio muy tenaz, pero, pues sí, habían otras cosas que nunca vi allá, que me hacía falta acá para reafirmar mi educación acá. (AFROM2)

\section{El ingreso a la universidad}

El paso del bachillerato a la universidad de los estudiantes no fue inmediato, algunos tuvieron que esperar años; por las condiciones económicas familiares debieron buscar trabajo y posteriormente sí ingresar. Debido a esto, la edad promedio de estos estudiantes es mayor que la del resto de la población estudiantil. El primer contacto con la universidad se realizó a través de amigos o familiares, que estudiaban o habían estudiado en la universidad. La mayoría se presentó primero a otras universidades, como la Nacional de Bogotá o a universidades privadas. En cuanto a la interacción con los compañeros resaltan que fue muy buena, y que algunos compañeros los ayudaron en su adaptación a la ciudad y al sistema académico universitario. También resaltan la colaboración y apoyo recibidos de los colectivos de estudiantes afrodescencientes de la universidad.

\subsubsection{2. ¿Y la escritura? Las primeras letras}

Para estos estudiantes el papá, la mamá o algún familiar fue el primer iniciador a la escritura; algunos ingresaron al sistema escolar sabiendo escribir y leer. De igual manera por el contexto diverso, las pedagogías eran diversas, incluían la música y otro tipo de composiciones líricas.

\section{Se enfatiza más como por los versos}

ENT.: En cuanto a la experiencia de la escritura, tú me decías que te tocó esperar, a que los demás chicos tuvieran el mismo nivel que tú traías, ¿las prácticas de escritura cómo eran, qué escribían, qué hacian, y a ti qué te gustaba hacer? 
INF.: Llegábamos a clase los lunes, la profesora de español nos ponía a escribir, lo que realizábamos en el fin de semana y se lo compartíamos a los compañeros, al igual que siempre escribir poemas, versos; allá se enfatiza más como por los versos, los currulaos, escucharlos y así mismo irlos cantando, primero todo era escrito, después, leerlo, después el sonido, a tomar el sonido, y después la música, y ya con la música era ir desarrollando también la parte musical, pues, no, como te digo, aunque eran cosas extraordinarias, no era, (( )), o sea, siempre nos basábamos en lo que, HABÍA que hacer en español. (AFROF1)

La casi totalidad de los estudiantes hacen mucho énfasis en la forma de la escritura, sea para señalar el tipo de letra: pegada o despegada, las dificultades del paso de la una a la otra y los aspectos relacionados con la ortografía y la redacción; para ellos, eso es la escritura:

\section{La ortografía es muy importante}

INF: Bueno, llegué al colegio, la parte escrita, normal, sobre todo la profesora de español, era un poco tradicional, y habían dos cuadernos de español, uno como digamos, cuando tú cometías errores, hacías una PLANA sobre el error que habías hecho, digamos, escribiste por ejemplo, trabajo con ge, por decir, entonces había una plana que decía, trabajo con jota, trabajo con jota, entonces, como que no, como el colegio también es comercial, entonces la parte de caligrafía es muy importante, la caligrafía, ehm, ¿cómo diría yo?

ENT.: ¿Y la ortografía?

INF: La ortografía es MUY importante, entonces uno allá, o sea, aprende.

ENT: Aprende o aprende. (AFROF8)

\section{El bachillerato}

El paso al bachillerato representó un cambio sustancial pues se pasó de tener un profesor para todas las materias a un profesor por cada una. La asignatura de español implicó también dar prioridad a la literatura y la lectura. La escritura se centró en la realización de resúmenes y en el tipo de texto que los estudiantes denominan consultas de investigación.

\section{Investigaciones}

ENT.: En cualquier materia, ¿sí?

INF.: No te voy a mentir, los pocos trabajos eran, sobre investigar a ALGUIEN, eh, como una bibliografía de alguien, sí, como trabajos investigativos sobre todo, y básicamente uno lo que hacía era escribir, exactamente 
lo que estaba en el texto, entonces, la parte, je, de comprensión, como que no nos la ponían nunca, en práctica. (AFROF8)

En general, resaltan que los trabajos eran presentados bajo los parámetros de las normas ICONTEC:

\section{Siempre las normas ICONTEC}

ENT.: Digamos, ¿recuerdas algunas indicaciones, orientaciones, que te diesen, en español o igual, en otras materias para hacer tus trabajos escritos?

INF.: Pues, siempre las normas ICONTEC, ehm, cómo hacer un objetivo, la conclusión, eh, cómo empezar a escribir, más que todo, pues a mí siempre me fue difícil (RÍE) escribir, pero siempre terminaba haciéndolo (RÍE), porque yo era muy DEDICADA, entonces ¿sí? (AFROF6)

También destacan que durante el bachillerato baja el nivel de intensidad en la enseñanza de la lectura y la escritura:

\section{En bachillerato hay menos atención hacia la lectura y la escritura}

ENT: Todo lo hiciste ahí, y la experiencia en bachillerato frente a la escritura ¿cómo fue?

INF.: Yo creo que en bachillerato hay menos atención hacia la lectura y la escritura, o sea, de pronto se da un poco por sentado que uno ya sabe escribir y leer, entonces, hay cosas que se obvian, eh, en primaria era muy recalcado la letra bonita, por lo mismo que uno usa el ferrocarril, que usa el lápiz mejor, que el esfero, en cambio en bachillerato uno escribe como quiera, bueno, yo en primaria escribía en letra cursiva, en letra pegada, en bachillerato ya tuve que dar el paso, a la letra habitual y nosotros, no, o sea, me parece que ese fue el gran tipo de problema, en el que digamos, mi letra no sea TAN redonda, ni sea TAN perfecta, $\mathrm{mmm}$; me he esmerado en cambiarla, en hacerla un poco más legible (RÍE), en que mi letra no es que sea muy bonita.

ENT.: ¿En toda primaria manejaron letra cursiva?

INF.: Gran parte de primaria.

ENT.: ¿Y no trabajaron letra script?

INF.: Sí, pero no exactamente en la áreas de español y eso, pues, en las otras sí, de pronto en sociales y eso.

ENT: ¿No te exigían?

INF.: No, no había una exigencia así como tal, en bachillerato, pues, como te digo de sexto a once, ehm, como se trabaja otros temas se deja de lado, 
como esa parte de la lectura y la escritura, yo tenía que LEER, obviamente, en el salón, en voz alta y todo esto, pero, en la parte ya en la escritura nunca tuve ni correcciones ni me decían esto tiene que hacerlo mejor, o trate de hacerlo más legible, teniendo en cuenta que los trabajos los presentábamos pues a MANO, porque en ese momento, no había computador, como en ese auge que tiene ahorita. (AFROM2)

Algunos señalan el poco gusto por la lectura y la escritura, debido a la falta de motivación de los profesores al pedir siempre el mismo tipo de trabajo, hasta cierto punto mecánico y poco reflexivo:

\section{No, porque era impuesto}

ENT.: ¿Te gustó la experiencia de escribir en bachillerato?

INF.: No, porque era impuesto, que tiene que escribir la síntesis, el análisis, pero nunca nos pusieron a escribir por... que escriban algo, escriban algo sobre lo que hicieron en vacaciones, que uno trata de echar memoria, pero no, o sea, no le encontré ni a la lectura ni a la escritura, por ese lado, porque siempre era a escribir la síntesis, hacer un ensayo, sobre la lectura, más no de cómo le pareció la lectura, que esto, esto y aquello. (AFROF5)

2.6.2.3. La escritura en la universidad. La mayoría de los estudiantes reconoce que su escritura es deficiente, y que al entrar a la universidad se presentó un choque cuando los profesores les señalaron sus deficiencias al hacer retroalimentación de los trabajos escritos:

\section{En el colegio jamás me lo dijeron}

INF.: Digamos, que el paso del colegio a la universidad es bastante fuerte; creo que yo escribía demasiado mal y eso en el colegio jamás me lo dijeron, escribía DEMASIADO mal, y el proceso del colegio, digamos, que a uno no le inculcan el proceso de la lectura, no es solamente escribir y entregue, sino, volver a leer y todo esto, y yo jamás hacía eso, yo escribía, terminaba y entregue, y a pesar de eso no me iba mal, pero yo decía, me puse a pensar aquí, ya después en la universidad, ¡cómo yo tenía una escritura tan mala! y no, nunca tuve ninguna reconvención o me dijeron que la mejorara. (AFROM2)

Los profesores desde el inicio hicieron visible las dificultades de la escritura en los estudiantes entrevistados, la experiencia de escritura ha sido calificada negativamente:

\section{Usted ya en la universidad y no saber escribir}

ENT.: ¿Cómo ha sido esa experiencia?

INF.: No, pues, un poco, o sea... horrible, horrible. Que los profesores lleguen y le digan a uno que, jah!, es que usted ya en la universidad y no 
saber escribir, como que, o sea, les paso las comas pero las tildes, entonces, es algo, siempre ha sido difícil, pero, ante eso, como que uno ha ido recogiendo, y ha ido mejorando, porque entonces, ya sabe cuáles son los errores que uno ha cometido, y ya, para la próxima uno sabe, así uno ya se va ubicando, la verdad, siempre ha sido horrenda. (AFROF1)

El enfrentamiento y aprendizaje de los diversos tipos de textos, resultó difícil dado que en el colegio no se habían trabajado:

\section{Lo que más dificultad se me presentó fue, en escribir artículos}

ENT.: En cuanto a la elaboración de trabajos escritos aquí en la universidad, de primer semestre a cuarto, ¿qué tipos de textos te han solicitado y qué dificultades tienes al enfrentarte a escribir esos textos?

INF.: Me han pedido buenos trabajos, (harticos), y lo que más dificultad se me presentó fue al escribir artículos, porque es la primera vez que escribía artículos y cuando iba a laboratorios hacer informes, me parecía tenaz, porque para mí escribir un informe ERA escribir mucha teoría, y como ir aprendiendo que los informes no son sólo teorías, sino que como que toca poner su punto de vista, me pareció muy difícil, pero después de que ya uno coge el ritmo, ya todo se le va haciendo más fácil. (AFROF3)

Los entrevistados manifiestan que escribir es un proceso difícil y que ellos no son buenos en esa práctica:

\section{Es algo difícil}

ENT.: Y digamos en las evaluaciones escritas, ¿qué hacen aquí en la universidad?, ¿cómo te va?

INF.: Los quiz, la verdad, es que para escribir, no soy buena, y pues, lo que me han dicho los profesores, cuando escribo ensayos, es que realizo muchas ideas pero de forma desordenada, entonces, que debo, primero, volver a leer para organizar las ideas, y ahí sí sacar lo que viene a ser el ensayo o el escrito como tal, pero es, no sé, es algo difícil... Proceso las ideas, pero al organizarlas me queda un poco difícil. (AFROF1)

Otros pocos estudiantes manifiestan no haber tenido problemas con la escritura:

\section{Nunca}

ENT: Digamos, ¿en algún momento le solicitaste a algún compañero que te colaborara con tus trabajos escritos?

INF.: No, nunca, de hecho, me han pedido el favor.

ENT: ¡Ah!, ¿ha sido al contrario?

INF: jah, sí! (AFROF8) 
2.6.2.4 Funciones de la escritura académica. La evaluación con fines de comprobación, es igualmente una representación recurrente en los estudiantes afrodescendientes:

\section{Comprobar}

ENT.: Laboratorios e informes, ¿cuáles crees qué son los propósitos de estos trabajos qué tu presentas escritos?

INF.: Es como comparar esa parte práctica con esa parte teórica, ¿sí?, porque es una brecha INMENSA, uno en la teoría; uno puede hacer cualquier cosa y puede ser que todo funcione ahí, pero en la práctica uno se da de cuenta que todo ese margen de error, y es allí donde uno muchas veces se da de cuenta de que esa teoría hay que replantearla, ¿sí? (AFROM4)

Los estudiantes entrevistados resaltan el hecho de que dentro del aprendizaje que se da con la escritura, lo más importante para el profesor es que el estudiante desarrolle la competencia escritora, la habilidad:

\section{Aprender}

ENT.: Cuando tú presentas un trabajo escrito, ¿cuáles crees que son los propósitos que tienen los profesores cuando los solicitan?

INF.: A ver, yo creo que, conocer un poco, o, ellos tratan de que nosotros conozcamos acerca del tema, pero en sí, EN Sí, lo que a ellos más les gusta es que de pronto sepamos cómo sacar un ensayo, cómo hacer el análisis gramatical, el análisis sintáctico a cierto tipo de tema puede ser científico, $\mathrm{mmm}$, científico, periodístico, a los diferentes tipos de temas o diferentes lecturas; eso es lo que quieren que nosotros aprendamos, a identificar los diferentes tipos de textos. (AFROM4)

Al hablar de destrezas producidas por la escritura no hay demasiada claridad en qué consisten esas destrezas:

\section{Desarrollo de destrezas}

INF.: Como encontrar la destreza que uno tiene para escribir y como inyectarle el gusto por la escritura, y que a la final escribir es bastante bueno, uno desarrolla muchas destrezas escribiendo, e interesante.

ENT: ¿Cuáles tipos de destrezas crees que se desarrollan al escribir?

INF.: No sé, cuando uno escribe, uno entiende más, aprende más, y da a conocer sus conocimientos, valga la redundancia. (AFROF3)

Otros estudiantes manifiestan una especie de tautología en los argumentos en la que los fines o funciones de la escritura se reducen a escribir bien: 


\section{Desarrolla capacidades}

ENT.: ¿Cuáles consideran que son los propósitos de estos trabajos escritos?, o sea, ¿los fines que los profesores buscan?

INF.: Eh, que desarrollemos nuestra habilidad de escribir, porque es que, como dicen ellos, estamos acostumbrados, con el Internet, a copiar y pegar, pero no leemos, entonces es lo que nos dicen ellos, que eso ayuda a desarrollar capacidades para, de pronto, escribir, leer, porque por ejemplo a mí me ha servido porque, o sea, yo soy floja para la lectura, pero con la lectura, las hago y me gusta la parte de escribir, porque es ya lo que yo digo, o sea, ¿cómo me pareció la lectura?, ¿qué me agradó?, lo que me pareció importante, entonces, aquí como que lo motivan más a uno, al contrario del colegio, que tienen que hacer la SíNTESIS del ensayo, del libro, que no sé qué. (AFROF5)

\section{Cuáles deberían ser las funciones de la escritura}

Al igual que los estudiantes indígenas, los afrodescendientes resaltan que en la universidad se escribe para el profesor, teniendo en cuenta que él o ella esperan una respuesta exacta. En ese sentido plantean que el fin de la escritura debería ser escuchar al otro, no partir de un único supuesto, de ideas fijas, sino establecer diálogos en los que mediante la argumentación se llegue a consensos, tal como claramente lo plantea este estudiante:

\section{Construir consensos, no imponer}

ENT.: En ese sentido, ¿cuáles consideras que deberían ser los propósitos de la escritura en la universidad?

INF.: Pues, primero, pues no sé, se supone que uno ve una serie de temáticas, ¿sí?, a lo largo de la universidad, y la idea es que eso le ACLARE un universo epistémico o político sobre ciertos temas, y que le dejan a usted claridades, yo creo que lo debería evaluarse es bueno, ¿qué tanto?, digamos, si vimos un autor específico, qué tanto de ese autor le quedó a USTED, qué aportes usted recupera, desde usted y su experiencia, porque en ocasiones, como que, bueno, y eso que más en las áreas que son, en los saberes que son pedagógicos, hay más posibilidades de hacer eso, decirlo, que los que tienen saberes como muy filosóficos, digamos, con Adrián, recuerdo un profesor que se fue, que también daba filosofía, (( )), bueno, un profesor que su saber era mucho los griegos, los filósofos, entonces, María Cristina también, entonces ellos, que su universo filosófico, que parece hay veces EXACTO y no filosófico, entonces, como que quieren UNA respuesta, que tiene que estar ORIENTADA, y no reconocen, que ellos tienen otra, pues, ya una información muy diferente a una persona 
que apenas accede a un PREGRADO; que en nuestra sociedad no ESTÁN esas reflexiones, o sea, no es nuestra, y que hay que hacerle una exigencia de los estudiantes, pero también uno da es desde sus posibilidades, y eso en ocasiones no se valora por muchos profesores, entonces yo creo que, debería ser una cosa que desde su punto de vista, pero desde un punto de vista argumentado, teniendo en cuenta cosas que hemos dicho así, lo que usted diga, no estoy como de acuerdo con lo que yo como profesor pienso, arguméntemelo, es más como rescatar los puntos de vista desde una labor clara argumentativa, no una cosa, yo creo y considero y ya, no, pero, que lo argumente, su punto de vista para sustentarlo y ver por qué, uno tiene que construir es CONSENSOS dentro de la universidad, no imponer, yo creo que debería ser como eso. (ÁFROF2)

\section{Medio de expresión}

Los fines comunicativos de la escritura también son resaltados, aunque tiende a igualarse la escritura con la ortografía y la redacción:

\section{Que la persona sepa redactar}

ENT.: ¿Consideras que la escritura en la universidad debería tener otros propósitos, además de los que ya me mencionaste?

INF.: Sí, porque se supone que somos futuros profesionales y no hay que pensar en a nivel nacional sino que vamos a SALIR, o sea, que se va a exportar un producto, que somos un producto que se va a exportar, y pienso que debería ser un requisito para graduarse, no sé si para graduarse - QUIZÁ debería un buen requisito para graduarse, que la persona sepa redactar, sepa LEER, porque es un problema del colombiano, no sabemos leer, sea bueno en ortografía; yo creo que eso es importante, siempre me ha aparecido que eso es muy importante, la ortografía, la redacción, porque eso es un medio de EXPRESIÓN, si yo quiero decir algo pero lo plasmo mal, y si esa persona entiende lo que yo plasmé pero no lo que yo quería expresar, pues, eso genera conflictos, me parece que sí debería reforzarse más esa parte, INCLUSIVE desde la primaria, porque es para la universidad, uno para la universidad ya debería estar una uvita en eso, desde la primaria. (AFROF4)

O como lo señala esta otra estudiante:

\section{Manifestar un mensaje:}

ENT.: Cuando tú presentas un trabajo escrito, un ensayo o cualquier otro tipo de trabajo escrito, ¿cuáles crees que son los propósitos de estos trabajos escritos?

INF.: Pues, que a través de lo que se escribe que le llegue a la gente un mensaje, ¿no?, como que, bueno, hay algo aquí y yo quiero manifestar, 
esto y esto, bueno, lo ideal es que si te llega a ti, pues que tú lo leas y entiendas que es mío y que a través de eso yo quiero, no sé, decirte algo, pues es como lo que yo. (AFROF7)

Como se señaló en el apartado anterior, la escritura es una práctica cuya finalidad sería la misma práctica:

\section{Aprender a redactar}

ENT: ¿Cuáles te GUSTARÍA que fuesen los propósitos de tus trabajos escritos?

INF.: Aprender a redactar igualmente, ja!, pues, que a la hora de presentar el proyecto de grado no se me haga tan difícil redactar, conozco gente que «GESTO DE NEGACIÓN» (AFROF6)

Tal como lo señalaron los estudiantes indígenas, se plantea la idea de escribir desde los propios intereses de los estudiantes, los cuales están muy relacionados con dar a conocer la propia cultura de los pueblos afrodescendiantes:

\section{Escribir lo que a uno le nazca}

ENT.: Aparte de ese, ¿cuáles propósitos crees que tienen los trabajos escritos?

INF.: Pues, yo no sé, es que a veces, depende también de cómo se escriban las cosas, ¿no?, pero si yo, por lo menos, si yo escribiría lo haría desde lo que me gusta a mí, como que sea algo que a uno le NAZCA, porque a veces también depende cómo se escriba, a uno, o lo que a uno le interesa, entonces, así uno lo recibe, yo escribiría para mi comunidad, por ejemplo, escribiría como lo que no, no está ahí, como que contado, y es básicamente nuestra historia o lo que está mal dicho o lo que realmente no se ha dicho, porque es que yo siento que cuando se habla del tema afro ni siquiera se ve como espacio, como que realmente necesitamos decir algo, sino como que hay algo más, no se le da realmente como la importancia, entonces, desde esa perspectiva me imagino yo que puede funcionar, que sea escrito con sinceridad, como con lo que realmente se requiere más que lo técnico, porque a veces lo técnico está, pero el valor agregado que es lo positivo de eso no se ve, porque uno a veces acá, lee o bueno, está en las cosas pero uno dice, ach!, ya lo académico o lo estructural RAYA muchas veces, entonces no sé, pa' mí la esencia, es lo más importante de todo. (AFROF7)

2.6.2.5. Las prácticas de escritura académica. El objetivo de este apartado se centró en describir las prácticas de escritura académica, durante el desarrollo de clase, en trabajos asignados fuera del aula y la escritura por interés propio. También interesó identificar las dificultades más frecuentes de esta práctica. 


\section{Toma de notas}

Tomar notas no es una práctica generalizada entre los estudiantes afrodescendientes entrevistados. Algunos las toman, otros no y otros, no regularmente. La práctica de tomar notas, en ocasiones está directamente relacionada con el gusto por la escritura en general:

\section{Te diría que muy poco}

ENT.: En la experiencia de escritura en la universidad, ¿tienes la costumbre de tomar apuntes?

INF.: Te diría que muy poco.

ENT:: ¿Por qué?

INF.: No sé, de pronto no tenga esos, o sea el gusto de tomar apuntes, pero no es todo el tiempo, si no que, pero, sí los más importantes, y en eso me baso como para la siguiente clase no ir tan, tan desubicado.

ENT:: ¿Te gusta escribir?

INF.: Muy poco.

ENT.: ¿Por qué?

INF.: No sé, si es que como tú sabes aquí, la educación de nosotros, eh, muy pocas, los profesores me decían escribe un artículo, lea estos libros, o sea nuestra cultura colombiana, tú sabes que es muy pocas las personas que les gusta leer y escribir, ¿sí?, se dedican es a otras cosas entonces creo que, debería obviamente, estarme preparando leyendo, pero, perdón, hay veces que uno deja de hacer esas cosas por ponerle atención a otras, entonces no es que tengo la rutina, de, pero LEO lo que a mí me interesa, lo que a mí me gusta, de lo contrario no.

ENT:: ¿No lo haces?

INF: No lo hago. (AFROF4)

Esta respuesta resalta particularmente interesante tratándose de un estudiante de licenciatura; de una carrera que supondría altos índices de escritura y lectura.

Una práctica frecuente resulta remplazar las notas por las fotocopias y sobre ellas resaltar las ideas importantes:

\section{Si uno tiene lectura y ahí tiene subrayados sus puntos de vista}

ENT.: ¿En tus clases tomas notas escritas? 
INF.: Sí, no siempre, pero, sí tomo notas.

ENT.: ¿Cuando las tomas, para qué, con qué objetivo lo haces?

INF: Porque o sea, depende de lo que estemos trabajando, si el tema me parece interesante, si yo sé que es algo que podré utilizar, a futuro, tomo nota, de eso, pero no lo hago constante, porque hay cosas que sí, uno tiene lectura y ahí tiene subrayados sus puntos de vista y es sólo el debate, pero cuando ya de pronto, se forma un debate, donde se está aclarando puntos que de pronto pueden servir, ahí, en esos casos, sí tomo nota, no lo hago muy seguido. (AFROF5)

En ocasiones, las notas se reducen a datos puntuales para reforzar la memoria:

Más que todo, como los años

ENT.:¿ ¿Tomas notas escritas en clase?

INF.: Sí, pues, más que todo, como los años, no sé, la página, tener en cuenta mucho eso, el autor, por si algo necesito el pie de página, no sé. (AFRO6)

También se toman notas, no de manera frecuente, sino en eventos especiales como en conferencias, y con fines específicos; por ejemplo, adquirir vocabulario:

\section{Lo hago, en los espacios que voy a eventos}

ENT:: ¿Tomas notas escritas en clase?

INF.: A veces, cuando digamos que el aporte del profe es positivo pa' mí (RÍE), o me gusta, entonces, lo tomo como referencia, o algún texto, o algún que yo diga, ah! sí!, o lo voy escribiendo así, pero, que sea algo, pues, que yo tenga como hábito o más que todo lo hago, en los espacios que voy a eventos, seminarios, taller, entonces, en eso sí, ahí sí como que o, ay!, dijo esta palabra, que yo no conozco. (AFROF7)

Los estudiantes que manifiestan tomar notas, no siempre siguen una redacción sino que elaboran esquemas o mapas conceptuales; para ellos la escritura es "carreta":

\section{Mapas conceptuales}

ENT.: ¿Acostumbras a tomar notas en clase?

INF.: Habitualmente, sí, claro, la teoría, lo que va dictando el profesor, normalmente trabajo lo que mapas conceptuales, ¿ves?, como para no escribir, tanta carreta. (AFROM1) 
Hay quienes desarrollan sus propios métodos, en este caso mediante guiones, como ayuda mnemotécnica para las evaluaciones:

\section{Guiones}

ENT.: ¿De qué forma?, ¿tienes alguna forma especial de tomar las notas?, ¿y para qué consideras que te sirven las notas?

INF.: Bueno, listo, últimamente lo que hago es, escribo fecha, el nombre de la materia y escribo el nombre del profesor porque a veces se me olvida, escribo el tema y lo que hago es, por ejemplo, estábamos tratando el tema, $\mathrm{mmm}$, estamos hablando por, estamos desarrollando exposiciones por departamentos en una clase de la profesora Sandra Luz, entonces, lo que hago es, el departamento tal y voy tomando apuntes sobre su constitución, sobre, básicamente, el contenido que están expresando en la exposición y lo que hago es guión y escribo el apunte, eh, está ubicado en tal lado, tiene tantos habitantes y ya punto, no tomo más datos sobre eso sino que sigo sobre otro tema, entonces, eh, su construcción económica es a partir del tabaco, no sé qué, entonces, básicamente esa es mi forma de tomar apuntes. (AFROM2)

Otros escriben sólo apartes de lo dicho por el profesor en forma de recomendaciones:

\section{Recomendaciones}

ENT.: ¿Tomas notas escritas en clase?

INF: Sí.

ENT.: ¿Tienes algunos criterios en especial, las tomas de alguna forma en especial, o, bueno, y las utilizas para qué?

INF: Mira, algo interesante, es que muchas veces uno se acostumbra a REESCRIBIR de lo que escribe, de lo que el profesor anota en el tablero, pero, lo más interesante, lo que uno se da cuenta, son esos, son esos tip, o esos recomendaciones que el profesor hace, porque y eso él NUNCA te lo escribe en el tablero, entonces es como lo más importante ahí, porque por ejemplo uno ve casos o ve cosas, o, como cuando, digamos de esas partes esas conclusiones, de ahí saca esas conclusiones uno, porque hay cosas, que la parte teórica ahí falla, ¿si?, entonces ellos ya CONCLUYEN, lanzando su punto de vista, su experiencia, eh, ya, quedan libres, quedan en la parte, en la charla, entonces esas anotaciones son aquellas que muchas veces dan el mensaje para no perderse, o algo así. (AFROM3)

Hay referencia a prácticas mecánicas que demuestran poca claridad sobre el método o los fines: 


\section{Trato de escribir TODO}

ENT.: ¿Acostumbras a tomar notas en clase?

INF.: Sí.

ENT:: ¿Tienes alguna forma especial de tomar notas, y para qué las utilizas?

INF: Digamos que están exponiendo algo y SÉ que van a hacer un parcial sobre eso, pues trato de escribir TODO lo qué yo ENTIENDA de lo que están hablando, voy escribiendo, a veces a la loca, sí, a veces digo como, ¡uy!, qué es esto que escribí?, pero pues trato de escribir y escribir lo más qué pueda y pues sí, la utilizo con esa finalidad, y digamos, al otro día preguntan sobre el tema o hay un parcial, un quiz, entonces, pues al menos tengo, lo que anoté. (AFROF8)

\section{Prácticas de escritura dirigidas fuera del aula}

Los ensayos son los tipos de texto que los estudiantes más identifican aunque no con la misma claridad que los estudiantes indígenas. En ocasiones la entrevistadora tuvo que orientar las respuestas y especificar los diversos tipos de textos.

Los informes de laboratorio son frecuentes entre los estudiantes. El ensayo es valorado por la posibilidad de expresar el punto de vista y por su funcionalidad en términos políticos, donde se requiere exponer diversos puntos de vista y argumentarlos:

\section{El ensayo me gusta mucho}

INF.: (...) El ensayo me gusta mucho porque digamos, por la dinámica en la que estoy, eso de poder argumentar y de plantear como una hipótesis, o respecto a una temática y sustentarla es muy necesario, entonces me gusta porque además uno ve también los vacíos que tiene y lo que es muy necesario llenar, es una cosa muy organizada, me gusta también el ensayo, y no, pues sí, digamos de los textos que más uso, el argumentativo, también me parece muy bonito, o sea, la forma de argumentar, las claves, o una o una oración, una frase se desprende de otra, cómo puedo ir yo reconstruyendo un texto, a mí me parece muy importante, y me gusta mucho lo que se hace en el análisis del discurso, la parte en que (SONRÍE) me parece muy bonita y me guío mucho y la mayoría de trabajos que me han tocado, los he tratado de hacer un poco con análisis del discurso, así de los textos, pero a mí me gusta casi todo (RÍE) sí, la mayoría. (AFROF2)

La libertad de expresión que ofrece el ensayo frente a otros tipos de texto es valorada positivamente: 


\section{El ensayo te da la libertad de cuadrar las temáticas}

INF.: Ensayos, reseñas... ¿sí?, los raes que son la mismas reseñas también, reseñas reconstructivas, ehmmm, cuentos, también, y, creo que hasta ahí.

ENT.: ¿De estos textos cual te gusta más elaborar?

INF.: Me siento más libre en los ensayos, me siento más amplio, creo que, me va como mejor, nunca, o sea, pues yo peleo mucho con la estructuras la reseña dice, tiene su parte y su parte y bien, completar, llenarlo y ya, en cambio el ensayo te deja, en cambio el ensayo te da la libertad de cuadrar las temáticas cómo tú consideres mejor. (AFROM2)

Algunos estudiantes manifiestan su gusto por los textos narrativos pues permiten más libertad de expresión en cuanto a la forma y el contenido:

\section{Me gustan los narrativos}

ENT:: ¿Todas las clases?

INF.: ¡Ay! sí, todas las clases de textos que hay, pero a Mí, así que me guste, me gustan los narrativos porque es una cosa que lo deja a uno ser muy libre, y me gusta porque yo puedo optar por comenzar de diferentes formas, no hay un orden todo establecido, que tiene que ser así (a los profesores le da por decir que tal orden entonces uno ay!), y entonces eso como que me gusta. (AFROF2)

Los estudiantes de ingenierías y las carreras técnicas presentan en su mayoría informes que se trabajan en grupo:

\section{Individualmente, se hace un POQUITO}

ENT.: ¿Y cuándo los haces individualmente?

INF.: Individualmente, se hace un POQUITO, porque algo, con toda sinceridad, porque pasa que comienza uno a recopilar mucha información, pero hay mucha información que sirve y hay otra que no y ahí me demoro, sin mentirte, me demoro mucho, porque comienzo a evaluar todo, TODO, y hay profesores, por ejemplo, hay un profesor de prototipos, que el man es, él comenzó a dictarme electrónica uno, introducción a la electrónica y prototipos, y el man es muy exigente en esa parte, en los informes, entonces, uno, es muy meticuloso en lo que uno escribe, en las conclusiones, en la parte teórica, que vaya acorde con la parte práctica, porque así a uno no se lo devuelve, entonces eso le enseña a uno cómo te digo, le exige a uno, que uno tiene que dar lo mejor, pues dar un informe bien, y uno trabaja con la triple e, con la norma triple e, entonces uno, entonces esos parámetros a uno le exigen, presentar algo de calidad. (AFROM3) 


\section{Dificultades en la escritura académica}

Una de las dificultades más frecuentes es el paso de las ideas al texto, allí los estudiantes identifican diversas problemáticas:

\section{Muchas ideas pero desordenadas}

ENT.: $Y$ en las evaluaciones escritas, que hacen aquí en la universidad, ¿cómo te va?

INF.: Los quiz, la verdad, es que para escribir, no soy buena, y pues lo que me han dicho los profesores, cuando escribo ensayos, es que yo, realizo muchas ideas pero entonces son de forma desordenada, entonces, que debo, primero, volver a leer, y volver a leer para organizar las ideas, y ahí sí sacar lo que viene a ser el ensayo o el escrito como tal, pero es algo difícil; proceso, sí las ideas, pero, al organizarlas me queda un poco difícil. (AFROF1)

\section{Tengo la idea pero no sé cómo escribirla}

ENT.: ¿Has tenido dificultad en el momento de escribir lo que tú sabes, en el papel?

INF.: Sí, al redactarlo, porque muchas veces me ha pasado, o sea, tengo la idea, pero no sé cómo escribirla, de tal forma que de pronto el profesor me entienda, porque yo puedo escribir y me entiendo, pero no todo el que lo lea lo va a entender, entonces, sí, también he tenido esa dificultad. (AFROF5)

Algunos estudiantes manifiestan que los primeros semestres presentaron dificultades pero con el paso del tiempo fueron mejorando y resaltan como dificultad la organización del texto:

\section{Al principio sí me daba más duro}

ENT:: Cuando presentas las evaluaciones escritas, ehm, ¿sientes algún tipo de dificultad, y en qué sientes esa dificultad?

INF.: AI PRINCIPIO sí me daba más duro además porque, primero, porque uno se estaba acoplando a un poco de términos que desconocía, de un universo, o sea, que uno viene a hablar de otras cosas y como que eso es muy ay! En ese momento es muy complicado y además cómo organizo y cómo cuadro mis ideas para escribir, responder acá y que me vaya bien, entonces, como que al principio se me complicaba mucho en las evaluaciones escritas, y aun en ciertos momentos, creo que sigue siendo complicado, como que el argumentar y decir tal, y que no me quede suelta una cosa. (AFROF2)

Otra dificultad depende de las tipologías textuales y la falta de práctica en la realización de estos tipos de texto: 


\section{Es la primera vez que escribía artículos}

ENT.: ¿Qué tipos de trabajos te han solicitado, de primer a cuarto semestre, y qué dificultades has visto que tienes frente a esos textos?

INF.: Me han pedido buenos trabajos, y lo que más dificultad se me presentó fue, en escribir artículos, porque es la primera vez que escribía artículos. Hacer informes de laboratorio me parecía tenaz, porque para mí escribir un informe ERA escribir mucha teoría, y como ir aprendiendo que los informes no son sólo teorías, sino que toca poner su punto de vista me pareció muy difícil, pero después de que ya uno coge el ritmo, ya todo se le va haciendo más fácil. (AFROF3)

Pero las dificultades en la redacción constituyen los problemas más frecuentes en los escritos de los estudiantes:

\section{La redacción}

ENT:: ¿Tienes alguna dificultad para escribir?

INF.: Sí. De hecho en un parcial, sabía la respuesta muy bien, pero entonces hubo un problema de redacción, el semestre pasado, y perdí ese punto, o sea, el profesor me calificó la mitad y tenía razón pues estaba MUY mal redactado, pero en sí la idea estaba ahí (RÍE). (AFROF4)

En ocasiones pareciera que algunos estudiantes confunden la idea de escritura como capacidad que se desarrolla socioculturalmente con la facultad del lenguaje, que supondría una especie de imposibilidad innata:

\section{No soy buena para redactar}

ENT:¿Reconoces fallas en la escritura?

INF.: Es que no soy buena para redactar, vuelvo y repito, a veces como incoherencias, no sé. (AFROF6)

Hay también una dificultad proveniente de los bajos hábitos de lectura. En general, es importante conocer sobre lo que se va a escribir, de lo contrario, los textos se limitan a opiniones un tanto descontextualizadas:

\section{No sé qué decir}

ENT.: ¿Y cuando has presentado evaluaciones escritas has tenido algún tipo de dificultad?

INF.: Sí. No todos los documentos me parecen interesantes y si no me parecen interesantes, hago la lectura muy superficial, o no la hago, entonces, de acuerdo al autor, qué plantea, que no sé qué más, y uno tiene la idea, pero de pronto yo respondo más a lo cotidiano, a lo que yo vivo, pero, de pronto es el problema, y también la memoria, a veces leo y leo, pero 
no guardo toda la información necesaria, entonces eso es una dificultad cuando tengo un parcial escrito. (AFROF5)

Cuando afirman que no tienen problemas, lo atribuyen a características formales de su escritura:

\section{No tengo la letra muy pequeña, ni exageradamente grande}

ENT.: ¿Cómo has sentido tu desempeño en las evaluaciones en el momento de escribir?

INF.: No, pues yo, estoy muy clara al escribirse entiende, tengo la letra muy pequeña, ni exageradamente grande, eh, sí lo que te digo es entendible, nunca se han quejado. (AFROF8)

Otros simplemente reconocen que no se trata de dificultades como tal, sino de pereza:

\section{Le da a uno como mamera escribir}

ENT:: ¿Qué dificultades has tenido en cuanto a la escritura en la universidad?

INF.: Nunca he tenido problemas así en cuanto a la escritura, ¿sí?, es que a veces entre comillas, ¿no?, le da a uno como mamera escribir, llamémoslo así, ¿ves?, pero no problemas como tal no he tenido. (AFROM1)

\section{Prácticas de escritura basadas en el interés propio}

La mayoría de los estudiantes manifiestan no tener hábitos de escritura fuera de los trabajos solicitados por los docentes. Aunque hay algunos que escriben textos narrativos como poemas, diarios o cuentos:

\section{Desde la primaria llevo un diario}

ENT.: ¿Y qué clases de cosas, sobre qué escribes?

INF: Pues, yo desde HACE mucho tiempo, o seas, desde la primaria llevo un diario, y lo continúo, el diario por ejemplo, me gusta escribir muchos poemas, o cosas así o me invento historias, narraciones, sobre cosas que porque yo creo que la (RÍE) es como un medio de desestresarme, también decir, como reflejar y dejar impregnado algo de lo que yo pienso, entonces yo escribo mucho de eso, poemas, historias, narrativas, pues por la dinámica del grupo, escribiendo ensayos, artículos, pues, sobre la temática de la comunidad afrodescendiente, y otras múltiples cosas, o sea, realmente yo uso, mucho la escritura, no queda para mí sólo para la universidad, como mis otros compañeros, que es sólo por lo que les pidieron el ensayo escriben, pero no, ya para mí es como una cosa muy rutinaria. (AFROF2) 


\section{Yo escribo cuentos}

ENT.: ¿Sobre qué escribes?

INF.: Yo escribo cuentos, a nadie se los he mostrado, je, pero escribo cuentos, me gustan las historias, me gusta, plasmar cosas que me pasan a mí, transformarlas de tal forma que parezcan cosas que le pasan a cualquier persona. (AFROM2)

\section{Cartas que me gustaría enviarle a una persona}

ENT.: ¿Escribes otras cosas a parte de los requisitos que te pide acá la universidad?

INF.: O sea, no aquí en la universidad no, pero a veces en la casa, escribo, qué te digo, no tanto poesía, sino como así cartas que me gustaría enviarle a una persona, o cosas que me gustaría decirle a una persona que no se las puedo decir de frente, y ahí las voy guardando y cuando tenga la oportunidad... (AFROF5)

La práctica de escritura está relacionada con el gusto. Los estudiantes manifiestan poco interés y gusto por la escritura:

\section{No es que me mate}

ENT:: ¿Te gusta escribir?

INF.: A veces, pues, como para lo necesario, no es que me mate, jasí no!, normal. (AFROF7)

También señalan cambios en los hábitos de escritura debidos a la necesidad de trabajar:

\section{Más que todo es por falta de tiempo}

INF.: Llamémoslo así, pues, obvio, te lo están dictando, entonces es importante, ¿sí? ¿ves?

ENT.: Mjm.

INF.: Pero digamos así, por fuera de la universidad, anteriormente lo hacía muchísimo, o sea, me gustaba escribir, leer mucho, escribía por ahí cosas, pero yo creo que ahorita más que todo es por falta de tiempo, ¿sí me entiendes?, o sea, como que un día mío como puedes ver, estoy acá y si tengo clase, tengo que salir corriendo a clase, REGRESAR al trabajo, porque igual, como que es muy diferente al RESTO de mis compañeros, que sólo llegan a clase o se pueden ir a la biblioteca a repasar, escribir o relajarse en el pasto de la universidad, pero no, yo no puedo hacer eso. (AFROM1) 


\subsubsection{La metacognición. Estrategias de producción de textos escritos:} ¿Y La teoría? Al reflexionar sobre las prácticas de escritura académica como la toma de notas y la realización de ensayos, informes reseñas y demás textos propios del aula de clase y su planificación, los estudiantes afrodescendientes presentan diferentes grados de apropiación de las teorías y sentido de su funcionalidad.

Algunos identifican los procesos producto de la escolarización y pueden dar cuenta de ellos en términos declarativos:

\section{Como que uno le tiene que dar orden}

ENT.: Tú me dices que consideras que redactas bien, te ha ido bien en eso, eso significa que también los profesores lo identifican como tu fuerte, pero cuando te sientas a escribir los trabajos, o cualquier tipo de texto, ¿a qué es lo que más le pones cuidado y qué pasos sigues?

INF.: Yo cuando, bueno, con lo que he aprendido (RÍE) porque eso me lo ha dado la universidad, o sea, como que uno le tiene que dar orden, todos los esquemas que hay que tener, yo normalmente, elijo el tema, cómo quiero empezar, siempre hago un borrador, o sea, como de ideas, ah! iniciemos así, pero hay que argumentar esto, cuando conozco mucho del tema lo hago más fácil, cuando no, primero me remito a leer sobre otras cosas, como decir, jay!, yo no entiendo tal, concepto, o cuando no entiendo muchas frases, que qué significaba para mí una frase, entonces vuelvo a buscar y trato en, hacer como un esbozo, de toda la cuestión y ahí sí comenzar a escribir, después de que escribo, ahí sí vuelvo a ver, cuando tengo tiempo, no siempre, eso no, no es tan ideal (RíE).

ENT.: No es tan ideal, yo sí iba a decir, esa mujer es un juicio...

INF.: Entonces me remito de nuevo como al texto y veo y verifico cosas para arreglarlo, entonces, digamos, eso es como el enfoque de FORMA, y como estructura tratar de ver que el argumento no se me caiga, que no se me caigan los argumentos. (AFROF2)

Otros estudiantes, además de resaltar la importancia de conocer bien el tema sobre el que se va a escribir, destacan los aspectos formales, como la ortografía y la redacción:

\section{Molestan mucho, por los pies de páginas}

ENT.: ¿Y ese sacrificio se representa en qué procesos de escritura?

INF.: Lo que yo hago es investigar, estar empapada del tema, porque molestan mucho por los pies de páginas, por darle créditos a los autores de los escritos que uno leyó, porque molestan mucho por lo del plagio, y pues lo que sigo es eso, leer mucho, saber del tema, para saber en QUÉ voy a enfocar y qué es lo importante que voy añadirle al artículo. 
ENT.: ¿Y cuando estás escribiendo a qué le pones cuidado?

ENT.: La ortografía, vivo obsesionada por la ortografía y que el texto vaya bien enfocado, que la gente empiece a leerlo y que se atrape en él, no que lo leyó así por encimita y, ay! no, no tiene nada interesante, no, que haya, no sé, que sea interesante, que la gente lo inicie a leer y quede como atrapada, embebido, y que SIENTAN, que el artículo explicó algo que no sabían o que si lo sabían no lo sabían profundamente, en eso más o menos me fijo. (AFROF3)

Esta idea es recurrente en las entrevistas, y se podría explicar por el excesivo interés puesto por los maestros de educación básica y media en ella, tal como lo señalaron los estudiantes al hablar de la escritura en los niveles básicos:

\section{Algo que yo tengo muy presente son las tildes}

ENT.: ¿Qué pasos sigues cuando estás haciendo los trabajos escritos?

INF.: A mí me gusta mucho que todo sea como muy ordenado, no sé, si eso va como que en todo (RíE), las normas, en cuanto a las márgenes, los títulos, espacios, y no sé, algo que yo tengo muy presente son las tildes, entonces yo vivo como medio obsesionada con la ortografía, yo sé que no tengo la mejor, pero sí me considero más o menos buena en ortografía, y comas, punto y coma, signos de puntuación, porque yo soy de las que redacto primero lo que voy a escribir, lo leo, lo organizo y luego sí lo paso al informe que tengo que entregar, a mí siempre me ha gustado hacer eso. (AFROF4)

Otros estudiantes restan importancia a los aspectos teóricos que fundamentan las prácticas escriturales y otorgan mayor atención al quehacer práctico del docente:

\section{Siempre me nace escribir la necesidad del niño}

ENT.: Académicos, y ¿cuando escribes cualquiera de estos textos a qué le pones cuidado y qué pasos sigues para hacer un trabajo?

INF.: Yo siempre me he basado en lo que, como tal, el niño, a la necesidad que él tiene, porque creo que mientras los niños de aquí tienen un buen cuidado, entre comillas, y los profesores están atentos, pues, y que, sea como sea voy a regresar a mi pueblo, y es un espacio muy diferente, porque allí prácticamente la mitad en sus casas no tienen como una atención, entonces siempre trato de basarme en el niño como tal, algunas citas de los autores, porque yo digo, que para qué seguir citas, si eso igual eso nace, ¿si? Yo no puedo estar siempre con lo que dice Piaget, porque todos, y hoy en día los niños están naciendo, con diferentes, entonces, no puedo quedarme sólo con eso, yo solamente analizo, yo no trato, de seguir lo que ya está escrito, sino lo que a mí me nace, lo que yo estoy viendo que es una 
necesidad para ellos, entonces siempre me nace escribir la necesidad del niño, y, relacionarlo con lo que se está viviendo en mi pueblo. (AFROF1)

De esta manera lo reitera otra estudiante, también de la licenciatura en pedagogía infantil, lo que podría implicar un asunto de aspecto curricular y políticas de los programas:

\section{Miro es eso, lo que a mí me gustaría}

ENT:: ¿Cuando estás escribiendo, qué pasos sigues para elaborar los trabajos, o qué tienes en cuenta para hacer un trabajo escrito?

INF: En este momento yo estoy trabajando en un jardín, o sea que me quedé en la práctica con el instituto, me quedé trabajando en el jardín, entonces, cuando son así autores que proponen nuevas metodologías educativas y eso, de pronto hago la lectura, y miro cómo de pronto se evidencia eso en el jardín y a partir de lo que de pronto, plantea el autor y de lo que a mí me gustaría cuando ya tenga la licenciatura, cuando esté ejerciendo en un colegio ya formal, entonces, miro es eso, lo que a mí me gustaría, teniendo en base el autor que estemos trabajando, es lo que tomo, son criterios que tomo para para realizar el escrito. (AFROF5)

Otro aspecto que se evidencia en los entrevistados es la poca posibilidad de dar cuenta de los procesos, apenas se señalan aspectos generales, como lo señala esta entrevistada:

\section{Yo siempre me quedo mucho en el título}

ENT.: Sí, ¿y qué pasos sigues?

INF: ¿Qué pasos sigo?, yo siempre empiezo por el título, yo SIEMPRE me quedo mucho en el título, como qué título le pongo, algo que llegue, no sé, y de ahí, pues empiezo a escribir y por último las conclusiones. (AFROF6)

La constante parece ser la poca preocupación por la planificación de los textos y el seguimiento de la intuición y la espontaneidad:

\section{No sigo pasos de ninguno}

ENT.: ¿Qué pasos sigues cuando elaboras un trabajo escrito?

INF: ¿Qué pasos? ija!, a veces (RÍE), no sigo pasos de ninguno, a veces empiezo a escribir y BORRO y ESCRIBO, no sé, empiezo como desde lo que se me ocurra primero, o sea teniendo en cuenta que, hay que regirse como por unos parámetros, pero casi siempre escribo algo que se me ocurre, lo primero, como palabras así que puedan ser conectoras, pero no tengo como un principio básico, de que cómo empiezo y cómo termino no, o sea, se me va dando en la medida en que voy dependiendo del tema, no?, pero no tengo así como porque no las TENGO, o sea, acá no hay 
como eso tampoco, o sea, a ti te PIDEN, escribe, pero el profesor no, de pronto en mi carrera no, nosotros vemos literatura y eso pero la profesora no se detiene como oiga!, mire, corrija.

ENT:: ¿No hay eso?

INF: No, ipara nada! (AFROF7)

Los estudiantes parecen no estar familiarizados con determinadas terminologías y teorías, lo que hizo que muchas de las respuestas fueran inducidas y bastante intuitivas:

\section{Se hace una corrección}

ENT.: ¿Cuándo estás elaborando los trabajos escritos y teniendo en cuenta las indicaciones del profesor, qué pasos sigues?

INF.: No te entiendo.

ENT.: Si vas a hacer el informe, o si vas a hacer el resumen, o si vas a hacer el ensayo, o el protocolo, ¿qué tienes en cuenta para comenzar a escribir?

INF.: Normalmente antes de hacer el trabajo completo, he hecho como una especie de borrador, entonces ahí determino, qué es lo que me sirve realmente, igual, es como muy normal, tú haces un TRABAJO pero empiezas a revisarlo, y te das cuenta o que te faltó algo o que pusiste algo que no iba, entonces, obviamente, se hace una CORRECCIÓN, corrección, hasta quedar más o menos como uno desea que quede. (AFROM8)

Los estudiantes de las licenciaturas implicadas directamente en los temas de enseñanza y aprendizaje de la lectura y la escritura conocen el metalenguaje y las teorías y sus prácticas académicas se centran en ellas, como lo señala este estudiante de lengua castellana:

Buscar el autor... leo... saco algunas temáticas... busco la relación... busco un tema central... empiezo como a escribir las ideas... empiezo a estructurar el texto...

ENT.: Cuando estás elaborando los textos, por ejemplo un ensayo, ¿qué pasos sigues?

INF.: Bueno lo primero que hago, incluso ahorita, en este momento estoy haciendo un ensayo para una materia, lo primero que hago es buscar el autor, porque es sobre un autor, eh, colombiano, busco el autor que ya lo tengo escogido, es Manuel Zapata Olivella, leo, eh, busco el texto que me interesa, entonces, tuve la fortuna de buscar tres textos y uno de esos lo escogí, después de eso, bueno, lo leo, saco algunas temáticas que contiene el texto, que contiene la novela y después de eso, busco la relación de ellos y entre los temas que encuentro en la novela, busco un tema central, eh, luego, empiezo como a escribir las ideas, lo que va surgiendo y en ese 
orden empiezo a estructurar el texto, entonces, digo, lo que quiero tratar en este tema es, mmm, la identidad, entonces, ehm, Manuel Zapata Olivella toca en la novela tal, el tema de la identidad desde tal punto y empiezo a desarrollar, de tal otro, empiezo a desarrollarlo y trato como de poner conceptos de autores que trabajen de identidad, eso es básicamente lo que hago. (AFROM2)

Otros estudiantes más que seguir pasos orientan sus escritos al lector, privilegiando aspectos comunicativos:

\section{Depende de la introducción}

ENT.: ¿Cuando elaboras un trabajo escrito qué pasos sigues y a cuál le pones mayor atención?

INF: Yo creo que lo primero que hago es la introducción, ¿por qué?, porque depende de la introducción es donde yo voy a dar mis ideas, ¿sí?, voy a tratar de que tú como lector, cuando tú tengas el texto, te enfabules, te guste y sigas, y quieras seguir leyendo; yo creo que ese es donde más, ¿si?, yo creo que ese es más que yo le doy más importancia, ¿sí?, y obviamente ya lo que es el trabajo ya en sí, desarrollado le pongo todo el interés, pero más que todo voy es a la parte de la introducción porque de ahí depende, de que tú como lector va a saber de que la lectura se va a tratar, entonces eso es como una motivación, para que el lector siga descubriendo, ESCUDRIÑANDO en la lectura para ver que le encuentra, el gusto de seguir leyendo. (AFROM4) 



\section{Sistematizando los datos: elementos para una discusión}

\subsection{Algunas salvedades}

Ante la ausencia de estudios concretos sobre la situación de los estudiantes afrodescendientes e indígenas en los distintos niveles de educación, es prioritario comenzar a indagar, más allá de las estadísticas de analfabetismo, por sus expectativas, desempeños y problemáticas en el sistema escolar, ya que aspectos determinantes del éxito o fracaso escolar pueden vincularlo al desarrollo de las competencias lecto-escriturales. En ese sentido, este trabajo indaga por las representaciones de los estudiantes sobre la escritura académica en el contexto universitario partiendo del presupuesto de que se habla de una cuestión a nivel de la actuación y en ningún caso se refiere a la competencia, que se reconoce igual para todos los individuos.

La perspectiva de análisis aquí planteada supone la existencia de problemáticas complejas, multidimensionales, de fenómenos en proceso, no de productos, acontecimientos, o realidades estáticas. Supone su naturaleza histórica y un carácter construido, con raíces dentro y fuera de los centros educativos. Por esta razón, antes de emplear lenguajes que designen un "ser", se opta por formas más propias del "devenir", del "ir haciéndose". En consonancia con investigaciones actuales en educación, no se habla de los hechos en abstracto, descontextualizados y asépticos, sino que se los ubica en contextos y dinámicas particulares, recuperados, como se vio, a través de relatos, historias de vida o narrativas de estudiantes que pueden ayudar a comprender mejor los fenómenos (Bolívar, Martínez, 2002, Escudero y otros, 2009).

\section{Recordando los sujetos y sus historias}

Los estudiantes indígenas y afrodescendientes entrevistados provienen en su mayoría de comunidades apartadas del país. Algunos vivieron en los cascos urbanos, otros en sectores más alejados y, otros pocos llegaron a Bogotá con sus familias desde muy niños. La educación básica la realizaron en escuelas 
pequeñas cerca a sus comunidades. La familia fue la encargada de trasmitir los primeros conocimientos, tanto tradicionales como respecto a la lectura y la escritura. El español es la lengua materna para casi la mitad de los entrevistados. En algunos casos la lengua indígena la perdió la totalidad de la comunidad hace ya muchos años; en otros, se está perdiendo por desconocimiento de los padres, quienes en ocasiones consideran más importante el español.

Para los indígenas, el ingreso a la escuela estuvo marcado por el desprendimiento de la familia y la comunidad y el ingreso a los internados, manejados en su mayoría por religiosos. El encuentro con nuevas realidades significó un choque cultural que implicó reconocerse diferentes y confrontar los conocimientos ancestrales con los occidentales; reconocer que había, por ejemplo, un Estado y que las teorías del origen no eran como se las explicaron los taitas. Lo que supone un doble proceso: desaprender y volver a aprender. La disciplina y el autoritarismo se convirtieron en la constante de estos primeros años, al igual que la discriminación. Las monjas y los curas, además de imponer una única lengua -el español-, también impusieron unas formas de vestir y unas prácticas que llevaron a los estudiantes indígenas a considerarse inferiores cognitiva y socialmente. Apelativos como brutos, ignorantes, cochinos, sucios y otros más provenían tanto de maestros como de compañeros de escuela. Como resultado: la creencia de que ellos estaban vetados para el conocimiento y que sólo podían interactuar con otros miembros de las comunidades indígenas y la idea de que debían mantenerse juntos para defenderse de las agresiones.

Para los afrodescendientes el cambio no fue tan traumático, recuerdan las precarias condiciones de sus escuelas, la falta de recursos físicos pero sobre todo humanos: la falta de profesores y su poca formación profesional, aunque también recuerdan con agrado ciertas prácticas diferentes de aprendizaje, como el uso de la música. De esta época son también sus recuerdos de las migraciones por diversas regiones del país. Cambios frecuentes de domicilio afectaban con frecuencia su vida escolar.

El paso al bachillerato implicó otro gran saltó para los indígenas: apartarse de las comunidades y desplazarse a las cabeceras urbanas donde sí había colegios de bachillerato, y encontrarse con poblaciones más numerosas. Durante el bachillerato, el castellano se convirtió en la única lengua, pero los indígenas ya habían adquirido una mejor competencia en esta lengua. Quienes mantenían sus tradiciones ancestrales, manifiestan seguir siendo discriminados. Otros reportan una adaptación al sistema escolar y buenos resultados producto de su perseverancia, del respaldo familiar y las ganas de salir adelante. Quienes realizaron su bachillerato en las grandes capitales sufrieron de nuevo el choque 
de encontrarse con otras culturas que los veían diferentes y poco los aceptaban. Y quien tuvo la fortuna de estudiar en colegios únicamente para indígenas, un único caso, manifiesta haber tenido un proceso normal y exitoso.

Para muchos indígenas terminar el bachillerato es el mayor logro educativo al que se puede llegar, sin embargo, unos pocos dan un paso adelante y acceden a la universidad; la mayoría, a través de los programas del gobierno de cuotas para comunidades indígenas. La familia y los amigos constituyen el primer referente de las universidades. Ellos son la segunda o tercera generación de miembros de las comunidades indígenas que acceden a la universidad.

El bachillerato para los afrodescendientes supuso el cambio de sus pequeñas comunidades a las capitales, a colegios grandes en los que las interacciones variaron, convirtiéndose en menos camaradería y más prevención y discriminación para quienes viajaron a las grandes capitales.

Para el ingreso a la Universidad, la casi totalidad de los entrevistados manifestó haber pensado inicialmente en la Universidad Nacional. Para algunos, ésta era la única institución que conocían o de la que habían escuchado. Casi todos se presentaron primero allí, pero "como es lógico", según ellos señalan, no pasaron. De ahí se abrió un abanico de posibilidades, aparecen las universidades privadas y otras públicas, como la Universidad Distrital, a la que finalmente, los entrevistados acceden después de varios intentos de ingreso a otras universidades.

Ingresar a la universidad implicó también un gran choque cultural, esta vez con la ciudad: grande, ajena, peligrosa, cerrada y difícil. Sin embargo, la casi totalidad de estudiantes manifiesta haber sido bien recibido en la universidad por compañeros y profesores, quienes sintieron, sobre todo, curiosidad por ellos, deseos de conocer sus tradiciones y costumbres. La discriminación directa parece haber quedado en la escuela y el colegio. Pero los consecuencias no. La timidez, el miedo y la inseguridad son recurrentes, en los estudiantes indígenas. Los profesores se convierten en ocasiones en figuras extraterrestres; preguntar en clase es todo un reto. Otros manifiestan haber aprendido las dinámicas escolares durante los años previos al ingreso a la universidad y llegan más seguros, sin agachar la cabeza, y con imposiciones: jaquí estoy yo y así soy! Son en todo caso, aquellos estudiantes que fueron líderes comunitarios y trabajaban o pertenecían a agremiaciones indígenas o afrodescendientes.

Los estudiantes afrodescendientes condicionan el ingreso a la universidad por las cuestiones económicas. Los escasos recursos los obligan a trabajar haciendo que el ingreso sea a edades mayores que las del resto del estudiantado; también deben intercalar sus actividades escolares con las laborales. 
Vemos entonces como el contexto de procedencia de los estudiantes marca una gran diferencia y supone desventajas para los estudiantes indígenas. El proceso escolar se inicia con fuertes choques culturales que incluyen discriminación y racismo que marcará a los estudiantes incluso durante años.

\subsection{Primera discusión: La escritura en la universidad, un pro- blema de contexto}

Para el caso de los estudiantes entrevistados, el contexto resulta básico para entender su desempeño académico, más exactamente su producción escrita. Mientras para la mayoría de la población que habita Bogotá, el ingreso a las universidades públicas no implica procesos de adaptación a la ciudad, a las costumbres, a la lengua o incluso al clima, para los estudiantes indígenas y afrodescendientes este encuentro supone un choque, un cambio duro, que en muchos casos los hace desistir y regresar a sus comunidades. Pero para quienes continúan supone una desventaja de entrada frente a sus compañeros.

Las variaciones en las prácticas académicas también son un factor de choque. Al provenir de contextos alejados del país, de sectores marginales, con niveles educativos bajos, producto de los pocos recursos invertidos por el Estado, de nuevo se encuentran en déficit frente a sus compañeros. La falta de instalaciones físicas, de laboratorios, de salas de audiovisuales, de materiales didácticos, de tecnologías o incluso de aulas y de docentes capacitados, crea diferencias entre los estudiantes desde el inicio. Si agregamos a esto los imaginarios de los estudiantes, sobre las diferencias entre los pueblos y las ciudades y sobre el estatus de los docentes y la calidad de la educación, y un amplio historial de discriminación desde la escuela por su condición étnica y cultural, se obtiene un cuadro desalentador de estudiantes tímidos, temerosos, inseguros y acomplejados. Pertinentes resultan las palabras de Hargreaves, quien citando al sociólogo Senett señala que: "La interiorización de la responsabilidad del fracaso, por ser diferente o inferior, es común entre aquellos que ocupan un bajo estatus en la sociedad, y es un proceso que comienza temprano, en la escuela" (2003: 6). Hargreaves postula entonces la existencia de dos tipos de emociones en la escuela: la distinción y el asco. La primera destinada a aquellos que son social y escolarmente exitosos. Los herederos de lo que Bourdieu llamó distinción, el "gusto puro", que les permite a sí mismos verse como separados, distintos, deslindados y que los faculta para decidir qué rechazar o qué evitar: sus opuestos. Los segundos, las víctimas de la distinción, los herederos del asco. En palabras de Hargreaves "aquellos que no tienen éxito, que fracasan, se convierten en 
las víctimas de la distinción, el objeto del asco y del desprecio" (Ibid: 7). Para este autor, la distinción y el asco constituyen la base de la exclusión social que determina el fracaso o el éxito escolar, que mediante el concepto de capacidad o competencia se asignará distintivamente a aquellos poseedores de distinción o asco.

Sin embargo, frente a estos hechos es importante establecer diferencias entre los dos grupos estudiados. Al hablar de los afrodescendientes en la universidad nos encontramos con un problema complejo que va más allá de las habilidades y que se reconoce como producto de un problema histórico y estructural en el que los afrodescendientes han sido invisibilizados y marginados social, política y culturalmente. En la práctica, no han tenido los mismos derechos educativos del resto de la población colombiana. La cobertura, la calidad, la permanencia y los logros en el sistema educativo de las poblaciones de mayoría negra ha sido ampliamente señalada como deficitaria, como, por ejemplo, lo señala el Primer informe sobre la discriminación racial y derechos de las comunidades afrocolombianas (Rodríguez Garavito et. al., 2008) quien concluye que mientras no se tengan satisfechas las necesidades básicas, priorizar la educación será complicado.

Por su parte, los indígenas aunque también han sido discriminados históricamente, en épocas recientes estos grupos han sido objeto de reconocimiento de derechos y su imagen se ha venido revalorando con el tiempo. Igualmente este grupo tiene una amplia tradición de organización de sus poblaciones ya sea para reclamar derechos o para trabajar dentro de las comunidades, por lo que algunos de los estudiantes que acceden a la universidad han sido líderes comunitarios, lo que les da ciertas facilidades para desenvolverse mejor en la ciudad y en la universidad. De igual manera, pertenecen a familias y comunidades que ya han vivido la experiencia de la universidad por varias generaciones. Algunos tienen padres profesionales que les han trasmitido sus experiencias y que los han preparado para su ingreso a la universidad. Otro aspecto diferenciador del contexto de indígenas y afro descendientes, lo constituye el hecho de que, en general, las comunidades religiosas se han encargado de la educación de los indígenas. Y, con todas las críticas que se puedan hacer a sus prácticas y métodos, son comunidades con amplia tradición en lo educativo a lo largo de la historia. Los estudiantes educados en estas tradiciones presentan desempeños diferenciados de los otros estudiantes que asistieron a la escuela pública, como es el caso de los estudiantes afrodescendientes. 


\subsection{Segunda discusión: Repensar la dicotomía oralidad y escritura}

Los y las estudiantes entrevistados reconocen que provienen de comunidades orales, en las que lo oral cumple un papel determinante en la transmisión de conocimientos, saberes y prácticas. Para ellos y ellas, la escritura alfabética es una práctica reciente y ajena pero a la cual han ido habituándose a través de la escuela. Para los y las entrevistados, más para los indígenas que para los afrodescendientes, es fundamental el peso y el valor que tiene cada una de estas prácticas en su tradición. En ese sentido nos parece pertinente contextualizar el tema frente a la teoría y proponer una discusión desde allí.

A partir de Ong (1982), la relación oralidad y escritura, culturas orales y culturas escritas ha sido objeto de innumerables debates; la primacía de la segunda sobre la primera ha sido la constante de las investigaciones, como se señaló en el apartado dos de este texto. Ong propone entender la naturaleza de la oralidad a partir de lo que él denomina psicodinámicas de la oralidad: La palabra articulada como poder y acción, uno sabe lo que puede recordar y las características del pensamiento y la expresión: acumulativos antes que subordinados, acumulativos antes que analíticos, redundantes o copiosos, conservadores y tradicionalistas, cercanos del mundo humano vital, de matices agonísticos, empáticas y participantes, no objetivamente apartados, homeostáticas y situacionales antes que abstractos.

Entender estas psicodinámicas es importante, porque se encuentran en el discurso de los estudiantes indígenas. La idea de que "uno sabe lo que puede recordar", es recurrente. La minoría se constituye en eje central de la escritura. Pareciera existir una correspondencia entre oralidad y escritura: la escritura es el proceso mediante el cual se reproduce lo que está en la memoria. A mayor capacidad de recordar, mayor posibilidad de escribir. Idea que es comprensible si se entiende que los y las estudiantes entrevistados pertenecen a comunidades de tradición oral, donde la escritura tiene un uso reciente.

Otras características propias de la oralidad también pasarían a formar parte de escritura, como la redundancia y el carácter acumulativo. Los estudiantes señalan que los escritos terminan diciendo lo mismo de diferentes formas, lo explican con la idea de que siempre faltan cosas y cada vez que se recuerda algo debe escribirse, la dificultad está en establecer relaciones, lo que supone en el proceso una acumulación de ideas más que un proceso de síntesis.

Tradiciones occidentales ampliamente difundidas y aceptadas también se han incorporado en el imaginario de los indígenas, así se manifiesta la creencia de que sólo lo escrito permanece; lo oral se lo lleva el viento. Olvidando así, que 
mucho de su conocimiento y sabiduría se ha mantenido a lo largo de los siglos gracias a la tradición oral.

Señala Ong que en la oralidad, dada la ausencia de categorías analíticas complejas que permitan estructurar el saber independiente o alejado de las experiencias vividas, se expresa el conocimiento de manera estrecha relacionada con el mundo objetivo. Para los estudiantes indígenas y afrodescendientes, ésta constituye una limitación de la escritura. Para ellos, la escritura debería ser vital, dependiente del contexto. Sólo así tendría un poder transformador. Implica sentirse reflejados en la escritura, ser y existir históricamente. Esta característica también está estrechamente relacionada con el carácter situacional antes que abstracto de la oralidad. Para los estudiantes, el conocimiento y la escritura como tal es relevante en tanto permita transformar o comprender las problemáticas más próximas a su existencia y las prácticas cotidianas. Esto se evidencia en un distanciamiento o hasta cierto punto desprecio por las teorías que ellos consideran ajenas y deja ver un cierto pragmatismo que, sin embargo, no es propio únicamente de estos grupos étnicos sino de los estudiantes universitarios en general.

\section{Tabla 15. Relación oralidad-escritura para los y las entrevistados}

\begin{tabular}{|l|c|l|}
\hline \multicolumn{1}{|c|}{ ORALIDADAD } & Relación & \multicolumn{1}{c|}{ ESCRITURA } \\
\hline $\begin{array}{l}\text { La oralidad requiere memoria } \\
\text { La oralidad se caracteriza por la } \\
\text { redundancia }\end{array}$ & $=$ & $\begin{array}{l}\text { La escritura requiere memoria } \\
\text { redundancia }\end{array}$ \\
\hline $\begin{array}{l}\text { La oralidad se caracteriza por } \\
\text { acumulación de ideas }\end{array}$ & $=$ & $\begin{array}{l}\text { La escritura se caracteriza por la } \\
\text { acumulación de ideas. }\end{array}$ \\
\hline La oralidad está apegada a lo vital & $=$ & La escritura es vital \\
\hline La oralidad es situacional & $=$ & La escritura es situacional \\
\hline La oralidad es existencia & $=/=$ & \\
\hline La oralidad supone conocimiento & $=/=$ & La escritura es copia \\
\hline
\end{tabular}

Las ideas plasmadas en la Tabla 15, parecieran mostrarnos que estamos frente a una etapa de transición de la oralidad a la escritura en la que las características de una se solapan con la otra, de manera más evidente que en las culturas con amplia tradición escrita. Y en la que las valoraciones positivas de una, la oralidad, determinan las características de la otra, la escritura. Sin embargo, de la Tabla, nos interesa centrarnos en las diferencias más significativas establecidas por los y las entrevistadas entre oralidad y escritura, y analizarlas a la luz de las teorías de Ong para ver aquellos elementos que coinciden pero sobre todo aquellos que representan un pensamiento otro, como una posibilidad de entender la escritura y la oralidad. 


\section{Más allá de la dicotomía oralidad y escritura 1: La palabra, un asunto existencial}

En la relación oralidad y escritura, los estudiantes indígenas manifiestan un aspecto que se sale de las psicodinámicas de la oralidad y que tiene que ver con el valor y el poder de la palabra para estas comunidades. Ong señala que en las culturas orales se percibe la palabra articulada como poder y acción refiriéndose al hecho de que al nombrar se le da poder a las cosas, contrario a las tradiciones escritas para quienes las palabras están muertas, no implican acciones. Para Ong, este poder atribuido a la palabra oral es asociado a la magia. Sin embargo, para los estudiantes indígenas la palabra (oral) tiene implicaciones existenciales, más que mágicas. Estaríamos más cercanos a la idea de Echeverría de una ontología del lenguaje en la que plantea tres principios clave de la ontología del ser: Interpretamos a los seres humanos como seres lingüísticos; interpretamos al lenguaje como generativo; e interpretamos que los seres humanos se crean a sí mismos en el lenguaje y a través de él (1996: 31).

Estas ideas aparecen en las epistemologías de los indígenas sobre el lenguaje y la palabra. Para ellos "la palabra es vida, la palabra es una presencia", como lo señala un estudiante. Es la semilla de la vida, por medio de ella se educa y se trasmite la sabiduría de la comunidad. Concepción también cercana a la filosofía de Heidegger, para quien el lenguaje es la morada del ser. Pero el lenguaje también posee carácter generativo, el lenguaje permite no solo hablar de las cosas sino alterar el curso de los acontecimientos. Los indígenas entrevistados señalan que la palabra "no es algo inerte", es energía transformadora, es acción. La palabra que es existencia, presencia, puede convertirse en acción: "Vamos a hacer amanecer esa palabra", señalan. De esta manera, los pensamientos se convierten en acciones. La palabra es llevada por la mujer a la siembra, es trasmitida a través del diálogo y las enseñanzas a los hijos. Pero también es creación, es vida; se siembra y en cada siembra permanece algo de quien la sembró, es su espacio existencial, "allí perteneces, es parte de ti”.

De cierta manera, desde esta concepción se podría explicar la resistencia de muchas de las comunidades indígenas a la escritura, que atrapa y mata la palabra, la fosiliza, le quita su energía, su vida, su poder de creación, acción y trasformación.

\section{Más allá de la dicotomía oralidad escritura 2:}

\section{La oralidad un asunto de conocimiento consensuado}

Frente a la relación oralidad conocimiento, los y las estudiantes señalan que la oralidad supone una posesión de lo que se está diciendo, a diferencia de la 
escritura en la que pareciera, según las prácticas de los maestros, que se trata simplemente de una copia. Este factor nos parece relevante pues contrario a ciertos imaginarios profundamente arraigados en la academia, la oralidad no sólo se relaciona con la narración sino con la argumentación. De esta manera, el conocimiento no es algo que se da por sentado, o que está allí, en alguna parte, fuera de los individuos; el conocimiento para muchas comunidades indígenas es una construcción, es producto del consenso, del diálogo, de la argumentación y se construye en la comunidad, de manera colectiva, en las asambleas y las reuniones $^{6}$; contrario a la escritura, que desde su aparición supuso una actividad netamente individual, solitaria, introspectiva y por tanto, el conocimiento desprendido de allí es igualmente individual. Escritura y oralidad y pertenecen entonces a dos órdenes diferentes: La primera, solitaria e individual, mientras que la segunda, comunitaria y colectiva. Prácticas que de alguna manera representan y dan cuenta de lógicas diferentes: por un lado las lógicas occidentales centradas en la individualidad y las lógicas "otras" en las que prima no el conocimiento producto de la capacidad de abstracción, reflexión, y argumentación de un individuo, por sofisticado que éste sea, sino el conocimiento discutido, analizado, consensuado y aprobado por la comunidad.

\subsection{Tercera discusión: Repensar las funciones de la escritura}

Según la literatura del tema, la escritura académica, posee varias funciones; entre las más destacadas estarían:

- Facilitar los procesos de memorización por medio del registro instrumental. Se estimula la toma de notas o la elaboración de textos que reconstruyan lo visto en clase.

- Evaluar. Se emplea como medio para comprobar la adquisición de conocimiento, es en esencia una forma de medir competencias.

- Servir como instrumento fundamental para la adquisición de conocimiento, para reflexionar sobre lo aprendido, para crear y renovar esquemas mentales y otras funciones de tipo metacognitivo.

Los y las estudiantes entrevistados, identifican de hecho estas funciones de la escritura; sin embargo, consideran que la escritura se emplea fundamentalmente como mecanismo de evaluación, pero con el único propósito de establecer una nota, no en el sentido amplio del concepto de evaluación.

6. Al respecto véase Biondi y Zapata (2009) quienes señalan que las culturas indígenas son culturas de la oralidad y culturas de la argumentación, como lo demuestran a partir del análisis de las asambleas de los indígenas quechuas del Perú. 


\section{Tabla 16. Funciones de la escritura}

\begin{tabular}{|l|l|}
\hline El ser de la escritura & El deber ser de la escritura \\
\hline Escritura como evaluación de productos & Escritura como evaluación de procesos \\
\hline $\begin{array}{l}\text { Escritura como aprendizaje de saberes } \\
\text { establecidos. }\end{array}$ & Escritura como aprendizaje de saberes otros \\
\hline Escritura como medio de comunicación & Escritura como práctica social \\
\hline
\end{tabular}

\section{La escritura como evaluación de productos versus la escritura como eva- luación de procesos}

La evaluación es uno de los temas más recurrentes en el ámbito académico; incluso en la actualidad, con el auge de las políticas de acreditación, diríamos que es uno de los conceptos más recurrentes. Se evalúa, según Perassi: "Aprendizajes, enseñanza, proyectos, unidades didácticas, desempeños de docentes, directivos, administrativos. Se evalúan las reuniones, los actos escolares, el uso del tiempo y del espacio, los textos, la distribución de recursos, los flujos de comunicación, el empleo de la tecnología, el diseño curricular, el plan institucional, etc." (2009:71). Sin embargo, los centros educativos poco se preocupan por investigar sobre el tema y profundizar sobre su influencia en los procesos de enseñanza y aprendizaje y en los logros o fracasos académicos; tampoco se cuestionan el sentido de la evaluación y las prácticas evaluativas. En general, la evaluación es un tema que se resuelve al interior del aula.

Para los y las estudiantes entrevistados, la escritura académica cumple fundamentalmente una función evaluadora, como forma de control y verificación de lo aprendido o desarrollado en clase. Se evalúan los productos. Por lo que prima la memoria y la capacidad de reproducir conocimientos más que la capacidad de relacionar o crear. Los y las estudiantes manifiestan que los docentes poco interés muestran por los escritos; dudan incluso que sean revisados pues la retroalimentación casi siempre es escasa o inexistente. Se escribe entonces para tener una nota.

Según Perassi, la evaluación como sinónimo de calificación es una de las ideas más frecuentes entre los profesores y estudiantes. Se trata simplemente de comunicar resultados, en general, en escalas cuantitativas, en las que no hay posibilidad de análisis, interpretación de la información ni elaboración de un juicio valorativo. Así el maestro se convierte en un informador, que devalúa el proceso realizado y lo convierte en un aspecto administrativo: la nota (2009: 75).

De la mano de esta concepción, está la fuerte tendencia a relacionar la escritura con la forma, ya sea en cuanto a la ortografía y redacción, como a las normas 
técnicas de presentación de trabajos escritos. Aspectos que sin duda serán evaluados por los maestros, más que los contenidos.

Sin embargo, aunque los y las estudiantes entrevistados, no cuestionan que la escritura académica sirva para evaluar, sí insisten en que se debe tratar de cambiar de foco: no como control o asignación de notas, centrada en el final del proceso, es decir, el producto, sino atendiendo a los procesos mismos. Señalan que se debe mirar la capacidad del estudiante en cuanto al aprendizaje, y detenerse en esos procesos. Es decir, lo que se conoce como aprender a aprender. Como posibilidad de la conciencia. Lo que presupone un proceso de lectura de los escritos de los estudiantes y retroalimentación. No se evalúa en abstracto, se evalúan textos. Para los estudiantes escribir y ser evaluados supone una nota, pero no una evaluación real de lo que se hizo. No hay aprendizaje pues no se sabe qué estuvo bien o en qué se falló. De esta manera, la escritura no posibilita la trasformación y el avance en los procesos de aprendizaje, no ofrece soluciones ni alternativas al conocimiento.

\section{La escritura como aprendizaje de saberes establecidos versus la escritura como aprendizaje de saberes otros}

Algunos estudiantes manifiestan que la escritura también cumple una función dentro del aprendizaje, que permite relacionar contenidos e ideas, teoría y práctica y facilita los procesos argumentativos. A través de la escritura se adquieren conocimientos disciplinares que permiten dar cuenta de saberes particulares propios de las carreras.

Según Perassi, y en consonancia con el apartado anterior cuando se aprende para la evaluación, la enseñanza se orienta en esta perspectiva "el profesor selecciona para el trabajo cotidiano aquellos contenidos que serán evaluados, desechando en consecuencia un universo de problemáticas, intereses y preocupaciones, que quedan fuera de lo previsto, de lo evaluable" (74).

Los y las estudiantes entrevistados parten de la existencia de saberes otros, diferentes a los establecidos por la academia como saberes válidos, es decir, los saberes de las disciplinas. Ellos y ellas se sienten portadores de saberes otros que pueden aportar a la comprensión de los fenómenos y que facilitarían el conocimiento. Lo que permitiría un crecimiento intelectual y tener una mentalidad más abierta. Esta escritura estaría vinculada a lo vital, a la experiencia, a los saberes ancestrales y supondría, como señalan, escribir a partir de la realidad, no centrados en las formas ni tampoco en los romanticismos. Se trataría de poner en circulación otras maneras de ver el mundo, no con el ánimo de ser comprendidas, sino para escucharlas y saber por qué se dicen y en qué contex- 
to. Nos enfrentamos así a otra de las grandes características de la evaluación: la exclusión del sujeto evaluado en el desarrollo del proceso de evaluación. Para los y las estudiantes es fundamental que los docentes se aparten de la idea de la masa homogénea, que reconozcan que no todos son iguales, que sus formar de ser, conocer y actuar no son las mismas. De esta manera, se abrirían múltiples posibilidades en el aula y frente a la escritura, por ejemplo, la posibilidad de no estar de acuerdo con los textos, de disentir, cuestionar, argumentar. Lo que implicaría también en asocio al tema de la evaluación, que no todas las respuestas serían iguales. Posición que cuestiona profundamente el monopolio del poder centrado en el maestro, quien bajo una pretendida veracidad y objetividad, se proclama como el "legítimo evaluador" (72).

El tema del conocimiento y, en particular, del conocimiento escolar debe convertirse entonces en centro del debate en el contexto académico. Preguntarse por las formas de producción, reproducción y consumo del conocimiento adquieren cada vez mayor actualidad. Reconocer como único conocimiento válido o legítimo aquel producido en los ámbitos científicos occidentales mediante prácticas igualmente legitimadas y justificadas en las lógicas positivistas de la modernidad, requiere un amplio debate (Soler). Interesantes resultan los planeamientos de autores como Banks quien propone la inclusión de al menos cinco formas de saber en la escuela, todas con la misma validez e importancia: el saber personal y cultural, el saber popular, el saber académico corriente, el saber académico transformador y saber escolar. Para este autor:

La descripción de los principales tipos de saberes puede ayudar a los maestros y a los especialistas curriculares a descubrir las perspectivas y contenidos precisos para elaborar un currículo multicultural. Cada uno de los tipos de saber descritos más adelante refleja determinados fines, perspectivas, experiencias, objetivos e intereses humanos. El hecho de enseñar a los alumnos diversos tipos de saber puede ayudarles a comprender mejor las perspectivas de los distintos grupos raciales, étnicos y culturales, así como a elaborar sus propias versiones e interpretaciones de los problemas y acontecimientos. (Banks, 1996)

\section{Escritura como medio de comunicación versus la escritura como práctica sociocultural}

La función comunicativa de la escritura, es una función, que algunos teóricos de la escritura académica dan por sentada e incluso pasan por alto, pero que para los y las entrevistados es importante. La escritura en la universidad es un medio de comunicación en la que se establece un diálogo entre estudiante y profesor, aunque no siempre al mismo nivel: el profesor es siempre quien tiene la razón y el conocimiento. 
Para los estudiantes, la función de la escritura va más allá de la comunicación, de decir o comunicar, es ante todo una práctica sociocultural, con implicaciones sociales y un poder trasformador. Escribir partiendo de la realidad y de los conocimientos en contexto posibilita alternativas de cambio de las prácticas cotidianas y por qué no, las macrosociales. Permite ver a los actores sociales en su aspecto más humano, reconocer sus saberes y sus diferencias. Porque como bien los señalan los estudiantes al centrarse en lo cognitivo y evaluativo se masifica a los estudiantes, pareciera que todos somos iguales, señalan.

Los y las entrevistadas reclaman reiteradamente ser reconocidos como actores sociales, como interlocutores validos. Reclaman el derecho a la presencia, a ser considerados sujetos; sujetos de saberes, sujetos de prácticas, sujetos de derechos, sujetos históricos y políticos; sujetos en todo caso. Lo que en el ámbito educativo pasa por individualizarlos, mencionarlos y reconocerlos.

\subsection{Cuarta discusión: Las prácticas de escritura académica en la universidad}

Reza el adagio popular que la práctica hace al maestro. Establecer la relación entre teoría y práctica, entre práctica y desarrollo de la habilidad escritural podría ser en cierto sentido problemático y no es nuestro interés; sin embargo, resulta interesante señalar cierta correspondencia entre la manifestación discursiva de la práctica de escritura, y los supuestos logros entre los y las estudiantes entrevistados. Los estudiantes fueron interrogados por tres tipos de prácticas de escritura: relativas a las prácticas de escritura en el aula, fuera de ella y por gusto propio, que no necesariamente corresponde a escritura académica, pero que puede influir en la práctica.

Al referirse a la toma de notas o apuntes en clase, la totalidad de los estudiantes indígenas manifiestan realizar esta práctica. Algunos señalan que apuntan todo lo que dice el profesor; otros solo aquello que les parece importante. Los emplean fundamentalmente como soporte nemotécnico o de recuperación de información para las evaluaciones, para aprender, para establecer relaciones posteriormente en el momento de redactar informes $u$ otro tipo de trabajo escrito; otros señalan que operan como un link o enlace que permite conectar ideas, autores y teorías.

Al referirse a las prácticas de escritura académica realizada fuera del aula como trabajo externo, los y las estudiantes manifiestan que el tipo de trabajo más frecuente es el ensayo, aunque los estudiantes de las ingenierías y de la licenciatura en ciencias manifiestan realizar sobre todo informes de laboratorio. Otras prácticas son las reseñas, los comentarios de textos, o los protocolos, más acordes con el tipo de carrera de los entrevistados. Respecto al ensayo señalan 
que en general los profesores dan por supuesto que los estudiantes saben qué es un ensayo y cómo se realiza, y muy pocos profesores dan instrucciones al respecto más allá de las temáticas. Esta práctica de escritura es valorada positivamente por los estudiantes quienes destacan que les gusta porque les permite dar a conocer su punto de vista, son más abiertos a la discusión y permiten el diálogo entre diversas teorías y autores. Sin embargo también manifiestan su dificultad por el grado de complejidad que implican. Las dificultades van desde no saber cómo iniciar, como expresar las ideas, desconocimiento de las teorías y los conocimientos disciplinares.

Respecto a la escritura por fuera del contexto universitario, es decir, la escritura basada en el interés propio, los estudiantes indígenas manifiestan interés por realizar textos relacionados con la comunidad, sean del tipo que sean, artículos, ensayos, informes, etc., lo que también incluye textos narrativos.

De acuerdo con las respuestas de los estudiantes indígenas a las entrevistas, la práctica constante de escritura es anterior a su ingreso a la universidad y de cierta manera está determinada por el tipo de educación que recibieron en la primaria y el bachillerato en escuelas y colegios administrados por comunidades religiosas, donde la escritura tiene un amplio valor y se trabaja de manera sistemática a lo largo de la escolarización, ya sea mediante prácticas tradicionales como la exigencia de llevar cuadernos, la toma de apuntes y su constante revisión, y el énfasis en la ortografía y la redacción e incluso en aspectos formales como el seguimiento de normas, tales como las ICONTEC para la presentación de trabajo. De allí que sea importante de cierta manera, sin olvidar la violencia con la que muchas veces se ejercían y aun hoy continúan ejerciéndose estas prácticas, reconocer el papel de las comunidades religiosas en el desarrollo de habilidades escritoras en los estudiantes indígenas.

Los estudiantes afrodescendientes, respecto a las prácticas de escritura, por el contrario, manifiestan en su mayoría no tomar notas y tener poco interés por las mismas. Remplazan la toma de notas por el subrayado de fotocopias o anotan solo aspectos puntuales, como fechas, autores o recomendaciones dadas por el profesor. Otros señalan que solo toman notas cuando se trata de conferencistas a quienes les atribuyen mayor autoridad. Sin embargo, otros pocos señalan tomar notas mediante mapas conceptuales, guiones, y hay también quienes apuntan todo.

Respecto a los trabajos fuera de clase, señalan las prácticas de escritura están determinadas en ocasiones por el tipo de carrera que se estudia: en las licenciaturas se escribe más y de manera individual; el texto más solicitado por los pro- 
fesores son los ensayos; en las ingenierías se escriben textos del tipo informes, caracterizados por ser descriptivos y en los que el punto de vista del estudiante y los argumentos no son lo que prevalece.

Los estudiantes señalan tener dificultades para la realización de textos escritos, tales como una supuesta excesiva abundancia de ideas y la dificultad para organizarlas y relacionarlas. Manifiestan mucha preocupación por los aspectos formales de los textos, señalan la mala redacción como constante y reducen la idea de escritura a la redacción y la ortografía.

Frente a la escritura por gusto propio, los estudiantes afrodescendientes señalan, de nuevo, poco interés o falta de tiempo para su realización aunque algunos señalan escribir textos narrativos del tipo: cuentos, diarios o cartas.

De esta manera, puede concluirse que los estudiantes entrevistados tienen poca práctica de escritura. Señalan que paradójicamente solo notaron sus deficiencias en la escritura al ingresar a la universidad; antes no se habían cuestionado al respecto y sus profesores de escuela y el colegio no se los habían dicho. Los contextos educativos de los que provienen estos estudiantes: zonas rurales alejadas de las capitales y con escasa inversión del Estado en profesores e infraestructura, parecen ser determinantes en el poco interés dado a la escritura y en las dificultades en la práctica. De igual manera, las condiciones de ingreso a la universidad pueden ser aspectos determinantes. Algunos de estos estudiantes no tienen dinero para costear su estancia en la universidad y deben trabajar por lo que el tiempo destinado al estudio es poco. Otros ingresan a extraedad - teniendo en cuenta el promedio de edad de los estudiantes-, lo que hace que se dificulte la adaptación a las prácticas universitarias y de interacción entre estudiantes y profesores.

\subsection{Quinta discusión: El saber sobre la escritura. Estrategias de producción de textos escritos}

Pareciera poder suponerse que la escolarización, o la institucionalización de la educación, permitiría, entre otras cosas, poder dar cuenta de los procesos llevados a cabo en la enseñanza y el aprendizaje; es decir hablar de las tareas o en términos metacognitivos (Scribner \& Cole, 1981); sin embargo no siempre es así, o mejor, está habilidad está condicionada por los logros educativos.

Al indagar por el saber de los estudiantes frente a los procesos de escritura, más exactamente por las estrategias de elaboración de los diversos tipos de textos, la totalidad de los estudiantes indígenas entrevistados manifestaron seguir algún tipo de estrategia o plan. Señalan, en todo caso, que esto depende 
del tipo de trabajo en particular, si se trata de ensayo, informe, reseña, protocolo y demás. Frente al ensayo manifiestan seguir métodos inductivos o deductivos. Resaltan la importancia de comenzar bien los textos con el ánimo de atrapar al lector. Hablan de la importancia de realizar borradores y corregirlos. Reconocen la importancia de señalar el punto de vista de quien habla, escribir a partir de contextos reales e identifican las diversas normas técnicas para la presentación de trabajos escritos, del tipo ICONTEC. En términos generales, podemos decir que los estudiantes están bastante familiarizados con las teorías y prácticas de la producción de textos escritos y que pueden hablar de ellas con solvencia.

Frente a este tema los estudiantes afrodescendientes evidenciaron grandes dificultades, incluso para entender las preguntas de la entrevistadora, quien se vio obligada a inducir las respuestas en varias ocasiones. Señalaron que para la elaboración de textos se debe seguir un orden, sin detallar demasiado en la respuesta; hablaron de no seguir ningún paso, pero sobre todo, se centraron en los aspectos formales de la producción, ortografía, redacción, tildes, pie de páginas, etc. Quienes manifiestan alguna estrategia no logran dar cuenta del proceso completo y se centran en una sola parte, generalmente el inicio o la introducción de los textos. Algunos señalan la importancia de la corrección y la reescritura de los textos. Aunque los estudiantes inscritos en licenciaturas manifestaron cierto grado de conocimiento del metalenguaje y las estrategias de producción textual.

Resulta entonces importante establecer la relación entre las prácticas de escritura y la posibilidad de dar cuenta de esta actividad. Así los estudiantes indígenas quienes manifiestan escribir con cierta frecuencia pueden hablar de ella. Han tenido que, en su práctica, cuestionarla y elevarla al nivel de la meta cognición, es decir, establecer ciertos grados de conciencia de ella. Los y las afrodescendientes al tener que practicarla menos han tenido menos posibilidad de reflexionar sobre ella y su grado de conciencia de ella es menor.

Pareciera que estuviéramos de nuevo frente al problema inicial planteado en este texto, respecto al problema de la escritura y la estructuración de la conciencia (Ong, 1982); sin embargo, y sin entrar en la discusión, nuestro planteamiento aquí, se refiere, no a la escritura y la conciencia en términos generales y abstractos, es decir, escritura igual conciencia; sino a la posibilidad que da la escritura, su práctica, de estructurar la conciencia de la escritura como fenómeno, simplemente. 
Se proponía al inicio de este texto indagar la relación escritura académica y poder a partir de las representaciones sociales de estudiantes afrodescendientes e indígenas en la Universidad Distrital. Los resultados muestran la complejidad del problema. La necesidad de dar un paso más allá de garantizar un acceso a la universidad de estas poblaciones. La discriminación escolar incluye aspectos relacionados con la permanencia, la pertinencia y los logros. Se evidencia la necesidad de ampliar el acceso, los derechos educativos no pueden ser simplemente cuestión de estadísticas y cumplimiento de mínimos. Una vez inmersos en el sistema, los estudiantes no pueden abandonarse a su suerte; es responsabilidad de las instituciones garantizar la permanencia y el logro de objetivos, es decir, la culminación de los estudios. La deserción escolar y los bajos logros deben ser objeto de reflexión y de políticas tendientes a superarlos. La escritura académica, el alto valor asignado a esta práctica, su complejidad y enseñanza, podrían constituirse en un primer paso de reflexión.

\subsection{Habría que pensar}

Parafraseando a Skliar, habría que pensar que el lenguaje no puede reducirse a su representación gráfica mediante signos alfabéticos. La comunicación, la trasmisión de ideas y la producción de conocimiento, es posible a través de otras formas de representar y de comunicar.

Habría que pensar que la palabra escrita no tiene la misma función y valor para todos los pueblos y culturas. Existen pueblos para las que la palabra hablada, oral, es la fuente de todo conocimiento y acción, y no se limita a una mera instrumentalización o tecnología. Comunidades para las que la palabra es vida, energía, trasformación.

Habría que pensar que la escritura no tiene un fin per se. Que alejada de otras prácticas su función es limitada. Que históricamente más que desarrollar habilidades cognitivas y sociales, ha sido empleada como dispositivo de poder y exclusión. Como mecanismo al servicio de la cultura hegemónica, con fines reguladores y homogenizadores.

Habría que pensar que la escritura no sólo se adquiere en el momento en que se ingresa a la institución escolar, pues como resalta Biondi, las personas se 
enfrentan a otras escrituras antes de ingresar a la institución escolar y habría que tenerlas en cuenta, pues quizá esto facilitaría los procesos escriturales alfabéticos (Biondi, 2003).

Habría que pensar que la escritura además de un conjunto de destrezas y habilidades, es una práctica sociocultural. Que se produce dentro de una cultura y con fines y propósitos diversos. Y que sus posibilidades dependen de poder relacionarla con las prácticas sociales de las comunidades.

Habría que pensar que enseñar a escribir no es enseñar una técnica. Que no existe la escritura en abstracto. Existen sujetos que escriben. Sujetos con historias e ideas. Sujetos que reclaman re-conocimiento. Presencia.

\subsection{Reflexividad}

Al hacer un ejercicio reflexivo sobre la investigación surgen algunos interrogantes y puntos a tener en cuenta para futuros trabajos. Al seleccionar la muestra, se optó por entrevistar estudiantes activos, esto determinó los resultados que no se compadecen con la magnitud del problema: la alta deserción y los bajos logros. La pregunta que queda es qué pensarán los estudiantes que se retiraron, que no pudieron continuar con el proceso educativo; son ellos la gran mayoría, son ellos los excluidos. Quienes permanecen están dando la batalla en la universidad, han resistido y de alguna manera han vencido; son quienes pudieron integrarse a las prácticas académicas y sociales de la universidad; sin embargo, son pocos.

Incluir indígenas y afrosdescendientes en el mismo nivel parece también sujeto a revaluación. Los procesos históricos y sociales que han vivido unos y otros son distintos. El grado de marginamiento social es diferente y su respuesta también. Los estudiantes indígenas se enfrentan a una educación en otro idioma diferente a su lengua materna, esto complejiza el problema, pero también les abre más posibilidades de reflexión sobre la lengua en general. Los afrodescendientes muestran menor preocupación por el tema y orientan sus discursos más hacia las reivindicaciones políticas.

Por último, reiterar que se requiere una educación basada en la diversidad, que luche contra todas las formas de exclusión, no solo étnicas, sino sociales, culturales y educativas, que "generan violencia, dificultan el desarrollo integral del individuo, la igualdad de oportunidades, y las posibilidades de entendimiento entre los miembros de los distintos grupos étnicos, y culturales" (López, 2002: 133). Estamos convencidos de que "de la educación depende, no como la panacea, sino como el real encuentro con el otro, en gran medida, el futuro de la humanidad" (De la Fuente, 1997). 


\section{Referencias bibliográficas}

Ames. P. (2002). Para ser iguales, para ser distintos. Educación escritura y poder en el Perú. Lima: Instituto de Estudios Peruanos.

Arroyabe, R. (2007). El Segundo Plan Decenal de Uribe Vélez y el Plan Visión II. Centenario 2019. En Educación y Cultura, 74, 31-37.

ASCUN (2007). Políticas y estrategias para la educación superior de Colombia 20062010. Bogotá: Corcas editores.

Ávila, J. (2007). La agenda del plan decenal de educación 2006-2015 en el contexto de la reforma a las transferencias. Un plan para la política de ajuste fiscal de la educación. En Educación y Cultura, 74, 26-30.

Ballesteros, A. L. (2008). La lectura y la escritura en la universidad: consideraciones desde una investigación. Facultad de Lenguas. Universidad Nacional de córdoba. Recuperado: Enero 26 de 2010. Fuente: http://www.congreso.bmayor.unc.edu.ar/ponencias/ 66ponencia.pdf

Banks, J. (1996). El debate canónico, la construcción del conocimiento y la educación multicultural. En Revista Kikiriki, 41, 4-16.

Bereiter \& Scardamaglia (1992). Dos modelos explicativos de los procesos de producción escrita. En Infancia y Aprendizaje, 58, 43-64.

Biondi, J. (2003). La lucha contra la corrupción de las palabras. Lenguaje, política y ética. En Vigil, N. y R. Zariquiey (eds.) Ciudadanías Inconclusas. El ejercicio de los derechos en sociedades asimétricas. Lima: Pontificia Universidad Católica del Perú y Cooperación Alemana al Desarrollo.

Biondi, J. \& Zapata, E. (2006). La palabra permanente. Lima: Fondo Editorial del Congreso del Perú.

Biondi, J. \& Zapata, E. (1994). Representación oral en las calles de Lima. Lima: Universidad de Lima.

Braidot, N. B.; Moyano, E.I.; Natale, Lucia \& Roitter, S. (2008). Enseñanza de la lectura y la escritura como política institucional a lo largo de las carreras de ingeniería del IDEIUNGS. Recuperado: enero 29 de 2010. Fuente: http://www.ungs.edu.ar/prodeac/descargas/PDF/braidot_moyano_natale_roitter_2008.pdf

Bublitz, W. (1988). Supportive fellow-speakers and comparative conversations. Amsterdan: John Benjamin.

Cadario, E. (2001). La lingüística del corpus como herramienta de investigación en escritura académica en campos disciplinares específicos al área de formación docente. Universidad Nacional de Río Cuarto. Recuperado: enero 29 de 2010. Fuente: http://www. feeye.uncu.edu.ar/web/posjornadasinve/area3/Lengua $\% 20-\% 20$ Didactica $\% 20$ de $\% 20$ la\%20lengua\%20-\%20TICs/176\%20-\%20Cadario\%20-\%20UN\%20Rio\%20Cuarto.pdf

Carlino, P. (2001). Enseñar a escribir en la universidad: cómo lo hacen en Estados Unidos y por qué. Recuperado: enero 27 de 2010. Fuente: http://www.rieoei.org/deloslectores/ 279carlino.pdf

Carlino, P. (2003). Alfabetización académica: un cambio necesario, algunas alternativas posibles comunicación libre en el tercer encuentro la universidad como objeto de investi- 
gación. Dpto. de sociología. Universidad Nacional de la Plata. Publicado en: Educere: Investigación, 6. (20). Enero-febrero-Marzo: 2003. Recuperado: enero 23 de 2010. Fuente: http://www.unne.edu.ar/institucional/documentos/lecturayescritura08/alfabetizacion_carlino.pdf

Carlino, P. (2004) El proceso de escritura académica: cuatro dificultades de la enseñanza universitaria. Dpto. de sociología. Universidad Nacional de la Plata. Publicado en: Educere: Artículos arbitrados, 8 (26). Julio-agosto-septiembre: 2004. Recuperado: enero 23 de 2010. Fuente: http://dialnet.unirioja.es/servlet/articulo?codigo $=1165762 \&$ orden $=38220$ \&info=link

Carlino, P. Enfoques didácticos para la enseñanza de la expresión escrita. Recuperado: Enero 23 de 2010: http://www.upf.edu/dtf/personal/danielcass/index.htm

Carlino, P. (2005a) Escribir, leer y aprender en la universidad. Una introducción a la alfabetización académica. México: Fondo de Cultura Económica.

Carlino, P. (2005b) Representaciones sobre la escritura y formas de enseñarla en universidades de América del Norte. Publicado en: Revista de Educación, 336 (2005), 143168. Recuperado: enero 29 de 2010. Fuente: http://www.revistaeducacion.mec.es/re336/ re336_09.pdf

Carlino, P. (2007) ¿Qué nos dicen hoy las investigaciones internacionales acerca de la escritura en la universidad? Publicado en: Cuadernos de psicopedagogía, 4. Universidad Tecnológica y Pedagógica de Colombia. Septiembre de 2007 Recuperado enero 28 de 2010. Fuente: http://www.ascun.org.co/eventos/lectoescritura/paulacarlino.pdf

Carlino, P. (2010). Exploración de géneros, diarios de tesis y revisión entre pares: Análisis de un ciclo investigación-acción en talleres de tesis de posgrado. Recuperado enero 28 de 2010. Fuente: http://www.escrituraylectura.com.ar/posgrado/articulos/Carlino_Diario $\% 20 \mathrm{de} \% 20$ Tesis $\% 20 \mathrm{y} \% 20$ Revision $\% 20$ entre $\% 20$ pares_analisis $\% 20 \mathrm{de} \% 20$ un $\% 20$ ciclo\%20de\%20investigacion-accion.pdf

Cassany, D. (1999). Describir el escribir. Como se aprende a escribir. Paidós: Barcelona.

Cassany, D. (2004) Reparar la escritura. Didáctica de la corrección de lo escrito. Graó: Barcelona.

Castellò, M.; Iñesta, A. \& Monereo, C. (2009). Hacia la escritura académica autorregulada: Un estudio exploratorio con estudiantes posgraduados en un entorno de aprendizaje situado. Publicado en: Electronic Journal of Research in Educational Psychology 7 (3), 1107-1130. 2009. Enero 29 de 2010. Fuente: http://www.investigacion-psicopedagogica. org/revista/articulos/19/espannol/Art_19_367.pdf

Castellò, M.; Iñesta, A. \& Monereo, C. (1996). Conferencia regional sobre políticas y estrategias para la transformación de la educación superior en América Latina y el Caribe.

Correa M., José Ignacio (2004). Asedios a una pragmática de la cognición y el lenguaje. Universidad Pedagógica Nacional. Recuperado: diciembre 16 de 2009. http://www.umbvirtual.edu.co/bibliovirtual/pedagogia/022_chomsky_cognicion_lengua.pdf

Chartier, R. (1999). Cultura escrita, literatura e historia. México: Fondo de Cultura Económica.

DANE (2007) La población étnica y el Censo General 2005. En Colombia: una nación multicultural. Su diversidad étnica (p. 35). 
De la Fuente, J. (1997), El lenguaje desde la biología del amor, En Literatura y lingüística, 10. Recuperado de http://www.scielo.cl/scielo.php?pid=S0716-58111997001000009 \&script=sci_arttext\&tIng=es.

Escudero, J. et al. (2009). El fracaso escolar como exclusión educativa: comprensión, políticas y prácticas. En Revista Iberoamericana de Educación, 50, 41-64.

Flower, L. \& Hayes, J. R. (1996). La teoría de la redacción como proceso cognitivo. En: Rosenblatt, Louise M. (1996). La teoría transaccional de la lectura y la escritura. Buenos Aires: Asociación Internacional de lectura.

Garcés, F (2005). De la voz al papel. Cochabamba: Plural Editores.

Gee, J. P. (2005) La ideología en los discursos. Madrid: Morata.

Goody, J. \& Watt, I. (1968). The consequences of literacy. En J. Goody (comp.) Literacy in traditional societies (1996). Cambridge: CUP (pp. 27-84).

Goody, J. (Comp.) (1968). Literacy in traditional societies. Cambridge: CUP. Versión en español (1996): Cultura escrita en sociedades tradicionales. Barcelona: Gedisa.

González P. (2006). Experiencia de alfabetización académica en la Universidad Sergio Arboleda De Colombia. Recuperado: Enero 29 de 2010. Fuente: http://www.ascun.org.co/ eventos/lectoescritura/blancagonzalez.pdf

Hargreaves, A. (2003). La distinción y el asco: las políticas emocionales del fracaso escolar. En Barbecho, Revista de reflexión socioeducativa, 3. Disponible en http://www. barbecho.uma.es/documentospdf/barbecho3/a3b3.pdf

Havelot, E. (1963). Preface to Plato. Cambridge: Belknap press of HUP.

Havelot, E. (1986). La musa aprende a escribir. Reflexiones sobre oralidad y escritura desde la antigüedad hasta el presente. Barcelona: Paidós.

Hernández R., G. Teorías implícitas de la comprensión lectora y la composición escrita en estudiantes de educación secundaria y superior. X Congreso Nacional de Investigación Educativa, área 1: aprendizaje y desarrollo humanos. Recuperado: febrero 2 de 2010. Fuente: http://www.comie.org.mx/congreso/memoria/v10/pdf/area_tematica_15/ ponencias/0282-F.pdf

Hevia, R. (Coord.) (2005). Políticas educativas de atención a la diversidad cultural. Brasil, Chile, Colombia, México y Perú. Santiago de Chile: UNESCO.

Jakob, I. \& Valle, M. (2008). El aprendizaje de contenidos disciplinares específicos y de prácticas de acceso al conocimiento. Una experiencia de innovación pedagógica en la universidad. Recuperado: febrero 2 de 2010. Fuente: http://www.unam.edu.ar/2008/educacion/trabajos/Eje\%203/299\%20-jakob.pdf

IESALC (2004). Diagnóstico sobre educación superior indígena en Colombia. UNESCO.

Kalman, J. (2003). El acceso a la cultura escrita: la participación social y la apropiación de conocimientos en eventos cotidianos de lectura y escritura, p. 39. En Revista Mexicana de Investigación Educativa, 8 (17), enero-abril 2003.

Kalman, J. (2008). Discusiones conceptuales en el campo de la cultura escrita. En Revista Iberoamericana de Educación, 46. Recuperado octubre 12 de 2009. Fuente: http://www. rieoei.org/rie46.htm. 
Lévi-Strauss, C. (1970). Lección de escritura. En: Tristes trópicos. Buenos Aires: Eudeba. López, M. (2002), Diversidad sociocultural y formación de profesores. Bilbao: Ediciones Mensajero.

Lund, S. (1997). On the margin: letter exchance among Andean non literates. En HowardMalverde, R. Creating context in Andean cultures. Oxford: Oxford University Press.

Martínez, B. (2002). La educación en la diversidad en los albores del siglo XXI. En M. Forteza y M. Rosselló (eds.), Educación, diversidad y calidad de vida. Actas de las XIX Jornadas de universidades y educación especial: Palma: universitat de les Illes Balears.

Marí, I. (2005). Leer entre dos mundos: barreras y puentes tecnológicos. Matute, E. ed. En Aprender a leer y a escribir en diferentes lenguas y realidades (pp. 135-148). Guadalajara (México): Universidad de Guadalajara.

Martínez, M. C. (1999). Comprensión y producción de textos académicos: expositivos y argumentativos (colectivo), (2). Cátedra UNESCO para la Lectura y la Escritura. Univalle. Cali, Colombia: Taller artes gráficas, Facultad de Humanidades.

Martínez, M. C. (2001). Aprendizaje de la argumentación razonada (colectivo) en Volumen 3, Cátedra UNESCO para la Lectura y la Escritura en América Latina. Univalle. Cali, Colombia: aller artes gráficas, Facultad de Humanidades.

Martínez, M. C. (2005b). La construcción del proceso argumentativo en el discurso. Perspectivas teóricas y trabajos prácticos. Cátedra UNESCO Lectura y Escritura, Univalle. Cali, Colombia: Taller artes gráficas, Facultad de Humanidades.

Martínez, M. C. (2005c). La argumentación en la dinámica enunciativa del discurso. Lectura y escritura dialógica 2. Seminario Internacional para el Fomento de la Argumentación razonada en la comunicación oral y escrita. Cátedra UNESCO Lectura y Escritura. UnivaIle. Cali, Colombia: Taller artes gráficas, Facultad de Humanidades.

Mignolo, W. (2003). Historias locales/ diseños globales. Madrid: Ediciones Akal.

Mignolo, W. \& Hill, E. (Eds.) (1994). Writing without words. Durham: Duke University Press.

Narváez, C., \& Cadena, S. (Comp.) (2008). Los desafíos de la lectura y la escritura en la educación superior. Cali: Universidad Autónoma de Occidente, Facultad de Comunicación Social.

Niño, S. (2007). El plan decenal de educación: víctima del olvido y del neoliberalismo. En Educación y Cultura, 74, 17-25.

ONIC, CRIC, IESALC-UNESCO, (2004). Diagnóstico sobre educación superior indígena en Colombia. UNESCO. Versión en línea: http://unesdoc.unesco.org/images/0013/001399/ 139947s.pdf (Consultada el 15 de agosto de 2011).

Olson, D. (1998) Cultura escrita y objetividad: el surgimiento de la ciencia moderna. En Olson, D. \& Torrance, N. (comp.). Cultura escrita y oralidad. Barcelona: Gedisa.

Ong, W. (1987) Orality and literacy. The technologizing of the word. Londres: Methuen. Version en español (1987). Oralidad y escritura. Tecnologías de la palabra. México: Fondo de Cultura Económica. 
Perassi, Z. (2009). ¿Es la evaluación causa del fracaso escolar? En Revista Iberoamericana de Educación, 50, 65-80.

Pérez, M. (2000). Hacia una pedagogía del discurso: elementos para pensar la competencia argumentativa en los procesos de escritura en la educación básica. En Bogoya, D. et al. Competencias y proyecto pedagógico. Bogotá, UNC.

Pérez Abril, M. \& Barrios, M. (2010). Cultura académica y escritura en la universidad análisis de interacciones y prácticas discursivas soportadas en herramientas virtuales de trabajo colaborativo. Recuperado enero 29 de 2010. Fuente: http://www.ascun.org.co/ eventos/lectoescritura/mbarriosmperez.pdf

Rama, A. (2004). La ciudad letrada. Santiago: Tajamar Editores.

Ratinoff, L. (1994). Las retóricas educativas en América Latina: la experiencia de este siglo. En: Boletín 35, diciembre, 1994, Proyecto principal de educación.

Rincón, G. et al. (2005). Enseñar a comprender textos en la Universidad: análisis de dos casos (1 ed.) Cali: Artes gráficas-facultad de humanidades.

Rodríguez et al. (2008). Primer informe sobre la discriminación racial y derechos de las comunidades afrocolombianas. Bogotá: Universidad de los Andes.

Rosenblatt, L. M. (1996). La teoría transaccional de la lectura y la escritura. Buenos Aires: Asociación Internacional de Lectura.

Santos, D. (2010). Hablemos sobre la escritura académica. Un diálogo en la universidad desde la interculturalidad. Trabajo inédito.

Scardamalia, M. \& Bereiter, C. (1992). Dos modelos explicativos de los procesos de comunicación escrita. En Infancia y Aprendizaje, 58, 43-64.

Scribner, S. \& Cole, M. (1981). The psychology of literacy. Cambridge: Harvard University Press.

Soler, S. (2009). Racismo y discurso en los textos escolares. Representación de la diversidad étnica y racial en los textos de ciencias sociales en Colombia. En: Nina S. De Friedemann: cronista de disidencias y resistencias. Bogotá: CES.

Soler, S. (2011). Análisis crítico del discurso de documentos de política pública en educación. En Forma y Función, 24 (1).

Soler, S. (2012). Between Dark Black and Light Brown. Discourses and Ethnic Identities among Afrodescendant Boys and Girls in School Context in Bogotá. En Colombian Applied Linguistic Journal,14 (1), 146-162.

Street, B. (1984) Literacy in theory and practice. Cambridge: Cambridge University Press.

Street, B. (1995). Social Literacies: Critical approaches to literacy in ethnography and development. Nueva York: Longman.

Torres, C. R. (2000). Una década de educación para todos. La tarea pendiente. Montevideo: FUM-TEP. Fuente: http://www.upnqueretaro.edu.mx/userfiles/file/educacion.pdf Recuperado noviembre 20 de 2009.

Treviño, E. (2005). Estado del arte. Desigualdad y discriminación en educación. En C. Mato (coord.). Políticas educativas de atención a la diversidad cultural. (pp. 23-51). Santiago de Chile: UNESCO. 
UNESCO (1990). Declaración Mundial sobre Educación para Todos.

UNESCO (1996). La educación encierra un tesoro. Informe Delors.

UNESCO (2001). LLECE-Laboratorio Latinoamericano de Evaluación de la Calidad de la Educación (2001). Primer estudio internacional comparativo sobre Lenguaje, Matemática y 24 factores asociados, para alumnos del tercer y cuarto grado de la educación básica. Santiago de Chile: UNESCO.

UNESCO (2004). Políticas educativas de atención a la diversidad cultural. Santiago de Chile.

Van Dijk, T. (1995). De la gramática del texto al análisis crítico del discurso. En Beliar (Boletín de Estudios Lingüísticos Argentinos), 2 (06).

Van Dijk, T. (1998). Ideología. Barcelona: Gedisa.

Van Dijk, T. (2004). Discurso y dominación. Grandes conferencias en la facultad de ciencias humanas. Bogotá: Universidad Nacional de Colombia.

Van Dijk, T. (2008). Nosotros y los otros. En Radar, 20 de enero de 2008. Versión electrónica:http://www.pagina12.com.ar/diario/suplementos/radar/9-4397-2008-01-26.html [recuperado el 12-4-2009.]

Vasilachis de Gialdino, I. (1998). La construcción de representaciones sociales. Discurso político y prensa escrita. Un análisis sociológico, jurídico y lingüístico. Barcelona: Gedisa.

Vigil, N. (2006). Pueblos Indígenas y escritura. En Interculturalidad, 3. Versión electrónica: http://interculturalidad.org/numero03/2_07.htm

Zavala, V. (2001). Vamos a letrar nuestra comunidad: Reflexiones sobre el discurso letrado en los Andes Peruanos. En Lopez Mañiga, S. et al. Discursos, poderes, pulsiones (pp. 233-252). Lima: Red para el desarrollo de las ciencia sociales.

Zavala, V.; Niño-Murcia, M.; Ames, P. (ed). (2004). Escritura y sociedad. Nuevas perspectivas teóricas y etnográficas. Lima: Red para el Desarrollo de las Ciencias Sociales en el Perú.

Zavala, V. (2002). (Des)encuentros en la escritura. Lima: Red para el desarrollo de las Ciencias Sociales. 


\section{Anexos}

\section{PROTOCOLO DE ENTREVISTA ESCRITURA ACADÉMICA GRUPO ESTUDIOS DEL DISCURSO}

\begin{tabular}{|c|c|c|c|c|}
\hline Contenido temático & Preguntas generales & $\begin{array}{c}\text { Subcategorias } \\
\text { encubiertas }\end{array}$ & Sub-preguntas & Observaciones \\
\hline \multirow{6}{*}{$\begin{array}{l}\text { Describir y analizar los } \\
\text { contextos } \\
\text { socioculturales } \\
\text { de los prácticas de } \\
\text { escritura de los } \\
\text { estudiantes indigenas } \\
\text { y afrosdescendientes } \\
\text { de la Universidad } \\
\text { distrital (OBJETIVO 1) }\end{array}$} & \multirow{4}{*}{$\begin{array}{l}\text { Preguntas } \\
\text { sensibilizadoras }\end{array}$} & Descripción del contexto. & $\begin{array}{c}\text { ¿Cómo es tu comunidad? ¿Qué lugar } \\
\text { tiene la escritura frente la oralidad en } \\
\text { tu comunidad? ¿Dónde aprendiste a } \\
\text { escribir? }\end{array}$ & \\
\hline & & Participantes & $\begin{array}{l}\text { ¿Qué edad tenías? } \\
\text { ¿Quién te enseñó a escribir? ¿Cómo } \\
\text { eran tus profesores? }\end{array}$ & \\
\hline & & Motivaciones, fines & $\begin{array}{c}\text { ¿Por qué empezaste a escribir? ¿Para } \\
\text { qué aprendías a escribir? }\end{array}$ & \\
\hline & & Acciones & $\begin{array}{c}\text { ¿Cómo aprendiste? ¿Qué tenías que } \\
\text { hacer? }\end{array}$ & \\
\hline & \multirow[b]{2}{*}{$\begin{array}{c}\text { ¿Nos puedes contar } \\
\text { cuándo aprendiste a } \\
\text { escribir? / ¿Nos puedes } \\
\text { contar tu experiencia en } \\
\text { primaria? }\end{array}$} & Instrumentos & $\begin{array}{c}\text { ¿En qué lengua aprendiste/ te } \\
\text { enseñaron a escribir? ¿Y en español, } \\
\text { cuándo empezó?[1] ¿Hablaban todo el } \\
\text { tiempo en español? ¿Qué tipo de } \\
\text { recursos tenías para escribir } \\
\text { (condiciones materiales: lápiz, papel, } \\
\text { libros de texto, otros)? }\end{array}$ & \\
\hline & & Normas & ¿Te decían cómo tenías que escribir? & \\
\hline
\end{tabular}

[1] En el caso de que haya aprendido a escribir en otra lengua que no sea el español 


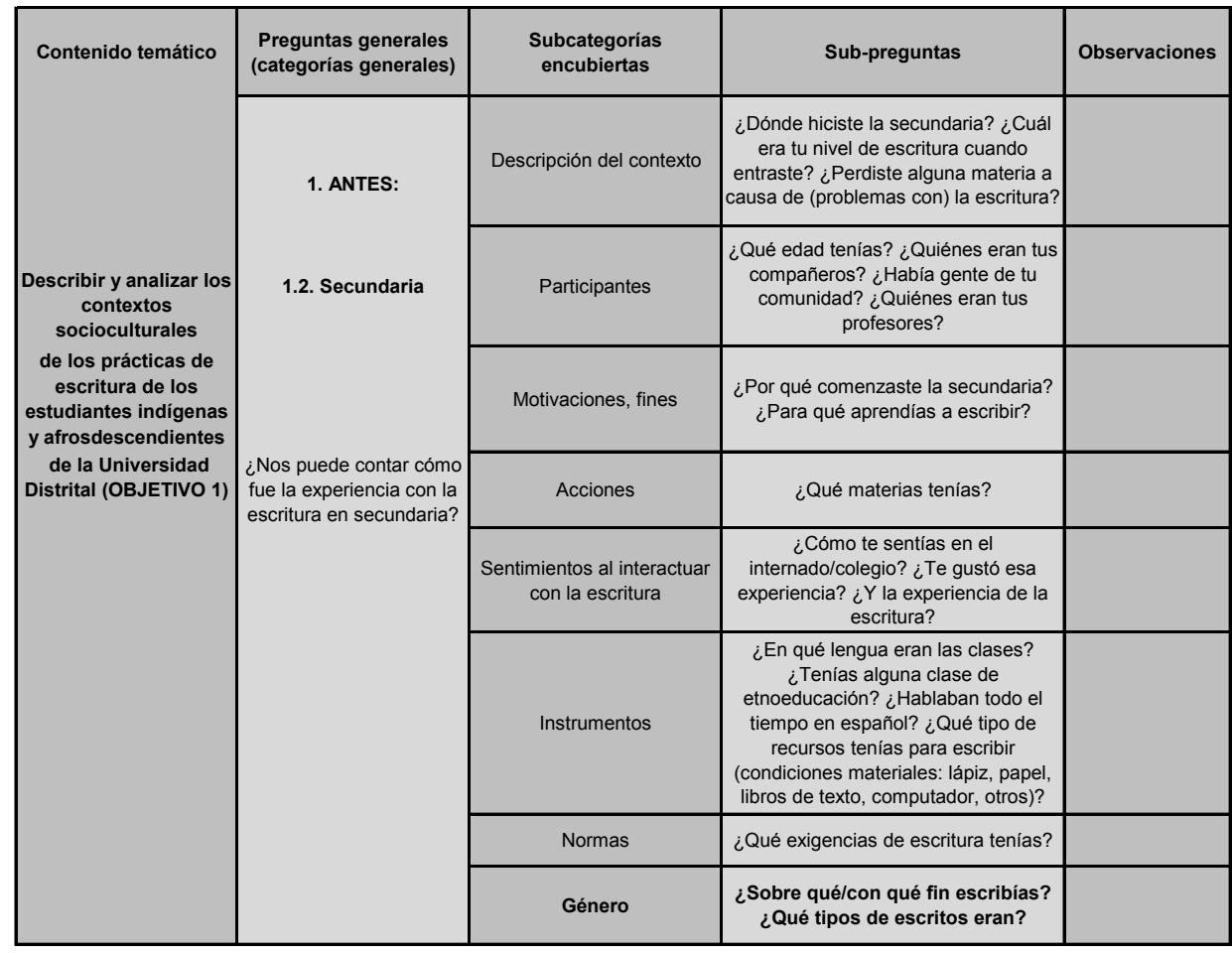




\begin{tabular}{|c|c|c|c|c|}
\hline Contenido temático & Pregunta general & Categorías encubiertas & Preguntas & Observaciones \\
\hline \multirow{4}{*}{$\begin{array}{c}\text { Describir las } \\
\text { necesidades, } \\
\text { expectativas e } \\
\text { intereses de este } \\
\text { grupo de estudiantes } \\
\text { hablantes de lenguas } \\
\text { indígenas y criollas } \\
\text { sobre la escritura } \\
\text { académica en la } \\
\text { universidad } \\
\text { (OBJETIVO 2). }\end{array}$} & \multirow{4}{*}{$\begin{array}{l}\text { 2. AL INGRESAR A LA } \\
\text { UNIVERSIDAD } \\
\text { ¿Te acuerdas cómo se } \\
\text { decidió tu ingreso a la } \\
\text { Universidad? }\end{array}$} & $\begin{array}{l}\text { Proceso de toma de } \\
\text { decisiones }\end{array}$ & & \\
\hline & & Proceso de admisión & $\begin{array}{l}\text { ¿Cómo fue el proceso para } \\
\text { presentarte a la Universidad? ¿Qué } \\
\text { tuviste que hacer? ¿Qué otras cosas } \\
\text { tuviste que hacer además de llenar el } \\
\text { formulario? ¿Cómo te fue en esa } \\
\text { escritura? }\end{array}$ & \\
\hline & & Examen de admisión & $\begin{array}{l}\text { ¿Presentaste examen de admisión? } \\
\text { ¿Cómo era? ¿Cómo te sentiste al } \\
\text { presentarlo? }\end{array}$ & \\
\hline & & $\begin{array}{c}\text { Necesidades examen de } \\
\text { admisión }\end{array}$ & $\begin{array}{c}\text { ¿Qué problemas tuviste al } \\
\text { presentarlo? Si sí, ¿Cuáles? }\end{array}$ & \\
\hline \multirow{4}{*}{$\begin{array}{l}\text { Describir las creencias } \\
\text { que los estudiantes } \\
\text { hablantes nativos de } \\
\text { lenguas indigenas y } \\
\text { criollas tienen sobre la } \\
\text { escritura académica } \\
\text { en la universidad. } \\
\text { (OBJETIVO 3) }\end{array}$} & \multirow{4}{*}{$\begin{array}{l}\text { 3. DURANTE LA } \\
\text { UNIVERSIDAD } \\
\text { ¿Nos podrías contar } \\
\text { cómo fue la experiencia } \\
\text { de la escritura en la } \\
\text { Universidad? }\end{array}$} & Descripción de la situación & $\begin{array}{c}\text { ¿Qué edad tenías al entrar? ¿Cómo } \\
\text { te sentiste? }\end{array}$ & \\
\hline & & Participantes & $\begin{array}{l}\text { ¿Quiénes fueron las primeras } \\
\text { personas que conociste? ¿Cómo te } \\
\text { recibieron? ¿Te han apoyado en tu } \\
\text { familiarización con la vida } \\
\text { universitaria? ¿Te han ayudado en las } \\
\text { labores académicas? ¿Te han } \\
\text { ayudado en tus actividades de } \\
\quad \text { escritura? ¿Cómo? }\end{array}$ & \\
\hline & & Funciones & $\begin{array}{l}\text { ¿Qué crees que se busca con esos } \\
\text { trabajos escritos? ¿Te gustaría que } \\
\text { esos escritos tuvieran otros } \\
\text { propósitos? ¿Qué esperas de tu } \\
\text { escritura en la Universidad? }\end{array}$ & \\
\hline & & $\begin{array}{c}\text { Acciones } \\
\varnothing \text { Escritura durante el } \\
\text { desarrollo de las clases } \\
\varnothing \text { Escritura de trabajos } \\
\text { asignados para realizar } \\
\text { fuera de la clase } \\
\varnothing \text { Escritura y evaluación } \\
\varnothing \text { Dificultades }\end{array}$ & $\begin{array}{l}\text { ¿Tomas notas escritas durante las } \\
\text { clases? ¿Qué pasos sigues cuando te } \\
\text { piden un trabajo escrito? ¿Qué } \\
\text { dificultades tienes en estos procesos? } \\
\text { ¿Cómo son regularmente las } \\
\text { evaluaciones? ¿Has tenido } \\
\text { dificultades en las evaluaciones } \\
\text { escritas? ¿Cuáles? }\end{array}$ & \\
\hline
\end{tabular}




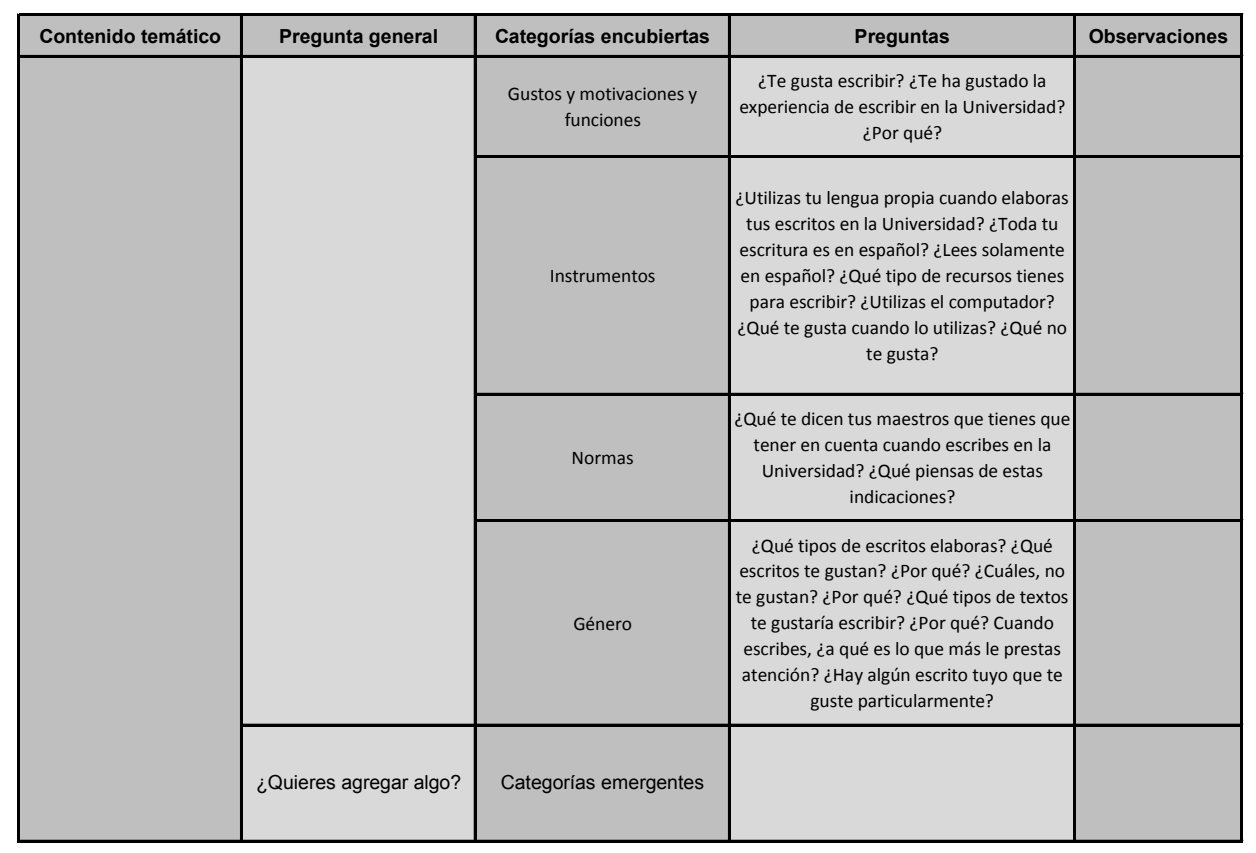




\section{Anexo 2.}

\section{Ejemplos de análisis de los datos}

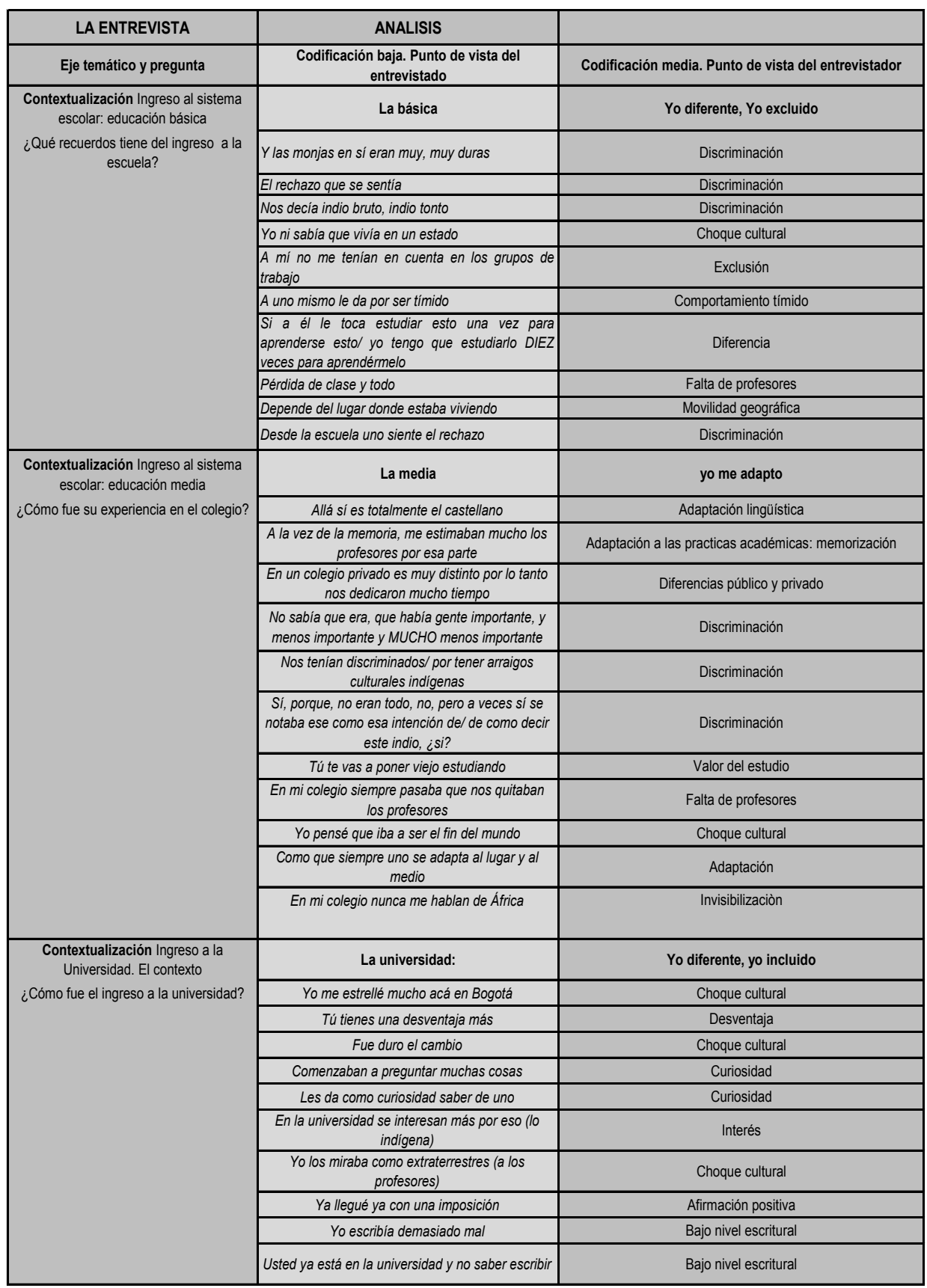




\begin{tabular}{|c|c|c|}
\hline (Cont.) LA ENTREVISTA & ANALISIS & \\
\hline Eje temático y pregunta & $\begin{array}{c}\text { Codificación baja. Punto de vista del } \\
\text { entrevistado }\end{array}$ & Codificación media. Punto de vista del entrevistador \\
\hline \multirow{11}{*}{$\begin{array}{l}\text { Representaciones de la escritura } \\
\qquad \text { ¿Qué es la escritura? }\end{array}$} & La escritura & Relaciones entre Oralidad y escritura \\
\hline & $\begin{array}{c}\text { Todo se maneja a través de la oralidad. La palabra } \\
\text { es vida }\end{array}$ & Comunidades orales: poder \\
\hline & Allá, nunca se ha manejado la escritura & Comunidades orales \\
\hline & La escritura es muy concisa & Características de la escritura: precisión \\
\hline & Figuras, símbolos & Otras escrituras \\
\hline & Habla lo que sabe & Característica de la oralidad: conocimiento \\
\hline & Estoy diciendo lo mismo & Caracteristicas de la oralidad: redundancia \\
\hline & $\begin{array}{l}\text { Usted habla bonito, pero entonces si no está } \\
\text { escrito es como si no valiera }\end{array}$ & Caracteristica de la escritura: valor \\
\hline & Se le acumulan tantas cosas & Característica de la escritura: redundancia \\
\hline & Entonces falta un poco de memoria & Característica de la escritura: memoria \\
\hline & La escritura es cuestión de práctica & Características de la escritura: práctica \\
\hline \multirow{12}{*}{$\begin{array}{l}\text { Funciones de la escritura } \\
\text { ¿Para qué sirve la escritura? }\end{array}$} & $\begin{array}{l}\text { Funciones de la escritura académica. El ser de } \\
\text { la escritura }\end{array}$ & Funciones de la escritura académica \\
\hline & El profesor va a mirar que tanto ha captado uno & Función evaluativa \\
\hline & Para ver el punto de vista de uno & Función evaluativa \\
\hline & Es como medir la parte académica & Función evaluativa \\
\hline & $\begin{array}{c}\text { Eso no era lo que yo quería que usted dijera del } \\
\text { autor }\end{array}$ & Función corroborativa \\
\hline & Uno aprende mucho escribiendo & Función cognitiva \\
\hline & Expresarme bien escritamente & Función comunicativa \\
\hline & Es para sentirme más seguro & Función testimonial \\
\hline & Para comparar esa parte práctica con esa teórica & Función evaluativa \\
\hline & $\begin{array}{l}\text { Que nosotros aprendamos a identificar los } \\
\text { diferentes tipos de textos }\end{array}$ & Función cognitiva \\
\hline & Para inyectarle el gusto por la escritura & Función emotiva \\
\hline & Que desarrollemos nuestra habilidad de escribir & Función cognitiva \\
\hline \multirow{16}{*}{$\begin{array}{l}\text { Funciones de la escritura } \\
\text { ¿Para qué debería servir la escritura } \\
\text { académica? }\end{array}$} & $\begin{array}{l}\text { Funciones de la escritura académica. El deber } \\
\text { ser de la escritura }\end{array}$ & Funciones de la escritura \\
\hline & Evaluar lo que se hizo & Función evaluativa \\
\hline & Que genere cambio & Función transformadora \\
\hline & Parece que todos somos iguales & Función diferencial \\
\hline & Aportar conocimiento & Función cognitiva \\
\hline & Comprender el saber que traen los estudiantes & Función cognitiva \\
\hline & Que uno tuviera libertad & Función diferencial \\
\hline & $\begin{array}{c}\text { Mirar la capacidad del estudiante en cuento } \\
\text { aprendizaje }\end{array}$ & Función cognitiva \\
\hline & Mirar la parte más humana & Función social \\
\hline & Mejor comprensión de las cosas & Función cognitiva \\
\hline & Aprender a leer bien & Función cognitiva \\
\hline & Comprender de una manera más fácil & Función cognitiva \\
\hline & $\begin{array}{l}\text { No hay cosa más deliciosa que tener una hoja de } \\
\text { papel y un lapicero e ir (armando) una letra, una } \\
\text { frase, un cuento, un texto }\end{array}$ & Función estética \\
\hline & $\begin{array}{l}\text { Uno tiene que construir consensos dentro de la } \\
\text { universidad no imponer }\end{array}$ & Función dialógica \\
\hline & Es un medio de expresión & Función comunicativa \\
\hline & Expresar un mensaje & Función comunicativa \\
\hline
\end{tabular}




\begin{tabular}{|c|c|c|}
\hline (Cont.) LA ENTREVISTA & ANALISIS & \\
\hline \multirow[t]{3}{*}{ Eje temático y pregunta } & $\begin{array}{c}\text { Codificación baja. Punto de vista del } \\
\text { entrevistado }\end{array}$ & Codificación media. Punto de vista del entrevistador \\
\hline & Aprender a redactar & Función práctica \\
\hline & Que sea algo que a uno le nazca & Función emotiva \\
\hline \multirow{16}{*}{ ¿Tomas notas de clase? } & Prácticas de escritura en el aula: Toma de notas & \\
\hline & Sí, trato de tomarlas todas & Práctica frecuente \\
\hline & Sí, yo tomo notas & Practica frecuente \\
\hline & Bueno, la práctica, era la de tomar apuntes & Practica frecuente \\
\hline & Te diría que muy poco & Poca frecuencia \\
\hline & Si, no muy frecuente, pero tomo notas & Poca frecuencia \\
\hline & Pues más que todo como los años & Práctica selectiva \\
\hline & $\begin{array}{l}\text { Más que todo lo hago, en los espacios que voy a } \\
\text { eventos, seminarios, taller }\end{array}$ & Practica selectiva \\
\hline & $\begin{array}{c}\text { Normalmente trabajo lo que son mapas } \\
\text { conceptuales }\end{array}$ & Práctica selectiva \\
\hline & Y lo que hago es guion & Practica selectiva \\
\hline & $\begin{array}{c}\text { Son esos tip/ o esos recomendaciones que el } \\
\text { profesor hace }\end{array}$ & Práctica selectiva \\
\hline & $\begin{array}{c}\text { Pues trato de escribir TODO lo qué yo ENTIENDA } \\
\text { de lo que están hablando } \\
\end{array}$ & Practica frecuente \\
\hline & Para poder entender y comprender cosas & Función cognitiva \\
\hline & Para relacionar cosas, teorias & Función cognitiva \\
\hline & Por aprender & Función comunicativa \\
\hline & Hay veces que ni siquiera sé para qué & Desconocimiento de la función \\
\hline \multirow[t]{6}{*}{ ¿Para qué tomas notas? } & Me llama la atención algo que el profesor ha dicho & Función cognitiva \\
\hline & Como un LINK, ¿si?, es un enlace & Función cognitiva \\
\hline & Como para reafirmar o recordar & Función memorística \\
\hline & Prácticas de escritura dirigidas fuera del aula & \\
\hline & Ensayos, ensayos, ensayos & Tipología Ensayos \\
\hline & $\begin{array}{c}\text { Me gustan mucho los ensayos/ sí/ por lo que } \\
\text { investiga }\end{array}$ & Ensayos \\
\hline \multirow[t]{13}{*}{$\begin{array}{l}\text { ¿Qué tipo de escritos te piden en la } \\
\text { universidad? }\end{array}$} & $\begin{array}{l}\text { Cómo es un ensayo, cómo asi tipo ensayo, ya se } \\
\text { supone que uno lo sobre entendió }\end{array}$ & Ensayo \\
\hline & $\begin{array}{c}\text { Que son como más abiertos a la discusión ... uno } \\
\text { puede igual dialogar }\end{array}$ & Ensayo \\
\hline & Mucho arial doce & La forma \\
\hline & El ensayo me gusta mucho & Ensayo \\
\hline & Me siento más libre en los ensayos & Ensayo \\
\hline & $\begin{array}{l}\text { Me gustan los narrativos porque es una cosa que } \\
\text { lo deja a uno ser muy libre }\end{array}$ & Textos Narrativos \\
\hline & Prácticas de escritura autónomas & \\
\hline & \begin{tabular}{|c|} 
Escribi una vez sobre desplazamiento forzado de la \\
comunidad indigena kankuama
\end{tabular} & Escritura sobre la comunidad \\
\hline & $\begin{array}{c}\text { Cuentos, leyendas, de, de la región o de la cultura } \\
\text { de, de nosotros }\end{array}$ & Escritura de tradiciones \\
\hline & Llevo un diario & Diario \\
\hline & Escribo cuentos & Cuentos \\
\hline & Cartas que me gustaría enviarle a una persona & Cartas \\
\hline & No es que me mate & Poca frecuencia \\
\hline $\begin{array}{l}\text { ¿Escribes cosas diferentes a las que te } \\
\text { dejan en la universidad? }\end{array}$ & $\begin{array}{l}\text { escribía por ahi cosas, pero yo creo que ahorita } \\
\text { más que todo es por falta de tiempo }\end{array}$ & Poca frecuencia por tiempo \\
\hline
\end{tabular}




\begin{tabular}{|c|c|c|}
\hline (Cont.) LA ENTREVISTA & ANALISIS & \\
\hline \multirow{4}{*}{ Eje temático y pregunta } & $\begin{array}{c}\text { Codificación baja. Punto de vista del } \\
\text { entrevistado }\end{array}$ & Codificación media. Punto de vista del entrevistador \\
\hline Los conocimientos: metacognición & Estrategias de producción de textos escritos & Tipologias textuales \\
\cline { 2 - 3 } & Depende de qué trabajo sea & Esquemas \\
\cline { 2 - 3 } & Hago un esquema & Planificación textual secuencias \\
\cline { 2 - 3 } & Primero... después & Métodos deductivos \\
\cline { 2 - 3 } & A raiz de una frase. & Los contenidos \\
\cline { 2 - 3 } & Uno tiene que ser REALISTA a la hora de escribir. & Secuencias \\
\hline & uno le tiene que dar orden & La forma \\
\cline { 2 - 3 } & Molestan mucho por los pies de página & la forma \\
\cline { 2 - 3 } & Vivo obsesionado por la ortografia & la forma \\
\cline { 2 - 3 } & Algo que yo tengo muy presente son las tildes & El contenido \\
\cline { 2 - 3 } & Siempre me nace escribir la necesidad del niño & Lo vivencial \\
\cline { 2 - 3 } & De pronto se evidencia eso en el jardin & El detalle \\
\cline { 2 - 3 } & Siempre me quedo mucho en el titulo & No planeación \\
\cline { 2 - 3 } & No sigo pasos de ninguno & Borrador \\
\cline { 2 - 3 } & Una especie de borrador & Planeación por ideas \\
\cline { 2 - 3 } & Empiezo como a escribir ideas & Detalles \\
\cline { 2 - 3 } & Depende de la introducción & \\
\cline { 2 - 3 }
\end{tabular}



Este libro se publicó en Bogotá, Colombia, en el año 2013, con la dirección gráfica de Común Presencia Editores. 
En este libro el lector encontrará reflexiones sobre la escritura académica como forma de exclusión en el contexto universitario. Sugiere la necesidad de ampliar la comprensión de la escritura más allá del desarrollo de una destreza a la que se le reconoce un fin per se, para ubicarla en el campo de las prácticas socioculturales en las que intervienen relaciones de poder. Escritura y poder conforman el hilo conductor de este libro en el que se escuchan las voces de estudiantes indígenas y afrodescendientes de la Universidad Distrital reflexionando sobre sus experiencias con la escritura: significados, aprendizajes, dominios y gustos, y en el que la autora discute la necesidad de comprender la universidad como un espacio plural donde se reconozca la existencia de sujetos diversos, con prácticas y conocimientos diversos, y donde tenga cabida la oralidad, el bilingüismo y otras formas de representación distintas a la alfabética. 